\title{
Metabolic synchronization of the liver circadian clock
}

\author{
Dissertation \\ for the award of the degree \\ "Doctor rerum naturalium" \\ of the Georg-August-Universität Göttingen
}

submitted by

Dominic Landgraf

from Fulda

Göttingen 2011 
Prof. Dr. Ernst A. Wimmer (Reviewer)

Department of Developmental Biology, University of Göttingen

Prof. Dr. Henrik Oster (Reviewer)

Circadian Rhythms Group, Max Planck Institute for Biophysical Chemistry

Prof. Dr. Gregor Eichele

Genes and Behavior Department, Max Planck Institute for Biophysical Chemistry

Prof. Dr. André Fiala

Department of Molecular Neurobiology of Behavior, University of Göttingen

Prof. Dr. Detlef Doenecke

Department of Molecular Biology, University of Göttingen

PD Dr. Moritz Rossner

Gene Expression Group, University of Göttingen

Date of the oral examination: 23.11.2011 


\section{DECLARATION}

Herewith, I confirm that I have written the present PhD thesis independently and with no other sources and aids than quoted.

Göttingen, October 2011

Dominic Landgraf 
„Wer finden will, muss erst wissen wie man versteckt."

Montag, "Fahrenheit 451" 


\section{TABLE OF CONTENTS}

DECLARATION __ 3

SUMMARY __ 8

ZUSAMMENFASSUNG ___ 9

ABBREVIATIONS___ 11

1. INTRODUCTION __ 14

1.1. The biological clock __ 14

1.1.1. Circadian system requirements

1.1.2. Molecular clockwork / TTL _ 16

1.1.3. Molecular clock output _ 19

1.1.4. Suprachiasmatic nucleus _ 19

1.1.5. Peripheral clocks _ 21

1.1.6. Liver clock__ 22

1.2. Entrainment of the circadian system ___ 24

1.2.1. Light _ 24

1.2.2. Food 25

1.2.2.1. Food entrainment of the periphery _ 25

1.2.2.2. Food anticipatory activity __ 29

1.2.3. Circadian disruption _ 30

1.2.3.1. Molecular disruption _ 30

1.2.3.2. Shift work _ 30

1.2.3.3. Jet lag _ 32

1.3. Postprandial physiology __ 33

1.3.1. Hunger and Satiety __ 33

1.3.2. Gut peptides in postprandial signaling __ 35

1.3.3. Postprandial signaling in the liver___ 39

1.4. Aims 40

2. RESULTS _ 41

2.1. Peptide hormone screen___ 41

2.1.1. Validation of screening method - Dexamethasone PRC ___ 41

2.1.2. Peptide hormone screen __ 43

2.1.3. Oxyntomodulin - Dose response curve

2.1.4. Oxyntomodulin - Phase response curve _ 46

2.2. Postprandial events___ 47

2.2.1. OXM induction in mice _ 47

2.2.2. Injection of OXM 48

2.2.3. Clock gene induction after refeeding __ 49

2.3. OXM actions on clock

2.3.1. Induction of liver clock genes in vitro and in vivo _ 50

2.3.2. Oxyntomodulin action in the $\mathrm{SCN}$

2.4. Connecting elements between OXM and liver clock___ 52

2.4.1. Effects of Gcgr and GLP-1r antagonists _ 52 
2.4.1.1. Liver phase shift in vitro in presence of Gcgr and GLP-1r antagonists __ 53

2.4.1.2. Induction of liver clock genes in presence of Exendin 9-39 in vitro and in vivo ___ 54

2.4.2. GLP-1r in liver___ 55

2.4.2.1. Absence of GLP-1r in liver __ 55

2.4.2.2. Induction of liver clock genes in GLP-1-r ${ }^{-/-}$mice in vitro __ 56

2.4.2.3. Induction of liver clock genes in GLP-1-r ${ }^{-/-}$mice after refeeding __ 57

2.5. Signaling pathways

2.5.1. Kinase array ___ 58

2.5.2. Investigation of single pathways___ 59

2.5.2.1. PKB _

2.5.2.2. JNK 61

2.5.2.3. CREB 61

2.6. Additional results: Circadian characterization of GLP-1r $r^{-1-}$ mice___ 62

2.6.1. Free-running behavior in DD___ 63

2.6.2. Development of food anticipatory activity ___ 64

2.6.3. Clock gene expression in GLP-1r ${ }^{-/-}$under restricted feeding ___ 64

3. DISCUSSION _ 66

3.1. The gastro-intestinal hormone Oxyntomodulin sets the liver clock __ 66

3.1.1. The liver clock is synchronized by peptide hormones ___ 66

3.1.2. Oxyntomodulin secretion is postprandially induced ___ 69

3.1.3. Oxyntomodulin actions on the liver clock ___ 69

3.1.4. Oxyntomodulin and restricted feeding____ 71

3.2. Oxyntomodulin signaling in the liver 71

3.2.1. Oxyntomodulin acts via a GLP-1r-like receptor in the liver___ 71

3.2.2. The signaling pathway of Oxyntomodulin remains unknown___ 74

3.2.3. Food entrainment in the liver of GLP-1r $r^{-/-}$mice is disturbed ___ 75

3.3. Outlook 76

4. MATERIALS AND METHODS___ 78

4.1. Animal handling and animal strains__ 78

4.1.1. Wild-type mice__ 78

4.1.2. PER2::LUC mouse strain___ 78

4.1.3. GLP-1r $\mathrm{G}^{-/-}$mouse strain 79

4.2. Animal experiments 79

4.2.1. Pharmacological treatment__ 79

4.2.2. Tissue collection_ 80

4.2.3. Blood collection 80

4.2.4. Activity monitoring _ 80

4.2.5. Restricted feeding _ 81

4.3. Tissue culturing __ 81

4.3.1. Liver slicing __ 81

4.3.2. Organotypic liver slice culturing _ 82

4.3.3. Luminescence measurement___ 82

4.3.4. Liver slice treatment _ 83

4.3.5. PER2::LUC data analyse__ 83

4.4. Molecular biology methods __ 84

4.4.1. Genotyping__ 84 
TABLE OF CONTENTS

4.4.2. RNA isolation 86

4.4.3. cDNA synthesis 87

4.4.4. quantitative real-time PCR (qPCR) 87

4.4.5. Primer sequences 88

4.5. Histological methods 90

4.5.1. Cryosections 90

4.5.2. In situ hybridization 90

4.6. Immunological methods 93

4.6.1. Radio immune assay (RIA)

4.6.2. Western Blot 93

4.6.3. Kinase Array 97

5. REFERENCES 99

6. CURRICULUM VITAE 114

7. ACKNOWLEDGEMENTS 115 


\section{SUMMARY}

The daily rotation of the earth around its axis determines the day length of 24 hours and the periodic change from day to night. Organisms evolved endogenous clocks to anticipate the light/dark alteration and associated occurrences. Endogenous clocks sustain, but with a period of approximately 24 hours. From this the name 'circadian' occurs (lat. "circa" = approximately, "dies" = day). Every day this clock is usually reset anew to keep the exact $24 \mathrm{~h}$ periodicity. Responsible for the resetting, called entrainment, are so called Zeitgeber, which is a German word for time-giver.

The circadian clock is based on transcriptional/translational feedback loop (TTL) of so called clock genes which are characterized by their own rhythmic expression and their ability to drive rhythmic expression of other genes, called clock controlled genes. All organs of an organism contain a circadian clock which is based on the same feedback loop. Light is seen as the predominant Zeitgeber, because it resets the master pacemaker of the circadian system, situated in the suprachiasmatic nucleus ( $\mathrm{SCN}$ ) in the hypothalamus. By this, light can entrain the organism's activity directly. In addition, food is an important Zeitgeber for peripheral clocks. If food is only available at certain times of the day, peripheral clocks phase uncouple from the SCN and shift towards the food time.

In this project we targeted to identify factors which are responsible for the food entrainment of the liver. We suggest that postprandial hormone signaling occurring from the gastro-intestinal tract synchronizes the liver clock in response to food uptake. We identified the peptide hormone oxyntomodulin (OXM), which is postprandially released in intestinal L-cells, as a potent factor to reset the liver clock. We could show that OXM induces the expression of period genes (Pers), which are a core part of the TTL. This, in turn, leads to phase shifts of the liver clock in vivo and in vitro. The in vitro experiments, done with cultured organotypic liver slices, confirm the direct effect of OXM on the liver clock. In agreement with the decoupling from the master pacemaker, the SCN was not influenced by OXM administration. We found that the action of OXM in the liver is dependent on a receptor, related to the GLP-1 receptors known from other organs. Blocking this receptor diminishes the actions of OXM in the liver and also the clock gene reaction on food in the liver in vivo.

In summary, we identified the gastro-intestinal hormone peptide OXM as a factor responsible for the synchronization of the liver circadian clock to food uptake. This finding is an important step in understanding the mechanisms of internal desynchronization which occurs for example in shift workers. 


\section{ZUSAMMENFASSUNG}

Die tägliche Rotation der Erde um ihre Achse bestimmt die Tageslänge von 24 Stunden und den periodischen Wechsel zwischen Tag und Nacht. Organismen haben im Laufe der Evolution eine endogene Uhr entwickelt. Diese hilft dabei, sich auf den Licht/Dunkel-Wechsel und die daraus resultierenden Ereignisse vorzubereiten. Endogene Uhren haben die Eigenschaft, auch ohne äußere Signale weiterzulaufen, dann aber nicht mehr mit einer Periodenlänge von exakt 24 Stunden. Daher leitet sich der Name ,circadian” ab (lat. „circa“ = ungefähr, „dies“ = Tag). Dies macht es notwendig die circadiane Uhr jeden Tag neu einzustellen.

Das circadiane System beruht auf einer transkriptionellen/translationellen Rückkopplungsschleife (engl.: transcriptional/ translational feedback loop; TTL) so genannter Uhrengene. Diese sind gekennzeichnet durch ihre eigene rhythmische Expression und durch ihre Fähigkeit die Expression anderer Gene, so genannter uhrenregulierter Gene, rhythmisch zu gestalten. Alle Organe eines Organismus besitzen eigene circadiane Uhren, welche alle auf denselben Uhrengenen beruhen. In der Regel wird Licht als der Hauptzeitgeber angesehen, da es in der Lage ist, die Zentraluhr im Nucleus Suprachiasmaticus (SCN) des Hypothalamus zu verstellen. Auf diesem Weg kann Licht die Aktivitätphasen eines Organismus direkt bestimmen. Zustätzlich zum Licht ist Nahrung ein wichtiger Zeitgeber, speziell für periphere Organe. Wenn Nahrung nur zu bestimmten Tageszeiten verfügbar ist, koppeln sich die peripheren Uhren vom SCN ab und versetzen in Richtung Essenszeit.

Diese Arbeit hat zum Ziel, einen Faktor zu identifizieren, der für die nahrungsbedingte Verschiebung der Leberuhr verantwortlich ist. Wir glauben, dass postprandiale Hormone mit Ursprung im gastro-intestinalen Trakt die Leberuhr auf die Zeit der Nahrungsaufnahme einstellen. Wir haben herausgefunden, dass das Peptidhormon Oxyntomodulin (OXM), welches postprandial in den L-Zellen des Darms sekretiert wird, die Leberuhr stark verstellen kann. Wir konnten zeigen, dass OXM die Expression beider Period Gene (Pers), welche einen wichtigen Bestandteil des TTL darstellen, induziert. Dies wiederum kann zu einer Verstellung der Leberuhr in vivo und in vitro führen. Alle in vitro Experimente wurden mit kultivierten Leberschnitten gemacht und machen einen direkten Einfluss von OXM auf die Leber deutlich. Wir konnten außerdem zeigen, dass OXM Behandlungen in vivo keinen Einfluss auf die Per Expression im SCN hatten. Dieses Ergebnis ist im Einklang mit der nahrungsbedingten Abkopplung peripherer Organe vom SCN. Unsere Ergebnisse lassen darauf schließen, dass OXM in der Leber über einen Rezeptor wirkt, der dem GLP-1 Rezeptor sehr ähnlich ist. 
Wird dieser Rezeptor geblockt, kann OXM seine Wirkung auf die Leberuhr nicht mehr voll entfalten. Außerdem werden dadurch natürliche nahrungsbedingte Reaktionen der Leberuhr verhindert.

Zusammenfassend haben wir das gastro-intestinale Peptid Hormon OXM als potentiellen Faktor identifiziert, der für die nahrungsbedingte Synchronisation der circadianen Leberuhr verantwortlich ist. Dieses Ergebnis trägt zum besseren Verständnis der internen Desynchronisation bei, wie sie zum Beispiel bei Schichtarbeitern zu beobachten ist. 


\section{ABBREVIATIONS}

\begin{tabular}{|c|c|}
\hline${ }^{\circ} \mathrm{C}$ & degree Celsius \\
\hline$\varnothing$ & diameter \\
\hline- & knockout \\
\hline$\mu \mathrm{M}$ & micro molar \\
\hline ß-MeSH & ß-mercaptoethanol \\
\hline$A C$ & adenlyte cyclise \\
\hline $\mathrm{AL}$ & al libitum \\
\hline ARC & arcuate nucleus \\
\hline BAT & brown adipose tissue \\
\hline BBB & blood brain barrier \\
\hline BHK & baby hamster kidney cells \\
\hline Bmal1/BMAL1 & $\begin{array}{l}\text { brain and muscle aryl hydrocarbon receptor nuclear translocator (ARNT)-like } \\
\text { (official Entrez gene symbol: } A r n t / \text { ) }\end{array}$ \\
\hline CAMP & cyclic adenosine monophosphate \\
\hline CCGs & clock controlled genes \\
\hline CCK & Cholecystokinin \\
\hline $\mathrm{CK} 1 \delta / \varepsilon$ & casein kinase $1 \delta / \varepsilon$ \\
\hline Clock/CLOCK & circadian locomotor output cycles kaput (gene/PROTEIN) \\
\hline CREB & CAMP responsive element binding protein \\
\hline Cry1/2/CRY1/2 & Chryptochrome 1/2 (gene/PROTEIN) \\
\hline d-GLU & (Des-His1,Glu9)-Glucagon (1-29) amide \\
\hline$D b p / D B P$ & D-site albumin promoter binding protein (gene/PROTEIN) \\
\hline $\mathrm{DD}$ & constant darkness \\
\hline des-GHR & des-octanoyl3 Ghrelin \\
\hline $\mathrm{DMH}$ & dorsomedial hypothalamus \\
\hline DN & dorsal neurons \\
\hline DPP-4 & dipeptidyl peptidase-4 \\
\hline DTT & Dithiothreitol \\
\hline eNOS & endothelial nitric oxide synthase \\
\hline ERK1/2 & Extracellular-regulated kinases 1 and 2 \\
\hline Ex-4 & Exendin-4 \\
\hline Ex9-39 & Exendin-9-39 \\
\hline FAA & food anticipatory activity \\
\hline FEO & food entrainable oscillator \\
\hline FFA & free fatty acid \\
\hline G6pt1 & glucose-6-phosphatetranslocase1 \\
\hline Gcgr & glucagon receptor \\
\hline Gck & glucokinase \\
\hline $\mathrm{GI}$ & gastro-intestinal \\
\hline GIP & Gastric inhibitory polypeptide \\
\hline GLP-1 & Glucagon-like peptide-1 \\
\hline GLP-1r & Glucagon-like peptide-1 receptor \\
\hline GLU & glucagon \\
\hline Glut2/GLUT2 & glucose transporter2 (gene/PROTEIN) \\
\hline GS & glycogen synthase \\
\hline
\end{tabular}




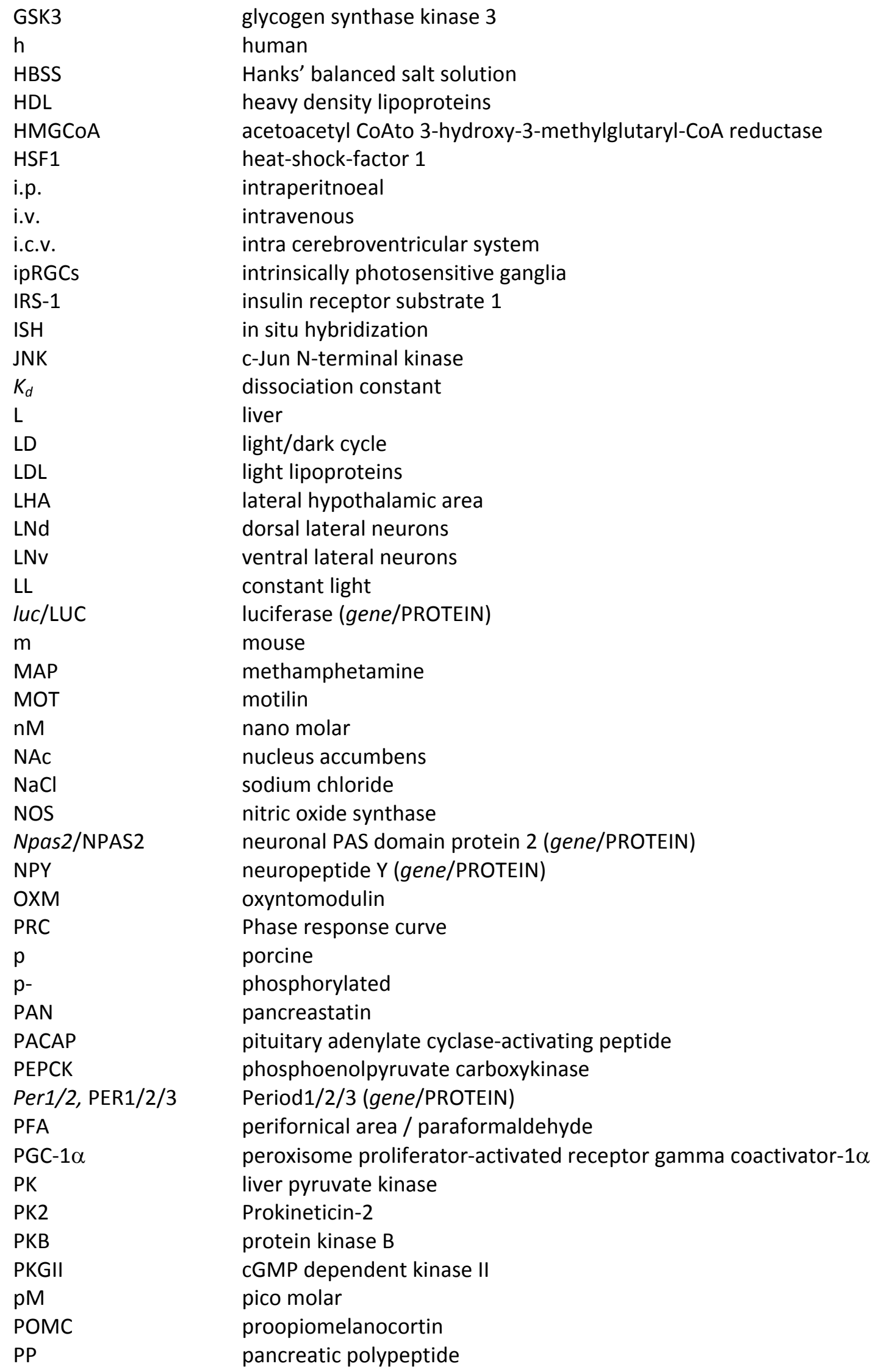




$\begin{array}{ll}\text { PPAR } & \text { peroxisome proliferator-activated receptor } \\ \text { PS }_{50} & 50 \% \text { phase shift } \\ \text { PVN } & \text { paraventricular nucleus } \\ \text { PYY } & \text { peptide YY } \\ \text { qPCR } & \text { quantitative real-time PCR } \\ r & \text { rat } \\ \text { RIA } & \text { radio immune assay } \\ \text { Ror- } \alpha & \text { retioid acid receptor-related orphan receptor } \alpha \\ \text { RF } & \text { restricted feeding } \\ \text { RHT } & \text { retinohypothalmic tract } \\ \text { SAL- } \alpha & \text { salusin- } \alpha \\ \text { SCN } & \text { suprachiasmatic nucleus } \\ \text { SIRT1 } & \text { sirtuin 1 } \\ \text { SON } & \text { supraoptic nucleus } \\ \text { SREBP } & \text { sterol regulatory element-binding protein } \\ \text { TGF- } \alpha & \text { transforming growth factor- } \alpha \\ \text { TTL } & \text { transcriptional/translational feedback loop } \\ \text { VLDL } & \text { very light lipoproteins } \\ \text { VMH } & \text { ventromedial hypothalamus } \\ \text { WAT } & \text { white adipose tissue } \\ \text { WT } & \text { wild type } \\ \text { ZT } & \text { Zeitgeber time }\end{array}$




\section{INTRODUCTION}

\subsection{The biological clock}

Biological rhythms range from milliseconds, observable in neuronal action, to annual rhythms, for instance hibernation, or even longer, like the 13 or 17 year long life cycle of cicadas in the genus Magicicadas [1, 2]. One of the most predictable environmental changes on earth is the alternations of day and night due to 24-hours earth rotation. This accompanies with daily changes in illumination, temperature, humidity, food availability and predator emergence. Predicting and anticipating such changes bears several advantages for organisms, from cyanobacteria to mammals [3], for several reasons. Calibrating and synchronizing internal events with external time information, so called "Zeitgeber" [4], of which light [5], temperature [6] and food [7] are the most important, an organism increases its physiological stability. A second facet of biological clocks is saving energy. The biological clock avoids that all actions of or within an organism occur with the same intensity at all times of day. During sleep time energy consumption is minimal. Thus, energy metabolism is not the same in the course of a day. Moreover, the risk of infections is highest if an organism is active. Hence, the immune system is lowered during sleeping time. Thirdly, temporal compartmentalization allows oppositional events to occur within an organism. Catabolic and anabolic pathways, work and relaxation, reductive and oxidative states which can not happen or appear simultaneously are separated and only occur at certain times per day. Fourthly, the ability to anticipation guarantees that events are fully utilized and not missed. Food for example might be only available at a concrete repetitive time every day. If a predator would merely react on the appearance of its prey every day anew, it might miss a certain amount or the complete feeding time. Furthermore, subterranean animals anticipate light dark conditions and do not need to control whether it is time to leaf their den. This is closely associated with the fifth advantage of bearing a biological clock. Under constant conditions, for instance in subterranean animals that are isolated from light dark signals, thus from an important Zeitgeber, the biological rhythms persist and organisms still benefit from the above-named advantages. Another advantage of biological clocks gets obvious in more complex systems. It is believed that circadian clocks help organisms to enhance their ability to survive in ecological systems. 
For instance, animals with disturbed rhythmicity were shown to fell prey for predators more often than control animals [8].

The impact of the biological clock was first described by the astronomer Jean-Jaques Dortous de Mairan in 1729. He observed that the diurnal leaf movement of Mimosa persists with nearly 24 hour (circadian; lat. circa = approximately, dies = day; [9]), even if the plant is kept in a complete darkened cupboard [10]. De Marian did not conclude the existence of an endogenous clock and it took until the twentieth century when scientists were definitely convinced of an internal circadian system. Experiments showing that plants and animals show rhythms different from 24 hours when they are kept under constant conditions brought the evidence that the biological clock was independent from factors related to the earth rotation. This was confirmed by the fact that these "free-run" periods depend on the intensity of light (constant darkness to constant bright light) [1113]. A very spectacular study showed that the circadian controlled conidiation of Neurospora was the same on earth and in a laboratory in space away from earth's influence [14].

The rhythmic organization of organisms investigated up to now cover social, behavioral, mating, developmental, metabolic/enzymatic and transcriptional levels $[15,16]$.

\subsubsection{Circadian system requirements}

In nature many rhythms are observable. Day and night, summer and winter, trees get leafs in spring and loose them in fall, animals change their coat in the course of a year, birds develop migration restlessness ("Zugunruhe") once a year and we wake up in the morning and fall asleep at night. But, do all these rhythms depend on intrinsic clocks? A real biological oscillator is defined by a minimum of three functional hallmarks.

Sustainment: Circadian rhythms are characterized by a period of about, but not exactly 24 hours. Rhythms shorter than 20 hours are named ultradian. If a rhythm is longer than 28 it is called infradian. The biological clock produces persistent rhythms even without any external time information. Under constant conditions the clock "ticks" under free-running condition with a period $(\operatorname{tau} / \tau)$ close to 24 hours. The free-run continues for a long time. But not all rhythms are selfsustained. Masking is a phenomenon when an external agent overlays internal rhythms without affecting their phase or period. This appears if organisms with a disturbed or without an internal clock (mutant or knock-out animals) still follow for instance the light-dark cycle. In this case activity is 
restrained only by the light signal not by the clock. As soon as this Zeitgeber signal disappears the ability to sustain this rhythmicity is lost or animals can easily adapt to rhythms with a period completely different from 24 hours. Some 24 hour rhythms need a daily activator and are for this reason called hourglass effects or interval timing. Once activated these rhythms continue running, but if the activator does not appear the rhythms are interrupted [17].

Entrainment: Oscillators are synchronized to external recurring signals. As internal clocks have period slightly different from 24 hours a daily resetting is necessary to maintain their phase relationship with environment. To certain extents, plants and animals can be entrained to light-dark cycles different from 24 hours [11]. Furthermore, biological clocks must be able to adapt to environmental changes. However, a real oscillator can not react immediately to alterations. That means if the environment changes, an organism with an intrinsic clock will need a certain transition time to adapt to the new conditions. A prominent example is the jetlag syndrome, caused by highspeed air travel across time zones. From this it follows that the internal time is different from the external time. Animals need several days to overcome jetlag symptoms because of an internal regulation to avoid a too fast adaption [18]. A slowdown of adaption is definitively eligible to prevent premature phase shifts after impermanent environmental changes.

Compensation: Pittendrigh found that the frequency of the free-running rhythm in Drosophila was hardly affected by temperature [19]. Usually chemical reactions run 2-4 times faster when the temperature is increased by $10 \mathrm{~K}$ (van't Hoff's rule). This obviously does not apply for circadian clocks. Biological clocks run with same period in summer and winter, on hot days and cold nights. The temperature compensation of the circadian clock is especially needed in poikilothermic organisms and in drastically changing environments. Nevertheless, despite temperature compensation some organisms can be entrained to daily fluctuations of temperature [20]. Temperature entrainment is only possible by rhythmic oscillations of temperature, whereas the clock itself is still temperature compensated.

\subsubsection{Molecular clockwork / TTL}

As it was shown that circadian rhythms are intrinsic and innate the underlying mechanism must be based on genetic material and thus heritable. In a time when the structure of DNA was not yet unraveled Bünning found by breeding two lines of plants (Phaseolus coccineus) with different 
circadian leaf movement free-running periods that the seedlings have an intermediate period [21]. After uncovering the attributes of genetic material first efforts were spent to find single genes being part of the circadian machinery.

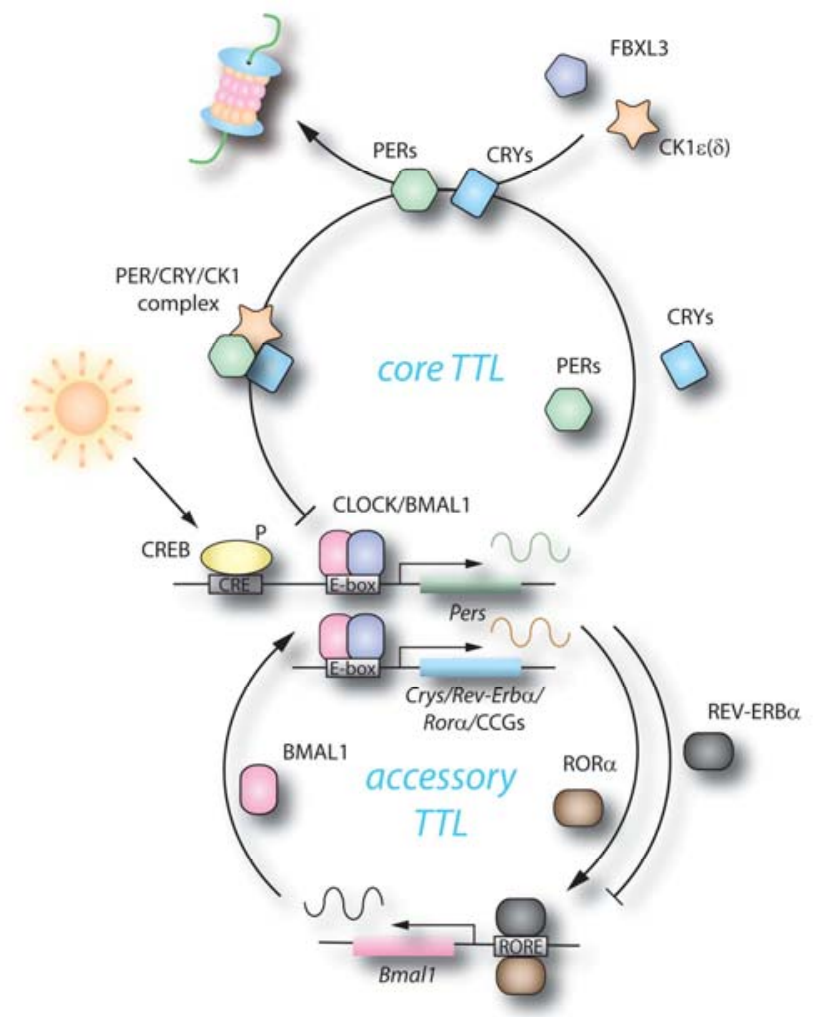

Figure 1: Model of the interlocked mammalian transcriptional translational loops (TTLs). The heterodimer of CLOCK/ BMAL1 activates E-box containing clock genes Per and Cry, and clock controlled genes (CCGs). PER and CRY proteins form a multimeric complex which inhibit CLOCK/ BMAL1. The additional loop contains Rev-erb- $\alpha$ and ROR- $\alpha$ which activated by CLOCK/ BMAL1. They inhibit or activate Bmal1 transcription, respectively. Casein kinase $1 \varepsilon$ phosphorylates the PER proteins which leads to their degradation ultimately. For details see text, (Oster, 2006).

In 1971 Konopka and Benzer treated Drosophila flies with mutagenetic agents hoping to find single mutations that change the rhythmic pupal eclosion of the insects. Indeed, they found three mutations leading to either a long free-running period of 28 hours, a short period of 19 hours or to complete arrhythmic animals. They found that all three phenotypes were based on a single gene called Period (Per) [22]. Henceforward, clock genes were identified in different species, like cyanobacteria, fungi, plants, flies, rodents and humans. In mammals the first mutation (tau) involved in the circadian mechanism was found in a golden hamster with a period of only 22 hours. The gene was later identified as casein kinase $1 \varepsilon(\mathrm{CK} 1 \varepsilon)[23,24]$. 
The idea of an interacting autoregulatory transcription-translation feedback loop (TTL) which regulates the rhythmic expression of clock genes and clock output genes came up several years before other clock components were found [25]. The identification of the other components leads to the current TTL model. This model describes a core and an auxiliary TTL (Figure 1). The core loop consists of positive components brain and muscle aryl hydrocarbon receptor nuclear translocator (ARNT)-like (Bmal1/BMAL1; official Entrez gene symbol: Arntl), Clock/CLOCK and Npas2/NPAS2 as well as the negative components Chryptochrome 1/2 (Cry1/2/CRY1/2) and Period 1-3 (Per1-3/PER1-3) (Gene/PROTEIN).

During the subjective day CLOCK and BMAL1 form heterodimers which bind to specific E-box elements on the promoter of the Per and Cry genes leading to an activation of the genes and expression of PERs and CRYs into the cytoplasm. At the subjective afternoon, when PER and CRY levels reach high cytoplasmatic levels the proteins are phosphorylated by Casein kinase $1 \delta / \varepsilon$ (CK1 $1 \delta / \varepsilon)$ and build complexes among each other and are translocated into the nucleus. The PER/CRY complex binds to CLOCK/BMAL1 which leads to an inactivation of their own transcription. Progressive degradation of the PER/CRY complex abolishes the inhibition at the end of the subjective night and the cycle restarts with the binding of CLOCK/BMAL1 to the E-box elements. Due to their inhibitory function PERs and CRYs build the negative limb, whereas CLOCK and BMAL1 build the positive limb of the TTL.

The auxiliary loop comprises two genes of the orphan nuclear receptor family, Rev-erb- $\alpha$ and retioid acid receptor-related orphan receptor alpha (Ror- $\alpha)$. Both bind to ROR elements which are part of the Bmal1 promoter and activate or repress its transcription, respectively. Further ancillary loops have been described. The CLOCK/BMAL1-regulated bHLH transcription factors DEC1 (BHLHE40) and DEC2 (BHLHE41) were shown to bind E-box elements and modulate BMAL1/CLOCK-driven circadian transcription $[26,27]$. An additional TTL is described involving D-site albumin promoter binding protein (DBP) and E4BP4 (NFIL3) as transcription factors binding on D-boxes at the promoters of Per1-3, Rev-erb- $\alpha$, Ror- $\alpha$ and several other clock-controlled genes (CCGs) not involved in the core loop of the clock $[28,29]$.

These components are found in every single cell of the body. Thus, it is suggested that every cell in the body produces circadian rhythms which are all based on the same molecular TTL. The rhythmic output of a complete organ is only possible due to the fact that the oscillators of all single cells are synchronized within one tissue. 


\subsubsection{Molecular clock output}

E-boxes, D-boxes and ROR elements are binding motifs in clock gene promoters, responsible for circadian activation or inhibition of clock gene transcription. Since these binding sites are also found in promoters of many other genes outside of the TTL the oscillation of the core clock is transferred to the expression of these genes. Promoters including E-boxes are directly controlled by CLOCK/BMAL1 heterodimers [30]. DBP and E4BP4 regulate promoters including D-boxes $[28,29]$ and REV-ERB-a and ROR-a those containing ROR-elements [31]. If genes are directly controlled by clock genes or clock gene heterodimers they are called first-order CCGs. Other rhythmic genes controlled by first-order CCGs are consequently downstream CCGs, since they are indirectly controlled by the clock [30]. Clock output can also appear in form of posttranscriptional modifications influencing mRNA stability or protein synthesis, stability and action $[32,33]$. In contrast to the TTL which is the same in all cell types of the body, the composition of CCGs is very tissue specific. According to the different function of organs a tissue-specific regulation of CCGs makes physiological sense. Thereby the circadian system regulates the transcription of around $10 \%$ of all expressed genes in mammals.

\subsubsection{Suprachiasmatic nucleus}

The central pacemaker of the circadian system in mammals resides in the suprachiasmatic nucleus (SCN) in the hypothalamus. The SCN sits in the lower part of the hypothalamus directly above the optic chiasm. That makes it optimal for this nucleus to receive direct light signals from the retinohypothalmic tract (RHT). These signals are transmitted via monosynaptic connections from the retina to the SCN $[34,35]$. Thereby the $\mathrm{SCN}$ can translate the light information into rhythmic outputs signals to the whole body. The SCN shows strong rhythmic electrophysiological activity and clock gene expression. Interestingly, these rhythms are in antiphase with its surrounding tissues. More remarkably, clock gene expression and activity patterns are the same in diurnal and nocturnal animals, suggesting that the SCN output is species-dependently translated in either activity or inactivity. Before the discovery of central pacemakers chronobiologists assumed a more diffused multioscillatory system. With the finding that the medulla of the optic lobe is a pacemaker in cockroaches [36] the search for such a pacemaker in mammals was initiated. It was shown that the optic lobe of cockroaches met all criteria of a central circadian pacemaker: 1 . the putative pacemaker 
is rhythmic itself, 2. it is entrainable to different Zeitgebers (most likely light) and 3. transplantation of donor pacemaker tissue restores rhythmicity of an arrhythmic host with same characteristics of the transplant [36].

In Drosophila the pacemaker is located in the brain [37] - or more specifically in ventral lateral neurons (LNv), dorsal lateral neurons (LNd) and dorsal neurons (DN) [38]. The pineal gland was shown to be the central pacemaker in birds [39]. The SCN as pacemaker of mammals was identified by two groups simultaneously in 1972 [40, 41]. After fractional or total lesions of the SCN corticosterone rhythms [40], drinking behavior as well as locomotor activity [41] were completely abolished. Its own rhythmicity was shown, when the SCN was isolated from the rest of the brain. The rest of the brain got immediately arrhythmic while the SCN remained rhythmic [42]. The neuronal network in the SCN is strongly coupled. This results in a very stable sustainment of rhythms, which cannot be found in other tissues [43]. The final evidence was given when the first mutant SCN were used for transplantations. SCN of wild type (WT) or tau hamsters were isolated and transplanted. The restored rhythms always exhibited the characteristics of the donor, regardless of the direction of transplantation [44]. Subsequent studies defined functionally different areas within the SCN and how signal transduction from the SCN to the rest of the body is accomplished [45]. Two possible candidates resulting from transmission to other brain regions might explain how locomotor activity is controlled by the SCN in nocturnal rodents. Prokineticin-2 (PK2) and transforming growth factor$\alpha$ (TGF- $\alpha$ ), two neuro-peptides, were shown to be strongly rhythmic and are both output signals of the SCN and/or retina $[46,47]$. Both peptides are potent activity inhibitors when injected into brain ventricles. Consequently, the rodent SCN sends presumably rather inhibitory than activating signals to surrounding brain regions, possessing a possible explanations why the clock gene expression in the $\mathrm{SCN}$ is in antiphase with most other brain regions. Another elegant study showed that additionally secreted factors are involved in signal transmission. SCN transplants were encased by a permeable capsule, preventing neuronal outgrowth but allowing diffusion of humoral signals. Albeit a long recovery time, the locomotor rhythms were restored, without any neuronal transmission [48]. Nevertheless, humoral signals were shown to be mainly relevant for peripheral targets outside of the brain. Because of its extraordinary role the $\mathrm{SCN}$ is often seen as the master pacemaker of the body. In contrast, peripheral clocks are denoted as slave oscillators. 


\subsubsection{Peripheral clocks}

Shortly after the discovery of clock genes it became clear that circadian oscillators are not restricted to the SCN. Rhythmic clock gene expression can be detected in most, if not all, peripheral tissues. Peripheral rhythmic clock gene expression was first detected in cell and tissue culture approaches. SCN neurons isolated from rats kept in culture display rhythmic gene expression for several days [49]. Cultured SCN cells reflect the in vivo period of WT, heterozygous or homozygous tau-hamsters, verifying that cell culturing does not influence the inherent circadian system [50]. Per1 and Per2 gene expression was shown to be expressed in many peripheral organs like heart, lung, liver, skeletal muscle, kidney and testis [51]. Also Dbp was shown to be expressed rhythmically in the liver mice [29].

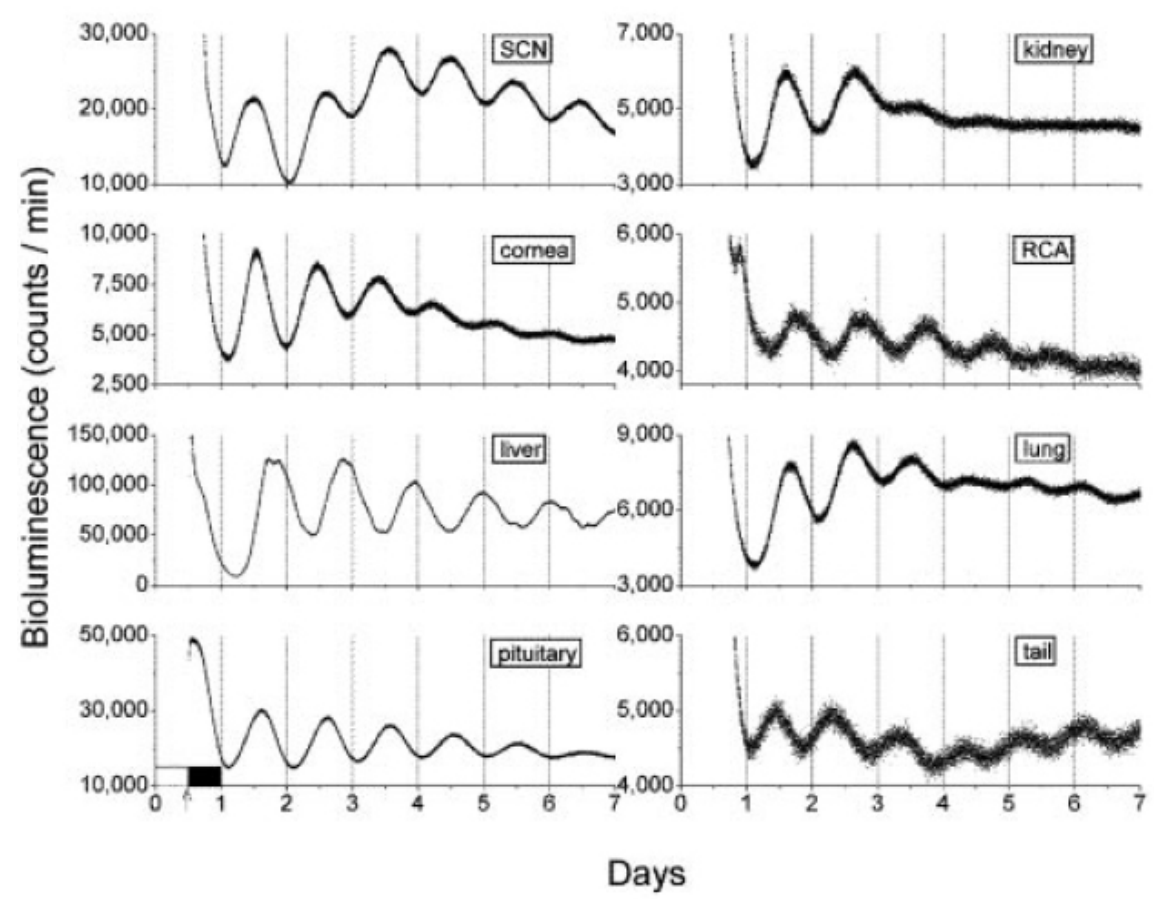

Figure 2: Representative data of bioluminescence showing PER2 expression of various organotypic PER2::LUC tissue cultures. The rhythmic expression is self-sustained in all tissues, including for example SCN and liver, (Yoo, 2002).

Although these studies showed that clock genes are ubiquitous expressed, they did not focus the question whether the peripheral clock genes run SCN independent in a self-sustained manner. The fact that Drosophila Per expression was self-sustained in cultures independent of the brain [52] led to the suggestion that this could be true for mammals as well. In 1998 Balsalobre and colleagues found that cultured (serum shocked) fibroblasts and H35 hepatoma cells show self-sustained 
rhythmic expression of clock genes [53]. Following studies expanded this finding by demonstrating that all examined peripheral tissues show all components of the TTL oscillating in a self-sustained manner [54, 55]. A very elegant study of Yoo et al. in 2004 using a luciferase (luc) coupled Per2 gene, resulting in a fusion protein of PER2 and LUC, showed persistent circadian oscillations in many peripheral mouse tissues in real-time [56]. Self-sustained rhythms of SCN, retrochiasmatic area, pituitary, cornea, kidney, liver, lung and the tail cultures were shown up to twenty days [56] (Figure 2). It was shown that peripheral clocks still oscillate in SCN-lesioned animals. Indeed, the phase of all organs exhibit larger differences than usual and the cells within an organ start to desynchronize as it was shown for fibroblasts and hepatocytes in the same liver $[57,58]$.

\subsubsection{Liver clock}

The liver clock is the most extensively studied peripheral oscillator. Several studies show that around 500-1,200 different genes in the liver involved in metabolic pathways, energy homeostasis, food processing and detoxification are under circadian control [59-61]. In the liver the need of segregation of physiological processes is particularly clear. Activity of glycogen synthase and glycogen phosphorylase, responsible for the conversion of glucose into glycogen and vice versa, is antiphasic [62]. A study of Panda and colleagues in 2002 brought evidence that a lot of elementary metabolic factors are under circadian control [63].

Rhythms of enzymes involved in rate-limiting steps in the metabolism of hexose sugars, like glucose-6-phosphatetranslocase1 (G6pt1), glucokinase (Gck), liver pyruvate kinase (L-PK) or glucose transporter2 (Glut2), were observed. Lipin1, a factor thought to be involved in sugar and lipid metabolism, was shown to be rhythmically expressed. The transport and synthesis of cholesterol is based on factors, like acetoacetyl CoAto 3-hydroxy-3-methylglutaryl-CoA reductase (HMGCoA reductase), which are strongly clock controlled. The liver is the only organ shown to convert cholesterol to bile acids. Cytochromes P450s are responsible for that and were found to be under circadian control [63]. In addition, the liver clock seems to be involved in clearance of xenobiotics, as strongly rhythmic PAR-domain basic leucine zipper transcription factors like DBP are involved in detoxification and drug metabolism [64]. Gating substrate transport and metabolism is an effective mechanism for temporal sequestration of metabolites in the liver. 
Clock mutant mice show different expression patterns for around 200 genes in the liver, whereof a considerable part deals with metabolic cues [65]. These studies highlight the importance of a liver specific oscillator. They show that the central pacemaker in the SCN alone is not sufficient to drive all the metabolic cues in peripheral organs, such as the liver. In a subsequent study of 2007, Kornmann and colleagues developed a mouse model with a conditionally active liver clock. When Bmal1 transcription was suppressed by an induced overexpression of Rev-erb- $\alpha$, the whole liver clock was shut down. Interestingly, around $10 \%$ of all rhythmic clock genes stayed rhythmic, suggesting that they are driven by systemic timing cues.

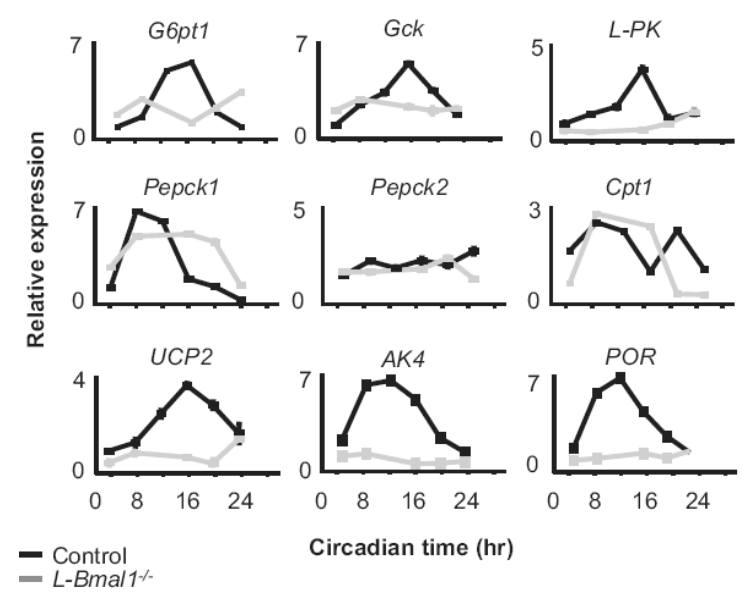

Figure 3: Loss of rhythmic expression of clock-regulated metabolic genes in the livers of $L-B m a / 1^{-1-}$ mice, (Lamia, 2008).

One year later, a liver-specific disruption of the circadian clock in a knock out model based on a deletion of Bmal1 (L-Bmal1 ${ }^{-1}$ ) generated by Lamia and colleagues [66] was the first direct evidence for a physiological importance of the liver clock. The L-Bmal1 ${ }^{-1-}$ mouse line shows neither rhythmic clock gene expression in the liver nor rhythms of liver-specific metabolic genes like G6pt1, Gck, L-PK or Glut2 (Figure 3). As a consequence they exhibit a disturbed glucose homeostasis because disruption of the circadian oscillation of glucose export leads to hypoglycaemia during their inactive phase. This result was not seen for complete $\mathrm{Bmal1}^{-/}$mice suggesting that the absence of BMAL1 alone was not responsible for this phenotype. Consistent with the observation that approximately $10 \%$ of all circadian controlled liver genes are under systemic control and therefore stay rhythmic in an intrinsic arrhythmic liver [60], not all genes become arrhythmic in L-Bmal1 ${ }^{-1-}$ mice. 
Rev-erb- $\alpha$ is a further link between liver metabolism and liver clock. Loss of Rev-erb- $\alpha$ or overexpression changes rhythms of sterol regulatory element-binding protein (SREBP) activity and its targets. Thereby cholesterol and lipid metabolisms in the liver are changed [67].

\subsection{Entrainment of the circadian system}

Light and food are the most important entrainment factors for the clock of most organisms. However, there is growing evidence that more nonphotic stimuli may exist. Restricted exercise, social contacts, temperature, sound, olfactory stimuli, electromagnetic fields and treatment with the psychostimulant metamphetamine (MAP) are suggested to be able to synchronize the circadian clock [68-70]. The impact of light and food on the circadian system are described in more detail in the following chapters:

\subsubsection{Light}

The light signal from the eye is transmitted through the RHT to the SCN. Blinding rats or monkeys, by removing the whole eyes, abolishes entrainment by light and the animals start to freerun [71]. A network of intrinsically photosensitive ganglia (ipRGCs) was found in the retina of mice. These ganglia are not able to perform visual perception. They receive input from rods and cones via amacrine and cone bipolar cells [72]. Nevertheless, after complete loss of rods and cones, the classical visual photoreceptors, animals still showed normal entrainment to light [73].

Furthermore, without conscious visual detection, many blind people are still entrained by daily light-dark cycles [74]. The ganglion cells contain melanopsin, an opsin based pigment, and directly innervate the SCN with glutamergic and pituitary adenylate cyclase-activating peptide (PACAP) signals from the RHT $[75,76]$. Activation of their receptors leads to a strong calcium influx in the SCN neurons, in turn leading to an activation of calcium-dependent kinases, proteases and transcription factors [77]. Depending on the internal phase of SCN neurons, different pathways are activated. Light exposure in the early night activates MAP kinases, PKA and calmodulin, causing a phosphorylation of cAMP responsive element binding protein (CREB) which, in turn, initiates Per1 and Per2 induction [78-80]. Furthermore, cGMP dependent kinase II (PKGII) is activated which inhibits the 
CREB activated Per1 induction. This initiates phase delays of the activity of nocturnal animals, because the light achieves a lengthening of the light phase $[5,81]$.

The opposite scenario can be seen in nocturnal mammals like the mouse. A light exposure during late night simulates a shortened night and thus leading to phase advances [5]. In this case nitric oxide synthase (NOS) and PKG are activated which also leads to a phosphorylation of CREB [78, 82]. Phosphorylated CREB ( $\mathrm{p}$-CREB) activates the expression of Per1 and Per2. The difference of clock response to light exposures and resulting $\mathrm{p}$-CREB enhancement is that light signals in the early night cause only Per2 expression, leading to a delay, and in the late night increase Per1 and Per2 expression, causing an advance [83]. The SCN also controls the clocks of peripheral organs via humoral and neuronal signals, which leads to an indirect light entrainment of the periphery [30]. For example, a surgically disruption of the liver innervation demonstrated that light may effect liver gene expression via autonomic input [84].

\subsubsection{Food}

As the circadian system is entrained by light, food is also a very strong Zeitgeber. In nocturnal animals daytime restricted feeding (RF) entrains clock gene expression in the central nervous system, with exception of the SCN, as well as in the periphery, such as liver, lung, heart and muscles. At present, the underlying mechanisms of food entrainment and especially uncoupling from the central pacemaker are still unknown. Furthermore, RF is able to cause food anticipatory activity (FAA) which is thought to be based on an unidentified food entrainable oscillator (FEO). In this chapter these two phenomena are described in more detail.

\subsubsection{Food entrainment of the periphery}

In 2000 Damiola et al. found that daytime restricted feeding phase shifts peripheral clocks of liver, kidney, heart and pancreas in mice (Figure 4). Expression of important core clock genes including Per1-3, Cry1, Rev-erb- $\alpha$ and Dbp were completely shifted after 6 days of daytime feeding. After 3 days the shift was only accomplished half. Interestingly, the SCN clock gene expression was not affected by the new feeding schedule, suggesting an uncoupling of the masterclock [85]. A subsequent study of 
Stokkan et al. showed that phase shifts of individual organs are dependent on the length of food access. In rats $4 \mathrm{~h}$ feeding time shifts the clock of liver and lung almost completely after two days, whereas $8 \mathrm{~h}$ of food access even after 8 days only shifted the liver clock and not the lung clock [86]. Based on the fact, that RF uncouples the SCN from the periphery, it was not surprising that feeding dependent phase shifts are also observed in SCN-lesioned mice [87].

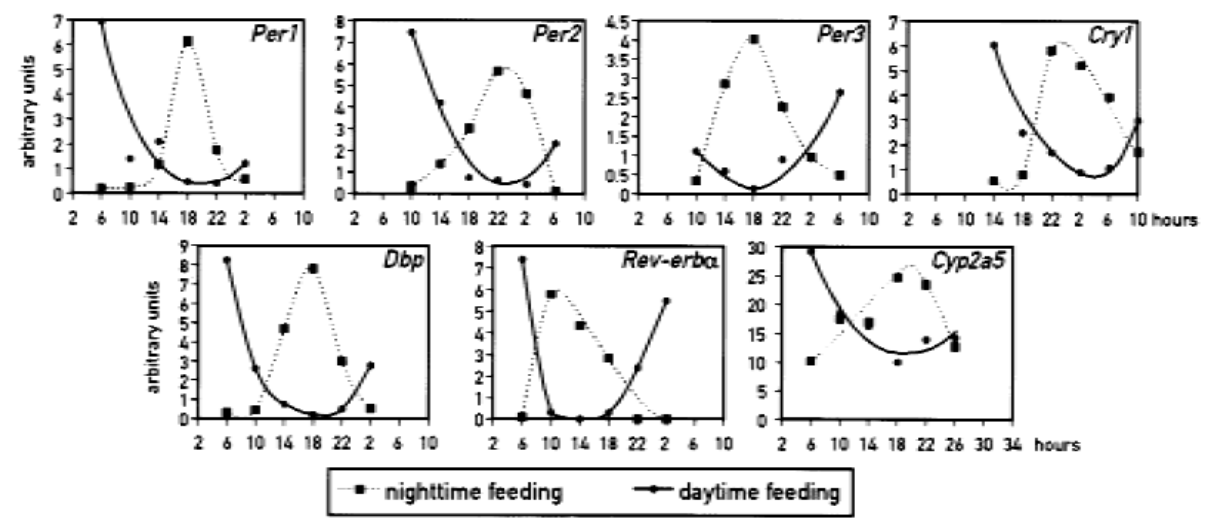

Figure 4: Daytime feeding changes the phase of circadian gene expression in the liver, (Damiola, 2000).

Nevertheless, a complete exclusion of the SCN can not be done. Dependent on the mouse strain the SCN also react to RF, at least in DD conditions [88]. Activity, a direct output of the SCN, measured in CS mice is under DD completely adapted to the feeding schedule. Additionally, Per1, Per2 and Bmal1 expression in the SCN show a strong relationship to feeding time. In contrast, clock gene expression in C57BL/6J mice continues to free run. Their activity is split into one with a freerunning period and a second component of activity adapted to the feeding time [88]. Interestingly, when RF is coupled with hypocaloric feeding both activity and SCN clock gene expression is phase shifted by several hours towards the feeding time in rats [89,90]. A very recent study of Nováková et al. indicates that arrhythmic SCN clock gene expression under constant light (LL) can be restored by restricted feeding [91]. These results indicate that energy metabolism is able to modulate the SCN clock machinery. 
To date, neither neuronal or a metabolic signals nor responsible pathways were identified to explain the uncoupling of the central clock in the SCN completely [92]. The entrainment pathways from feeding-fasting cycles may include postprandial peptide hormones, food metabolites (like glucose), glucocorticoids, postprandial temperature elevations, neuronal connections and intracellular redox state [93] (Figure 5).

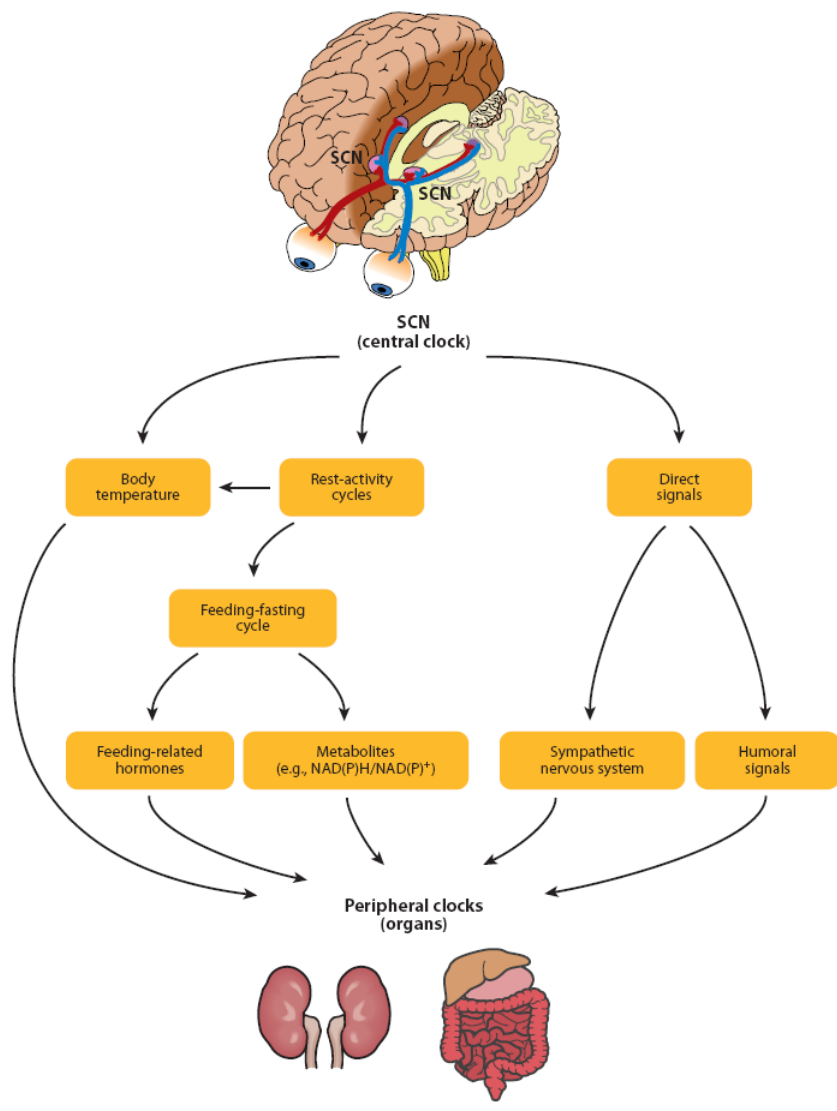

Figure 5: Peripheral entrainment pathways. The SCN sends direct neuronal and humoral signals to the periphery. Additionally, it directly and indirectly controls body temperature and feeding rhythms. Food intake, in turn, may entrain peripheral organs by hormones and metabolites, (Dibner, 2010).

The magnitude of phase shifts of peripheral organs in response to RF is dependent on the amount of food [94]. Starvation of $48 \mathrm{~h}$ itself caused significant but weak phase advance. If under the same conditions different amounts of food are given the liver clock phase shifts in a volumedependent manner. As more food was given as more pronounced was the phase advancement.

To further test which amount of total food must be given to an unusual time to cause phase shifts food was either given during the inactive phase or during the active phase, when mice anyway eat. A minimum of $60 \%$ from the total food volume must be eaten during the inactive phase to cause 
phase shifts [95]. Besides the quantity of food it is also its composition which is important for proper entrainment of the periphery. A convincing study showing that nutrient induced phase shifts of peripheral clock gene expression depends on quality of food was done by Hirao et al. in 2009. After $24 \mathrm{~h}$ starvation PER2::LUC mice were fed for 6 hours with different compositions of nutrients. A mixture of $86 \%$ glucose and $14 \%$ casein caused strongest phase shifts after 2 days RF. Different types of sugar, casein, starch and oil alone were inadequate for inducing phase shifts in the liver [94] (Figure 6).

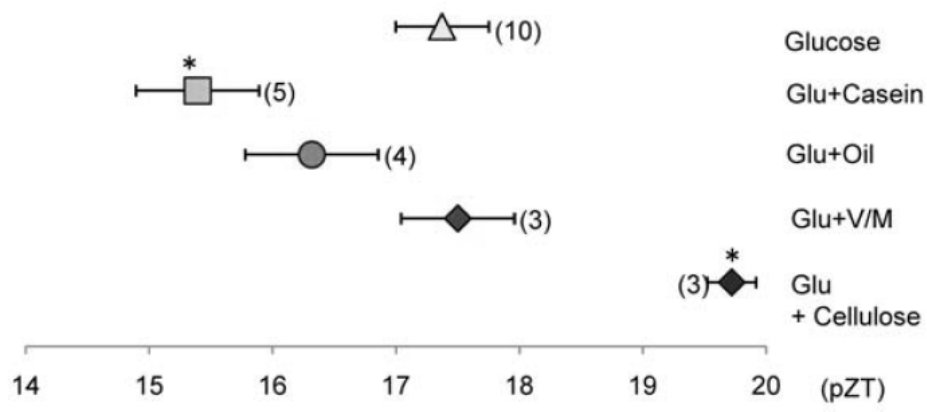

Figure 6: Phase shifts induced in mice fed with different compositions of nutrients. A mixture of $86 \%$ glucose and $14 \%$ casein causes strongest phase shifts, (Hirao, 2009).

In their study of 2001, Le Minh and colleagues demonstrate that the relatively slow phase adaption to daytime feeding is not caused by an intrinsic inertia of peripheral oscillators in mice [96]. In the absence of glucocorticoids in adreanlectomized mice or of glucocorticoid receptors phase shifts in liver and kidney process much faster. They demonstrate that glucocorticoids, which are usually highly secreted at the beginning of activity onset, react within 1-2 days on RF, resulting in a double peak, one at feeding time and one at the activity onset. Due to these results and the absence of glucocorticoid receptors in the SCN [97], they suggested that glucocorticoids may control the phase entrainment of peripheral clocks [96].

Energy metabolism, including glucose conversion, modifies the redox states, defined as the $\mathrm{NAD}^{+}$to NADH ratio, of cells. Mammalian sirtuin1 (SIRT1), a NAD+-dependent deactetylase, has been identified as a regulator of DNA binding of the CLOCK-BMAL1 complex. Thereby it promotes the deacetylation and subsequent degradation of PER2 and alters peripheral clocks [98, 99]. A postprandial rise in body temperature is observed in mice [85]. Either the temperature difference itself or the activation of heat-shock-factor 1 (HSF1) is suggested to synchronize peripheral clocks [100]. However, to date, a direct effect of postprandial elevation of peptide hormones has not yet been shown. 
INTRODUCTION

\subsubsection{Food anticipatory activity}

The phenomenon of FAA is known for a long time [101, 102]. These studies show that animals fed during their inactive phase start to be active several hours before they expect food. Several years later this finding was linked to internal circadian rhythms. FAA caused by restricted feeding is believed to be controlled by a so called food entrainable oscillator (FEO). Even though the location of this oscillator is not detected yet, there is strong experimental evidence for its existence [103].

The FEO conforms to all requirements of a circadian oscillator (see chapter 1.1.1). Some early studies showed, that rats can anticipate to feeding every 24 hours but not to feeding times every 19 or 29 hours which led to the suggestion that other feeding schedules are too far from the internal circadian timing [104-106]. However, a certain entrainment to non-24 $\mathrm{h}$ feeding rhythms is possible. Rats in constant light show anticipation to a 25 hour feeding schedule; simultaneously they displayed a second free-running period different from $25 \mathrm{~h}$ [107]. In contrast to the limited adaption to periods different to 24 hours, another interesting finding in this study is that rats fed at two different time points per day can anticipate to both feeding times [107]. Albeit with difficulties, rats, exposed to two feeding rhythms with different period, were still able to entrain [108]. The discovery of the SCN as central pacemaker of the circadian system $[40,41]$ raised the question for the location of the FEO. Unexpectedly, SCN-lesioned animals were still able to anticipate their temperature, corticosterone levels and activity to restricted feeding schedules $[109,110]$. Even if the SCN is not the location of the FEO it regulates ability of anticipation. Rats with SCN lesions show broader limits of entrainment ranging from about $22 \mathrm{~h}$ to $31 \mathrm{~h}$ [111].

Another evidence for being a circadian oscillator is that transient resetting of the FEO appears when the feeding time is shifted in SCN-lesioned rats. Split transients were observed in a number of rats. Coincidental, these transients had both advancing and delaying proportions [112]. Only a real oscillator needs a certain time to adapt to new conditions and does not immediately shift.

Furthermore, after restricted feeding FAA persists during food deprivation. The persistence implicates that the FEO is able to free-run. Impressively the food entrainable rhythm can persist for around 50 days in rats, although these animals were fed ad libitum (AL) in the meantime [113]. To date the location of the FEO is not assured. SCN-lesion, lesions of dorsomedial hypothalamus, hypothalamic ventromedial nucleus, paraventricular nucleus, lateral hypothalamic area, pituitary, hippocampal formation, amygdala, nucleus accumbens and adrenalectomy all failed to abolish FAA [114]. Lesions of the parbrachial area caused disruption of FAA. However, it appears that in this study the connection between gut signals and brain were disrupted rather then the FEO itself [115]. As 
clock gene expression in peripheral organs is immediately entrained by RF, Davidson and colleagues assumed the location of the FEO in the digestive system [116]. This convincing study excluded the gastro-intestinal tract (GI-tract) and the liver as anatomical locus of the FEO. As expected Per1 expression in the gut and the liver shifted its peak to daytime during RF. During the following $A L$ phase it shifted rapidly back to its nocturnal phase. The important finding was that FAA was still evident in animals that were food deprived after 10 days AL while the phase of Per 1 expression remained nocturnal in gut and liver. This excluded the digestive system as the locus of the FEO [116]. Furthermore, Per2 mutants exhibit very weak FAA whereas peripheral organs are strongly shifted under RF [117]. Together these studies show that the FEO is independent of RF induced phase shifts of the peripheral clock gene expression.

\subsubsection{Circadian disruption}

\subsubsection{Molecular disruption}

Effects of molecular disruption, like mutations or loss of a gene, on the clock are discussed in the chapter 'Clock mutants and knockouts'. Metabolic effects of molecular disruption in comparison to sleep disturbances are reviewed in [118].

\subsubsection{Shift work}

Pursuant to the 'Statistische Bundesamt Deutschland', around 15\% of all German citizens were shift workers in 2003, which is comparable to US conditions. Shift work defines people that work outside of the general defined working times, such as 9 am - $5 \mathrm{pm}$. Some shift work schedules restrict the working hours even completely to night time, but most shift workers have irregular, sometimes unpredictable or rotating work schedules. This might cause stress to the circadian system, because the clock may never be properly entrained and always be in a transient state. Furthermore, shift workers catch up their missed sleep during daytime, resulting in a poorer sleep quality [119]. 
Statistically seen shift workers suffer more from metabolic syndrome, including obesity and diabetes, weaker immune functions, mental disorders, cardiovascular problems, stroke, cancer and other diseases than daytime workers [120-124] (Figure 7). Below some typical risks and symptoms of shift workers are described in more detail:

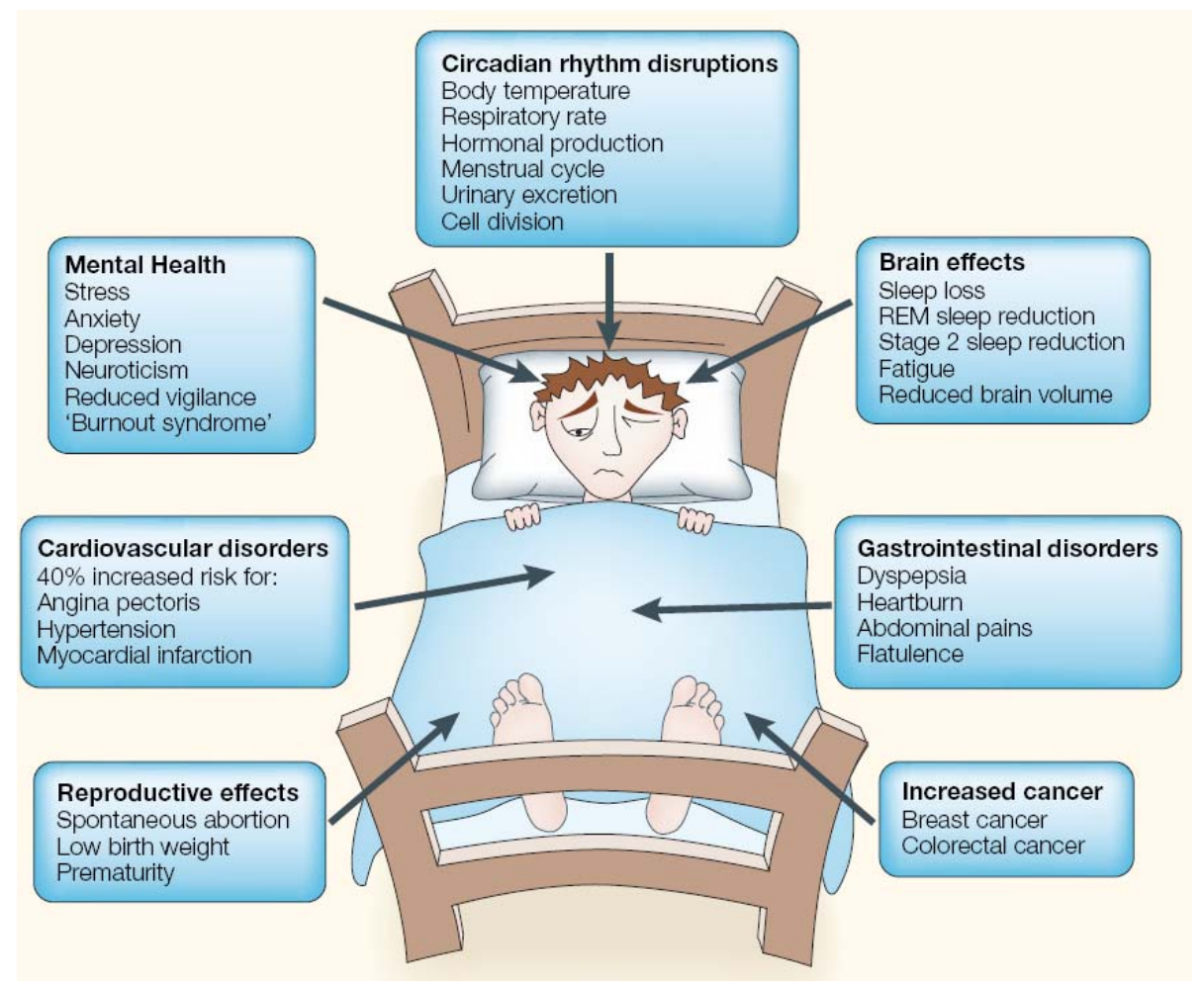

Figure 7: Health problems associated with shift work. The figure illustrates the many physiological and mental health problems that could result from long-term shift work and the associated sleep disruption. REM, rapid eye movement, (Foster, 2005).

Alertness: It was shown that alertness and performance of shift workers is disturbed during night time working hours, leading to increased incidence of accidents [125].

Cardiovascular diseases: Interviewing 14,500 Swedes offered that shift work was strongly correlated with myocardial infarction [126]. Another study observing American nurses for four years showed that the appearance of CVD correlates with the amount of years, when shift work was done [127]. Taken several studies together it is concluded, that the risk of CVD increases by around $40 \%$ in contrast to daytime workers [122]. However, another study did not approve these results [128]. Elevated triglyceride levels were suggested as a possible reason for increased risk of CVD [129]. 
Cancer: Some studies showed close connections between shift work and cancer, mostly breast cancer [130-132]. The rhythm of cell division is controlled by the circadian system [133] as well as the expression of many oncogenes like estrogen receptor [134] or cancer suppressing genes like p53 [135]. In addition, higher or permanent light exposure during night was shown to be a risk factor of breast cancer. It was suggested, that lower melatonin levels caused by light, charge cancer [136, 137]. A special high-risk group are pregnant women. Independent studies reveal adverse effects on women and children. Low birth weight, early abortion, premature birth and irregular menstruation are reported [122].

Gastrointestinal disorders: These disorders are partly accompanied with diabetes, gets more common in shift workers. Already older studies named peptic ulcers as possible symptom of shift workers [138]. Additionally, changes in bowel habits, constipation or diarrhea are reported. Serum concentration of uric acid, total lipids, cholesterol, potassium and glucose are altered by shift work [139]. This indicates an inefficient nutrient metabolism. High glucose levels and insulin resistance are marked signals for diabetes and are obvious in shift workers [140, 141]. Studies on weight gain yielded inconsistent results. Some studies report similar body weights in shift workers, whereas others demonstrate clear differences $[142,143]$.

Night time eating: As a result of awakeness during night, shift workers tend to eat more during the night as during the day [144]. This was previously shown in animal experiments with rats, which were forced to 'work' during day in a slowly rotating cylinder [145]. Eating during sleeping time has been shown to be a reason for weight gain in animals and humans [146, 147]. Especially night time eating is interesting due to the fact that eating during the rest phase uncouples the periphery from the SCN master clock (see 1.2.2). The developed desynchronization within one body might be directly or indirectly responsible for all the symptoms described for shift workers.

\subsubsection{Jet lag}

Advances or delays in timing of light lead to a temporary circadian disruption, because the organism is neither in synchrony with the environment nor are the internal oscillators synchronized. In principle, jetlag evokes the same symptoms as shift work. Jetlaged people suffer from gastrointestinal disturbances, depressed mood and reduced cognitive skills. Besides, acceleration of cancer growth was reported [148]. In animals repeated jetlag increases even mortality [149]. 


\subsection{Postprandial physiology}

\subsubsection{Hunger and Satiety}

Hunger is a feeling to cause the uptake of food. When enough nutrients are taken up satiety enters. The adjustment of energy uptake and expenditure is important to keep body weight stable over time and to regulate the interval to the next meal. The regulation of energy homeostasis and food uptake occurs in the brain. Responsible brain regions are the brain stem, nucleus accumbens (NAc) and mainly the hypothalamus. The hypothalamus contains many nuclei which are important regulators for appetite and energy balance: the arcuate nucleus (ARC), the paraventricular nucleus (PVN), the dorsomedial hypothalamus (DMH), the ventromedial hypothalamus (VMH), the lateral hypothalamic area (LHA) and the perifornical area (PFA) [150].

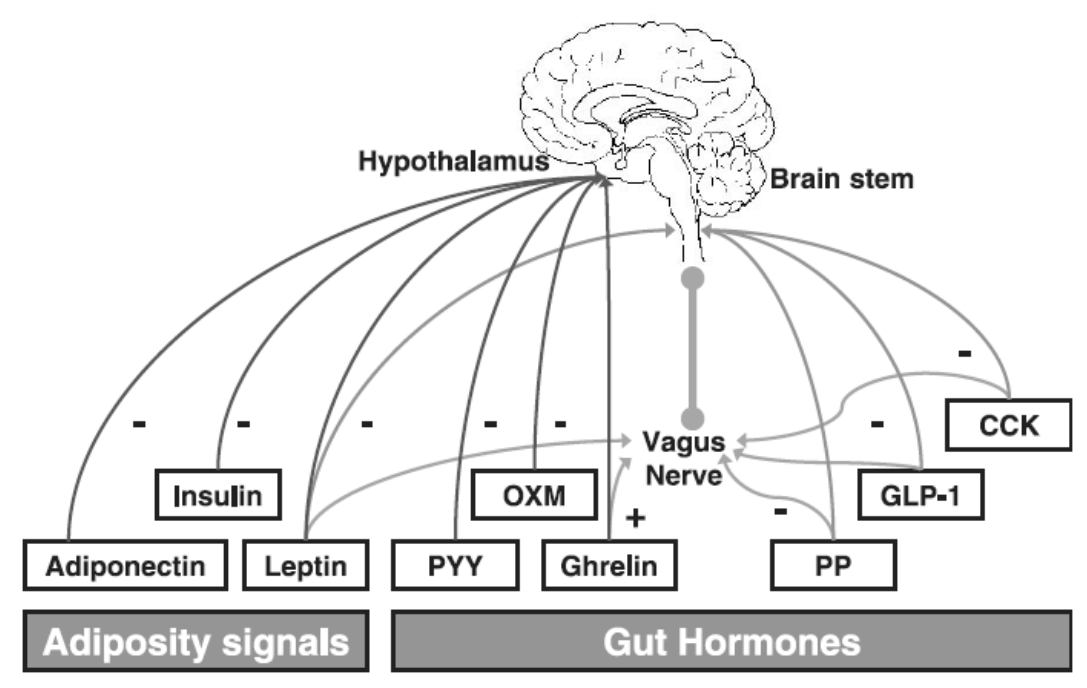

Figure 8: Energy homoestasis is controlled by peripheral signals from adipose tissue, pancreas, and the gastrointestinal tract. Peripheral signals from the gut include peptide YY (PYY), oxyntomodulin (OXM), ghrelin, pancreatic polypeptide (PP), glucagon-like peptide 1 (GLP-1), and cholecystokinin (CCK). These gut-derived peptides and adiposity signals influence central circuits in the hypothalamus and brain stem to produce a negative (-) or positive (+) effect on energy balance. Thus the drive to eat and energy expenditure are adjusted so that over time, body weight remains stable, (Stanley, 2005)

One main feature of these brain areas is the higher permeability for peptide signals crossing the blood brain barrier [150, 151]. Peripheral signals reach the ARC, which, in turn, integrates the incoming signals. It releases activating or inhibitory signals to other nuclei. The PVN is the secondary order hypothalamic integrator for incoming signals and receives signals, which are responsible for 
both hunger and satiety [152]. Signals reaching the VMH and the DMH are causing satiety [153, 154], whereas the LHA and the PFA are seen as centres for hunger $[155,156]$. Peripheral alimentary organs like stomach, adipose tissue, pancreas, the gastro-intestinal tract and the liver secrete pre- and postprandial hormone signals. The stomach produces ghrelin, the only known peripheral orexigenic peptide. Ghrelin administration enhances food intake and, conversely, preprandial ghrelin blockade decreases food intake $[157,158]$ (Figure 8). Ghrelin's action on food intake is via the ARC, the caudal brain stem and mesolimbic reward centers [159]. Furthermore, the stomach reacts via stretch, protein and $\mathrm{pH}$ receptors signaling that it is filled with nutrients. As response the stomach secrets gastrin which, in turn, leads to higher gastric acid secretion and gastric motility tonus [160, 161]. Adipose tissues react to food uptake with secretion of adipokines, for instance the anorectic factors leptin and adiponectin. Leptin receptors are found in the ARC, VMH, DMH and LHA and the nervus vagus [162-164]. In the hypothalamic nuclei leptin has a double function. On the one hand it inhibits the action of orexigenic NPY neurons, whereas on the other hand it increases the action of anorectic proopiomelanocortin (POMC) neurons [165]. After injection of Adiponectin, c-fos expression increases in the PVN, which points up its role in hunger and satiety signaling [166].

The hypothalamus is also receptive for pancreatic peptides. The most prominent role of the pancreatic hormone insulin is the initializing conversion from glucose to glycogen. Therefore, it increases rapidly after a meal. It was shown that insulin receptors are present in the ARC, DMH, PVN and also in the SCN [167]. Pancreatic polypeptitde (PP) belongs together with neuropeptide Y (NPY) and peptide $Y(P Y Y)$ to the PP-fold family which members share the G-protein coupled receptors $Y_{1}-Y_{5}$. It shows diurnal variation with highest levels in the evening but is also increases after food intake [168]. Mice overexpressing PP have a lean phenotype and reduced food intake [169]. According to this, some studies show that PP levels are reduced in obese subjects which might lead to elevated calorie uptake [170]. However, other reports do not show comparable effects [171].

Even before the plasma glucose level increases, GI incretin hormones like Glucagon-like peptide-1 (GLP-1), Gastric inhibitory polypeptide (GIP) and Oxyntomodulin (OXM) are secreted. Incretins are responsible for decreasing gastric activity, and OXM activate pancreatic insulin production to prepare the organism for glucose uptake and prevent short-term hyperglycemia. Other postprandial GI peptides are Cholecystokinin (CCK) and PYY. When the acescent food enters the duodenum, pH-receptors are activated followed by production of secretin. Secretin increases bicarbonate solution from pancreatic duct epithelium to neutralize the gastric acid of the food bolus and simultaneously decreases gastric acid production $[172,173]$. 
Indirectly, via glucose utilization, the liver may control food intake. As higher the plasma glucose level is as lower is the subjective appetite and thus, food intake. The same effect holds true for free fatty acids (FFAs). Inhibition of FFA oxidation is associated with enhanced eating in animals and humans [174].

\subsubsection{Gut peptides in postprandial signaling}

Peptide YY: PYY is secreted in L-cells of the Gl-tract, in particular ileum, colon rectum [175] and activates receptors $Y_{1-5}$. It is likely that PYY secretion is neuronal regulated as it increases much earlier after food intake as the food bulb reaches the secreting regions [176]. After secretion parts of the full-length peptide are cleaved into a truncated form of PYY by dipeptidyl peptidase-4 (DPP-4). The truncated peptide is seen as the main agonist for the $Y_{2}$ receptor subtype [177]. It is mainly increased after fatty meals and may act as an orexigenic or an anorectic factor. Administration of PYY directly in the ARC inhibits local NPY neurons and lowers plasma ghrelin levels $[178,179]$. The same results were shown for peripheral administration. However, injected into the CNS it shows opposite effects [180]. The different effects of PYY can be explained by the distribution of $Y$ receptors, as the $Y_{2}$ receptor is mainly detected in the ARC whereas subtypes $Y_{1}$ and $Y_{5}$ are distributed throughout the whole hypothalamus $[178,181]$. Peripheral-administrated PYY may only reach the ARC through the higher permeability of the median eminence, which describes the more relevant situation. The complete mechanisms how PYY influences food intake remain unclear [150].

Cholecystokinin: The postprandially upregulated CCK is mainly secreted in the duodenum and the jejunum [182]. It is known to advance digestion by stimulating pancreatic secretion and gall bladder emptying and intestinal motility. Additionally it delays gastric emptying, leading to an earlier satiety feeling [183]. In fact, it reduces meal size [184]. Studies with the $\mathrm{CCK}_{\mathrm{A}}$ receptor knockout rat suggest that it might act via the DMH where it suppresses NPY neuron activity [185].

Products of the Pre-proglucagon gene: Tissue-specific post-translational cleavage of the preprohormone called pre-proglucagon gives, among others, rise to production of GLP-1/2, GIP, glucagon, glicentin and OXM, also known as Glucagon-37 [186] (Figure 9). The amount of end products is strongly dependent on the tissue. Glucagon is exclusively secreted in the pancreas, whereas GLP-1/2 are produced in the pancreas and the GI-tract. The degradation of GIP, GLP-1/2 and OXM, is achieved by DPP-4, a cell surface serine dipeptidase [103]. 
GLP-1 is secreted in the intestinal endocrine cells, the pancreas and the brain stem and belongs to the principal incretin hormones [187]. It is released postprandially by the L-cells of the small intestine [188]. GLP-1 injected directly into the third ventricle of the brain activates neurons in the PVN and powerfully inhibits food uptake in rats [189]. Interestingly, it induces c-Fos only in the brainstem and the PVN but not in the ARC [190]. Systemically injected GLP-1 also reduces food intake in rodents and humans $[191,192]$. However, GLP-1 administration is not an eligible treatment against obesity, since nausea is a frequently reported side-effect [193].

Pre-proglucagon

Proglucagon

Cerebral and intestinal processing

Pancreatic processing
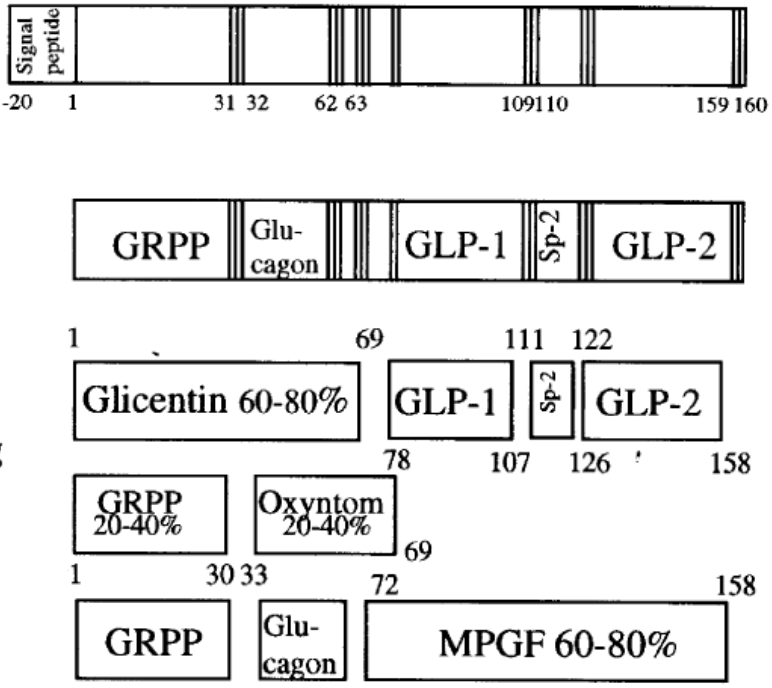

1

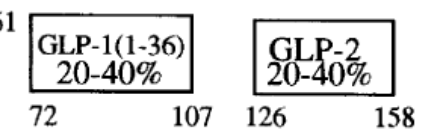

Figure 9: Post-transcriptional processing of pre-proglucagon. At different cleavage steps processing yields glucagon, oxyntomodulin, GLP-1 and GLP-2, (Tang-Christensen, 2001).

In this study we concentrate on the pre-proglucagon product OXM. The secretion of OXM is constricted to the L-cells in the jejunum, the ileum and the colon as well as to pancreatic A-cells [194]. OXM contains all 29 amino acid sequence of glucagon plus a basic octapeptide at the C-terminus, known as spacer peptide-1 $[187,195,196]$. It was first described by Bataille et al. in 1981. This group showed that bioactive enteroglucagon contains OXM which was able to activate rat liver membraneadenylate cyclase and cyclic AMP in gastric glands isolated from the rat stomach [195]. At this time the role of enteroglucagon was not well clarified and it served like a general term describing glucagon-like factors with unknown function. 
OXM is released into blood in response to food ingestion. LeQuellec and colleagues did a diurnal profile in human subjects. Blood OXM increased postprandially, but the clearance of OXM was shown to be under circadian control as it was delayed during the night. Furthermore they showed a clear proportion to calorie intake [197].

Gastric acid secretion: The actions of OXM are in many cases comparable to those of GLP-1/2 and glucagon. Injections of OXM during fasting conditions almost abolishes gastric acid secretion after pentagastrin stimulation [198] or after refeeding in rodents [199]. Even in humans synthetic OXM inhibits pentagastrin-stimulated acid secretion [200]. GLP-1 and GLP-2 as well as glucagon show comparable but much weaker actions on gastric acid secretion [201-204].

Gastric emptying: Besides acid secretion Schjoldager and colleagues investigated in 1989 a set of other potential roles of OXM in humans [205]. Interestingly the structural analogy of OXM to glucagon was mirrored in the functions of OXM. They found that gastric emptying was strongly delayed after OXM infusion and the liquid test meal remained twice as long in stomach. The same effect was shown before for pancreatic glucagon [206].

Pancreatic actions: Moreover, other publications comparable effects of GLP-1 and OXM on the pancreas. OXM mimics GLP-1 actions on ß-cell survival inhibiting apoptosis [207]. Both GLP-1 and OXM show insulinotropic effects. GLP-1 is well known for its actions on insulin production [208-210]. Comparably, a dose-dependent increase of insulin production in isolated perfused pig and rat pancreases was shown for OXM $[211,212]$. The parallel increase of glucagon in both studies was counterintuitive of the fact that glucagon and insulin are physiological antagonists. Although OXM is able to increase pancreatic insulin secretion it is as well responsible for a decrease of total pancreatic juice secretion studied on three parameters: volume of juice, bicarbonate and total protein output. This study demonstrated that OXM was approximately ten times more potent than glucagon [213]. A subsequent study showed that this effect was transmitted through the vagus nerve and independent of GLP-1.

Anorectic function in rodents: More recently OXM has been shown to be an effective anorectic factor in rodents and humans [214, 215]. This may in part be due to the previously described delayed gastric emptying which correlates with appetite. An anorectic function was also previously described for GLP-1. When administered to the cerebroventricular system (i.c.v.) or the paraventricular nucleus (PVN) GLP-1 reduces food intake significantly in rats [189, 216, 217]. Dakin and colleagues reported in 2001 that OXM works even stronger on food intake than GLP-1. They demonstrated GLP-1 and primarily OXM reduced food intake significantly under refeeding conditions 
as well as under ad libitum conditions. The effect on the PVN was comparable for GLP-1 and OXM. Notably, all presented effects of GLP-1 and OXM were completely abolished by parallel injection of Exendin-9-39 (Ex9-39) [214]. Ex9-39 has been reported to be a potent and highly selective antagonist for GLP-1r [218]. i.c.v. injections of OXM do not only reduce food intake and as a consequence a great reduction in body weight gain in rats caused by reduction of white adipose tissue (WAT) and brown adipose tissue (BAT). Furthermore OXM induces an increase of body core temperature, suggesting that OXM might also enhance energy expenditure in rats [219]. The same group reported systemic intraperitnoeal (i.p.) injections led to comparable effects on food intake and body weight [220]. An oral delivery system using transfected OXM secreting bacteria caused reduced food intake and loose of body weight in overweight BALB/c mice on HFD [221]. In contrast, another study showed that OXM reduces food intake only via i.c.v. but not via i.p. injection in mice [191]. However, the effects of GLP1 were demonstrated via both i.c.v. and i.p. administration. The effects of both agonists were abolished in GLP-1 receptor knockout mice (GLP-1 $r^{-/}$) but not in glucagon receptor knockout mice $\left(\mathrm{Gcgr}^{-/}\right)$mice. This leads to the suggestion that although OXM and GLP-1 interact with GLP-1r but regulate food intake and energy expenditure through distinct pathways [191].

Anorectic function in humans: Shortly after the investigations in rats comparable results were shown in humans who received intravenous (i.v.) infusions of OXM. Total energy uptake was significantly reduced, which might be based on the fact that also blood ghrelin levels were significantly decreased during the infusion time in these subjects [222]. Of note, the subjective hunger score was not changed [222]. Comparable to the results in rats, OXM also leads to weight loss in humans up to $2.3 \mathrm{~kg}$ within 4 weeks [215]. In addition, to reduced food intake OXM increased total energy expenditure in overweight and obese humans [223]. On the other hand GLP-1 application caused a decrease in energy expenditure in humans [224]. Furthermore, OXM and GLP-1 appear to act differentially in distinct brain regions. Peripheral administration of OXM causes reduction in neuronal firing rate of the ARC, the PVN and the supraoptic nucleus (SON) in the hypothalamus, whereas GLP-1 application caused decreased neuronal activity in PVN only but increased activity in the VMH [225]. 


\subsubsection{Postprandial signaling in the liver}

Comparable to the stomach, the gastrointestinal tract, adipocytes and the pancreas the liver reacts sensitively on food uptake and the organism's energy state. Under fasting conditions or postprandial it receives signals changing the internal metabolism or, additionally, secretes hormone signals by itself [174].

The liver plays the most important role in energy homeostasis. As it has very fine sensors for metabolic signals it is involved in many mechanisms related to nutrient metabolism and energy expenditure. Most prominent functions in this context are glucose storage in form of glycogen, gluconeogenesis, storage of fat and utilization and control of food intake.

After a carbohydrate containing meal plasma glucose levels immediately increase. To prevent hyperglycemia, insulin is released by the pancreas. More commonly is a resistance to insulin, causing type II diabetes, also resulting in low glucose absorption. Binding of insulin to the extracellular $\alpha$ subunits of the insulin receptor ends in autophosphorylation of insulin receptor substrate 1 (IRS-1). A signal transduction including protein kinase B (PKB) and glycogen synthase kinase (GSK3) is activated and leads via glycogen synthase (GS) to production of insoluble glycogen [226].

The opposite effect under fasting conditions is caused by glucagon, a product of the preproglucagon gene. Under starvation plasma glucose levels might decrease drastically. To prevent hypogylcemia, the pancreas releases glucagon. Glucagon causes the liver to convert stored glycogen into glucose, which is released into the bloodstream. Glucagon binds to the hepatic glucagon receptor activating adenlyte cyclise (AC) and this, in turn, manufactures cyclic adenosine monophosphate (CAMP). Finally activated glycogen phosphorylase (phosphorylase A) converts glycogen into glucose which is released to the blood via GLUT2 [227]. The glucose transporter GLUT2 is under circadian control with peak in the morning and trough at the evening [66].

Other pre- or postprandial mechanisms to keep blood glucose levels constant are glycolyse and gluconeogenesis. Glycolysis is the metabolic pathway that converts glucose into pyruvate producing ATP. Conversely, gluconeogenesis is a metabolic pathway that results in the generation of glucose from non-carbohydrate carbon substrates such as lactate, glycerol, and glucogenic amino acids. Important components of both pathways like Gck, G6Pase and phosphoenolpyruvate carboxykinase (PEPCK) are circadian controlled and show strong rhythmicity [66].

Ingested fat occurs in three different variants: Lipoproteins, cholesterol and FFAs. The liver is responsible for the uptake of fat through the intestines the metabolism of FFAs and the conversion of 
ingested fat to lipoproteins. Secretin, postprandially produced by the gastrointestinal tract (see chapter 'Gut peptides in postprandially signaling'), leads to a higher production of bile acid, which, in turn, elevates the resorption of fat [228]. Afterwards, gastrin and CCK signal leads to gall bladder emptying [229]. Once the fat is in the blood the liver converts it into very light, light and heavy density lipoproteins (VLDL, LDL and HDL). PPAR gamma coactivator-1 $\alpha$ (PGC-1 $\alpha$ ) stimulates hepatic lipid metabolism by enhancing FFA release from triglycerides [230].

\subsection{Aims}

When food access is restricted to certain periods of the day (restricted feeding) the expression of clock genes in peripheral organs resets to synchronize to the time of food availability and uptake independently of the SCN. Hence, it seems like metabolic signals provided with food uptake are able to uncouple peripheral clocks from the central pacemaker, since the SCN remains locked to the LD cycle. The nature of these signals remains unclear.

Our hypothesis is that postprandial signals released by the Gl-tract are responsible for food synchronization of peripheral clocks. Representative for peripheral organs we chose the liver as it is strongly involved in the digestive system, shows robust rhythmic clock gene expression in vitro as well in vivo and can be robustly entrained to feeding schedules. The aim of this study was to identify a GI hormone peptide which is able to reset the liver clock independently of the SCN in vitro and in vivo and to characterize the associated pathway. A screen of GI hormone peptides was done to identify factors capable of resetting circadian rhythms in vitro. It would be interesting to describe the impact of one of the detected candidates on the circadian system. Of particular interest would be how TTL components react on treatments with the candidate in vitro and in vivo. Furthermore, it would be important to find the molecular pathway responsible for the synchronization of the liver and consequently the uncoupling from the SCN. An additional focus will be the inhibition of liver resetting by antagonistic factors. This would encourage the relevance of the GI peptide and gives an idea how to prevent internal desynchronization.

This study might also be interesting in the context of shift work, which is characterized by internal desynchronization. Peripheral synchronizing pathways could provide a possible target for medical drugs to counteract the physiological consequences of this condition. 


\section{RESULTS}

\subsection{Peptide hormone screen}

\subsubsection{Validation of screening method - Dexamethasone PRC}

This thesis is based on the identification of a Gl-peptide hormone which is able to alter the liver intrinsic circadian clock. We used liver slices of PER2::LUC mice to observe the expression of the PER2 protein in real-time. Liver slices were cultured on a permeable membrane which is in permanent contact with the culture medium containing luciferin. This guarantees a sufficient supply with water, nutrients, oxygen and luciferin. Usually, at the second day of culturing a clear PER2::LUC expression rhythm is detectable which last up to 12 days (Figure 10). In average liver slices showed a very stable period of around $23.75 \mathrm{~h} \pm 0,077$ (Mean \pm SEM).

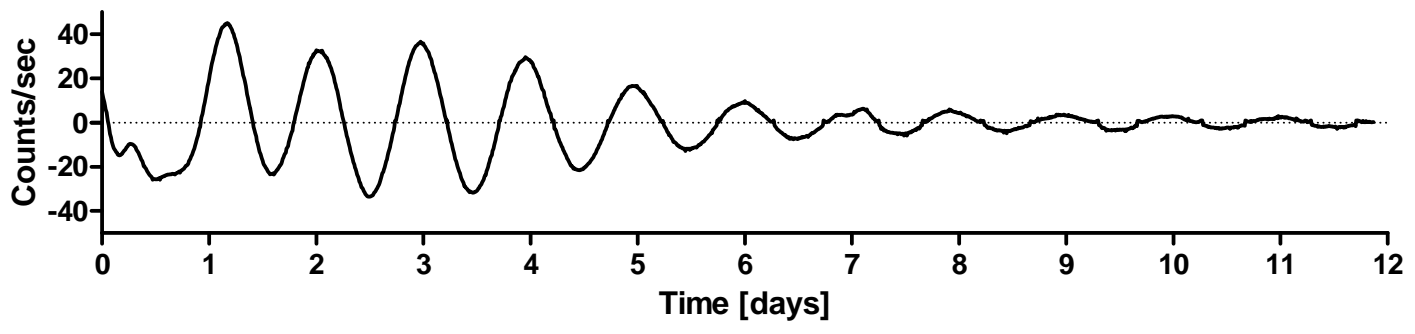

Fig. 10: Representative curve of PER2::LUC measurement of a single liver slice. The signal was measured for 12 days. Rhythmic expression of PER2::LUC is not observed until second day. As of day 5 a gradual dampening of signal begins which continues until the end of the recording.

In principle four different reactions on treatment are possible: 1) A phase shift of the PER2::LUC expression, either phase advances or phase delays. 2) Without any treatment we expected a period of approximately 24 hours. Shortening or lengthening of the period are potential reactions on treatment. If period was changed by more than $3.5 \mathrm{~h}$, liver slices were excluded from evaluation. 3) The amplitude can be elevated or dampened. 4) The treatment can cause no reaction. 
A

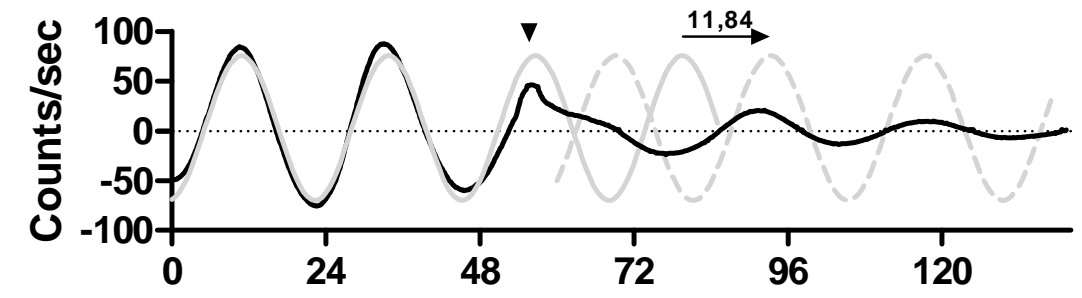

B
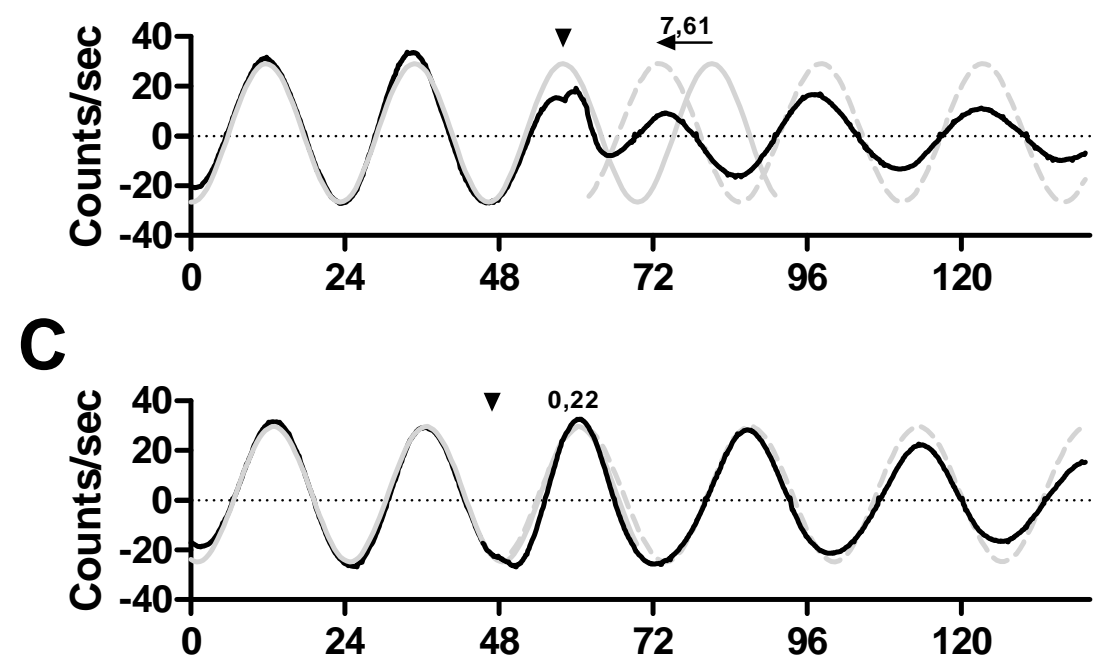

Fig. 11: Representative curves of PER2::LUC measurement of dexamethasone treated liver slices. (A) Treatment at $81^{\circ}$ caused a strong phase delay whereas (B) treatment at $128^{\circ}$ caused a strong phase advance. (C) Administration of dexamethasone at $258^{\circ}$ did not change PER2::LUC expression. Arrowhead: time point of treatment; black line: baseline subtracted data of PER2::LUC measurement; grey solid line: sinus curve fits of data before treatment; grey dashed line: sinus curve fit of data after treatment; arrows: distance from the next expected peak without treatment to the new upcoming peak after treatment.

To validate the experimental setup liver slices were treated with dexamethasone, an artificial glucocorticoid which was already shown to reset the clock of peripheral organs [231]. Liver slices were cultured until a minimum of two proper PER2::LUC expression cycles were measured. These data were used as reference values with which the expression after treatment has been compared (Figure 11). We treated individual liver slices with $100 \mu \mathrm{M}$ dexamethasone approximately each hour throughout 24 hours to show different reactions at different phases of their internal clock (Phase response curve, $\mathrm{PRC})$. 
Dexamethasone was able to phase shift the PER2::LUC expression of the liver slices. The resulting PRC exhibits phase delays between $0^{\circ}-120^{\circ}$, mainly phase advances between $120^{\circ}-240^{\circ}$ and a dead-zone during which nearly no resetting was observed between $240^{\circ}-360^{\circ}$ (Figure 12).

\section{Dexamethasone PRC}

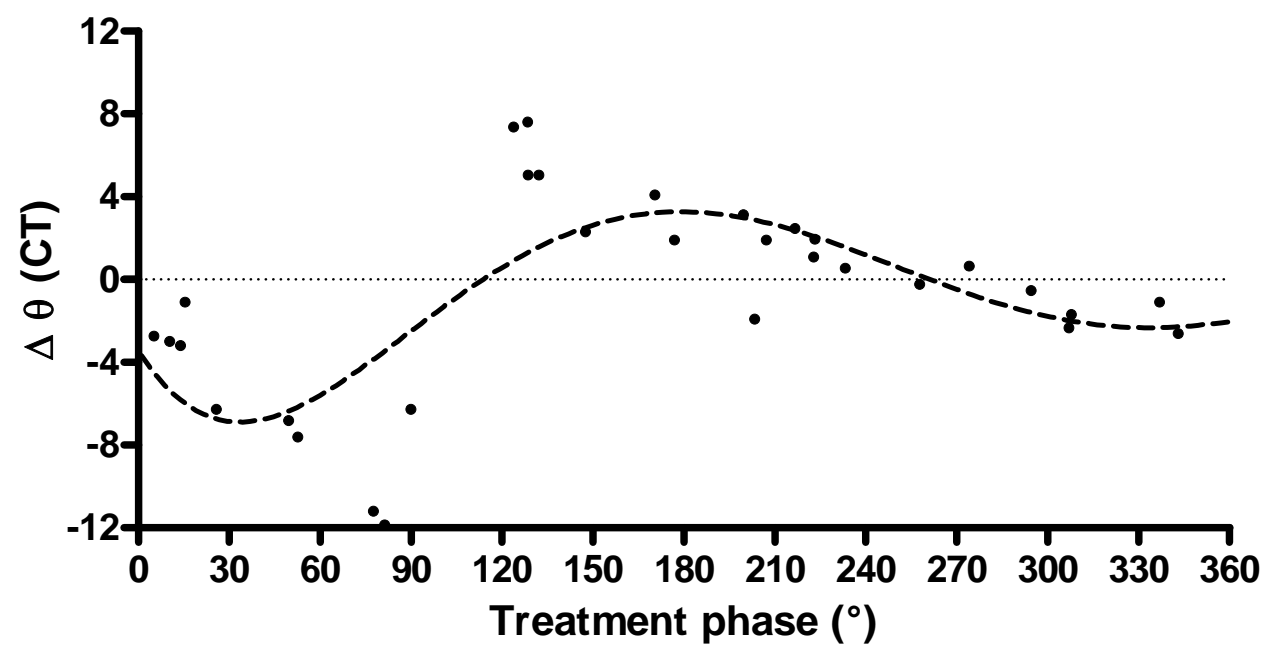

Fig. 12: Dexamethasone-induced phase shifts in the expression of PER2::LUC were dependent on treatment time with strongest delaying phase shifts at approximately $80^{\circ}$ and strongest phase advances at approximately. $130^{\circ}$. Grey dots: raw data of individual liver slices; dashed line: regression, CircWave.

\subsubsection{Peptide hormone screen}

As the dexamethasone treatments show that we have an appropriate experimental setup, we treated individual cultured liver slices with GI-hormone peptides. Each liver slice was treated once after minimum two and maximum three complete per2 expression peaks. Treatment was done at approximately $200^{\circ}$ with different peptide hormones each with the concentration of $455 \mathrm{pM}$. A total of 200 different peptides were tested (Phoenix pharmaceutics). We quantified the phase shifts by comparing the time point of the next expected peak after treatment with the time point of the new peak after treatment. The expected peak and the actual peak were extrapolated from data before the treatment alternatively from data beginning with the second proper peak after treatment. 

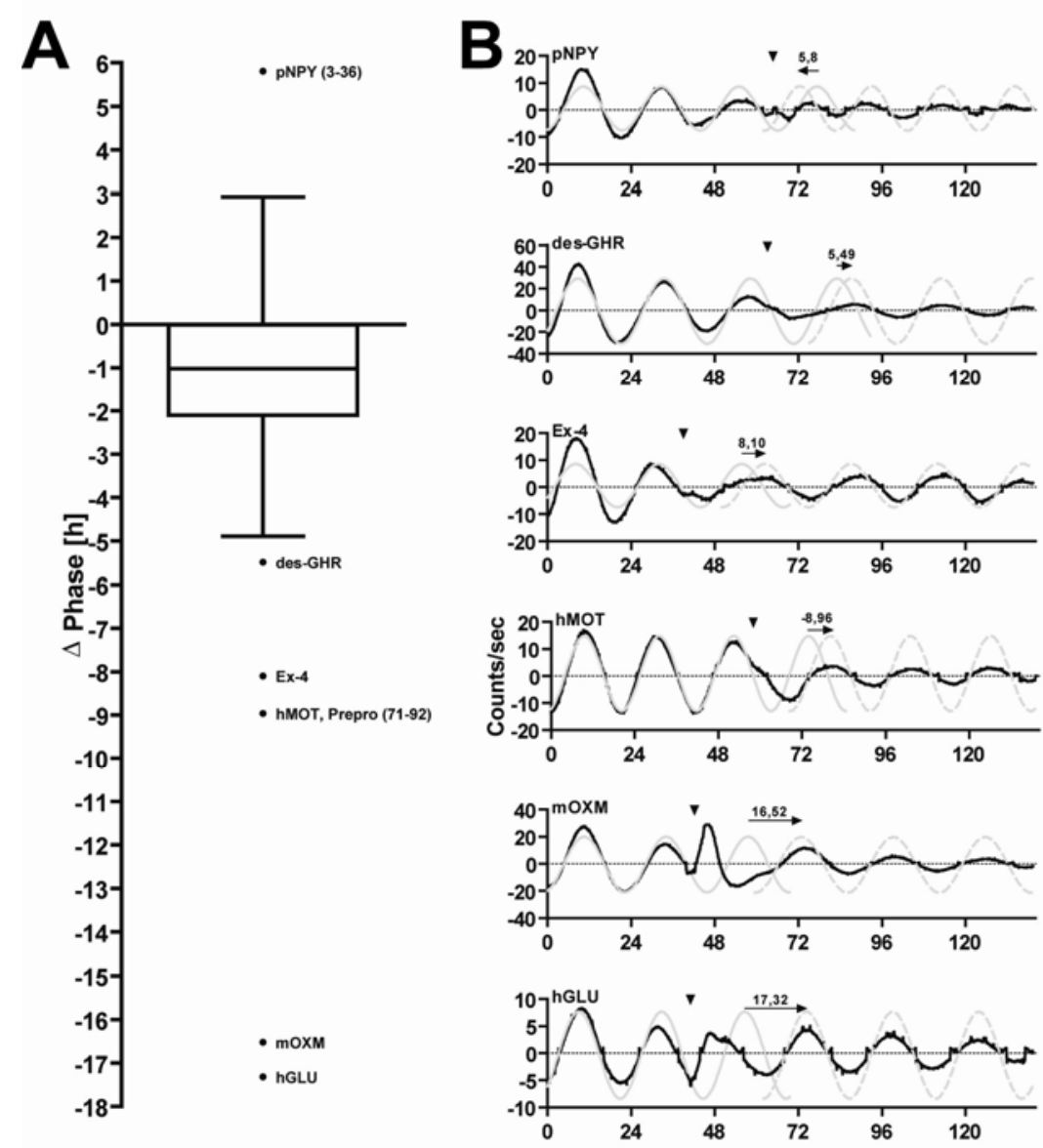

Fig. 13: Oxyntomodulin and other peptide hormones are able to phase shift PER2::LUC expression in the liver. (A) Organotypic Per2::Luc liver slices were treated with 200 different GI-peptides. Candidates were detected by Whiskers: Tukey Boxplot, pNPY (3-36): Neuropeptide Y (porcine) (3-36), des-GHR: des-octanoyl3 Ghrelin, Ex-4: Exendin-4, hMOT, Prepro (7192): Motilin, Prepro (71-92) (Human), mOXM: Oxyntomodulin (mouse), hGLU: Glucagon (human). (B) Representative curves of PER2::LUC expression of candidate and control treated liver slices. Arrowhead: time point of treatment; black line: raw data of Per2::Luc measurement; grey solid line: sinus curve fits of data before treatment; grey dashed line: sinus curve fit of data after treatment; arrows: distance from next expected peak without treatment to actual peak after treatment.

Only six of 200 peptides caused significant phase shifts of PER2::LUC expression. Most peptides caused phase delays when administered to the liver slices whereas only a few peptides caused advances. NPY was the only peptide leading to a significant phase advance $(\sim+5.8 \mathrm{~h})$. In contrast des-octanoyl ${ }^{3}$ Ghrelin (des-GHR; -5.5 h), Exendin-4 (Ex-4; -8.1 h), human Motilin (hMOT; -9 h), mouse OXM (mOXM; -16.5 h) and human Glucagon (hGLU; -17.3 h) caused significant phase delays (Figure 13). Only a few peptides, human GLP-1 (hGLP-1), rat Pancreastatin (rPAN) and Salusin alpha (SAL- $\alpha$ ), interrupted PER2::LUC expression rhythms completely. Data of Neurotensin 8-13, PACAP-27 and PYY 2-36 were excluded from evaluation, since they caused period changes greater 
than $3.5 \mathrm{~h}$. Control treatments with sodium chloride $(\mathrm{NaCl})$ solution caused only weak phase delays of approximately $0.2 \mathrm{~h}$.

\subsubsection{Oxyntomodulin - Dose response curve}

Since OXM was the GI-peptide hormone which caused the strongest phase shift and its secretion is induced by food consumption [197] we suggest that OXM is the most potent GI-peptide signal for bearing food signals to the liver clock. Its action on the liver clock in vitro was validated for the same concentration used in the screen $(455 \mathrm{nM})$ and to address more realistic and physiological properties slices were tested with lower concentrations. We found that the action of OXM on liver clock is strongly dose dependent. Concentrations from 150 nM to 455 nM cause significant phase shifts with increasing intensity from lower to higher concentrations. Lower concentrations in the range from 0.455 - $45.5 \mathrm{nM}$ were not able to cause significant phase shifts (Figure 14A).
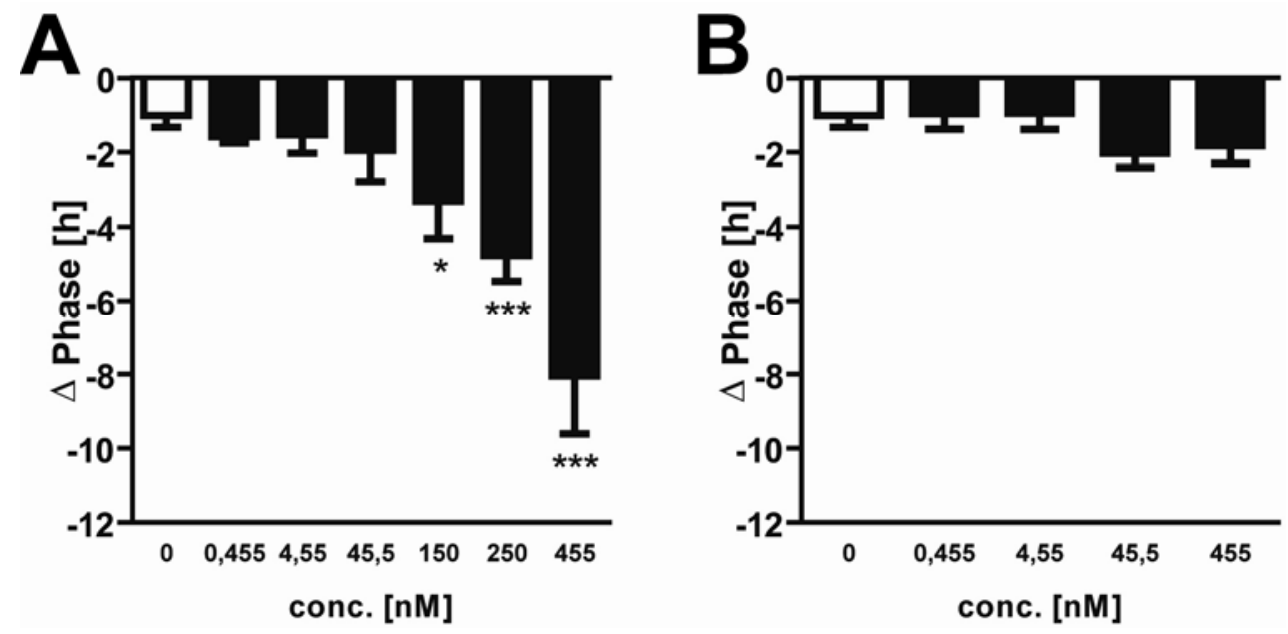

Fig. 14: The reaction on Oxyntomodulin but not on GLP-1 is dosage dependent. (A) The phase shifts increase with higher concentrations of OXM (B) GLP-1 did not cause phase shifts with any tested concentration. $455 \mathrm{nM}$ was the concentration used in the screen. White bar: control treatment with $\mathrm{NaCl}$, black bars: OXM treatment with different concentrations. Data are presented as mean $\pm \mathrm{SEM}$, respectively. Asterisks show significance to control treatment with $\mathrm{NaCl}$ solution. Student's ttest: *, $\mathrm{P}<0.05 ; * *, \mathrm{P}<0.01 ; * * *, \mathrm{P}<0.001$.

However, we also found that the OXM related peptide GLP-1 abolished the PER2::LUC expression completely. GLP-1 and OXM were shown to bind to the same receptors. Thus we also 
tested lower GLP-1 concentrations due to the possibility that GLP-1 is also able to phase shift the clock but the concentration used in the screen was too high. $40 \%$ of all liver slices treated with the highest concentration lost rhythmicity immediately. $20 \%$ became arrhythmic after the first peak under treatment and only $40 \%$ continued to oscillate for further three days. Lower concentrations did not disrupt rhythmicity. Those liver slices, which stayed rhythmic for at least one post-treatment peak, did not show any significant phase shift (Figure 14B).

\subsubsection{Oxyntomodulin - Phase response curve}

To examine the reaction on OXM in the range of $24 \mathrm{~h}$ we treated liver slices at different time points and calculated the resulting phase shifts. On the basis of these data we found few if any phase advances but mainly phase delays. Treatments between $270^{\circ}-60^{\circ}$ caused no significant phase shifts. Whereas the strongest phase shifts were observed between $150^{\circ}-180^{\circ}$. A phase response curve was acquired by plotting the phase shifts against the circadian time of treatment (Figure 15).

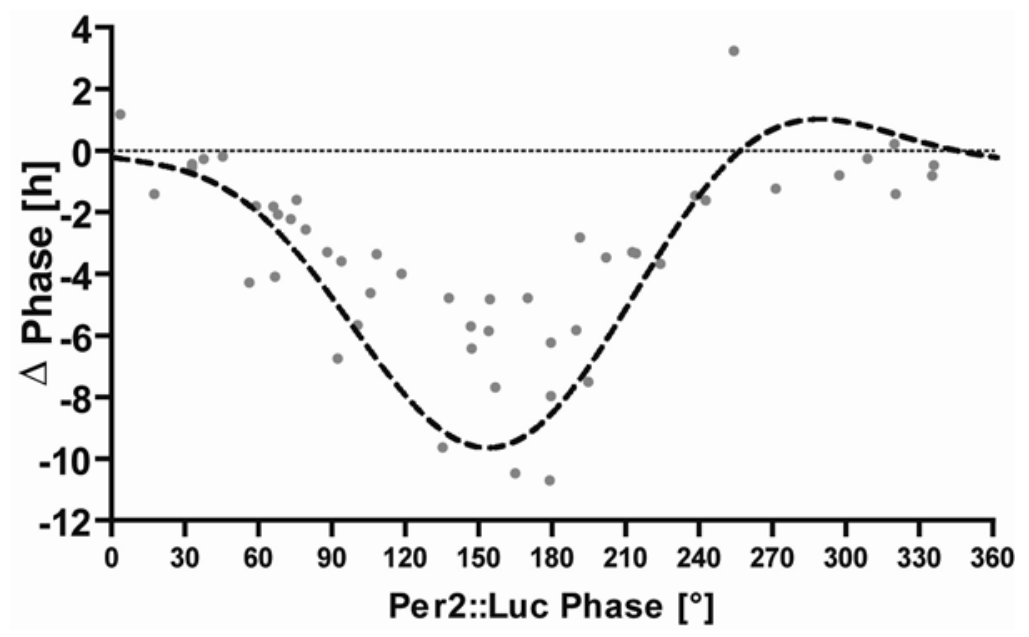

Fig. 15: Phase response curve for Oxyntomodulin. OXM-induced phase shifts in the expression of PER2::LUC were dependent on treatment time with strongest reactions at approximately. $170^{\circ}$. Grey dots: raw data of individual liver slices; dashed line: regression, CircWave. 


\subsection{Postprandial events}

\subsubsection{OXM induction in mice}

Previous human studies already showed that OXM secretion is strongly dependent on food intake. After ingestion OXM is rapidly released and causes a feeling of satiety [220].

To test whether OXM is postprandially released in mice as well, we took blood samples after refeeding from mice. WT male mice were fasted for $12 \mathrm{~h}$ beginning at Zeitgeber time (ZT)13 throughout the whole night. At ZT1 of the following day reference blood samples were taken, still under starvation conditions ( 0 min refeeding reference). For blood collection mice were carefully fixed in a towel. A small piece of the tail was cut and blood was milked out of the tail within maximally two minutes to reduce strong stress impact. After two days recovering the experiment was repeated. This time mice were refed, after $12 \mathrm{~h}$ starvation, at ZT1. To increase the food intake soaked standard chow was used for refeeding. Mice were split in three groups and blood was again milked from the tail of the first group after $20 \mathrm{~min}$, the second group after $60 \mathrm{~min}$ and the third group after 120 min feeding time. Serum was extracted from blood and this, in turn, was used for OXM radio immune assay (RIA) (Pheonix pharmaceutics).
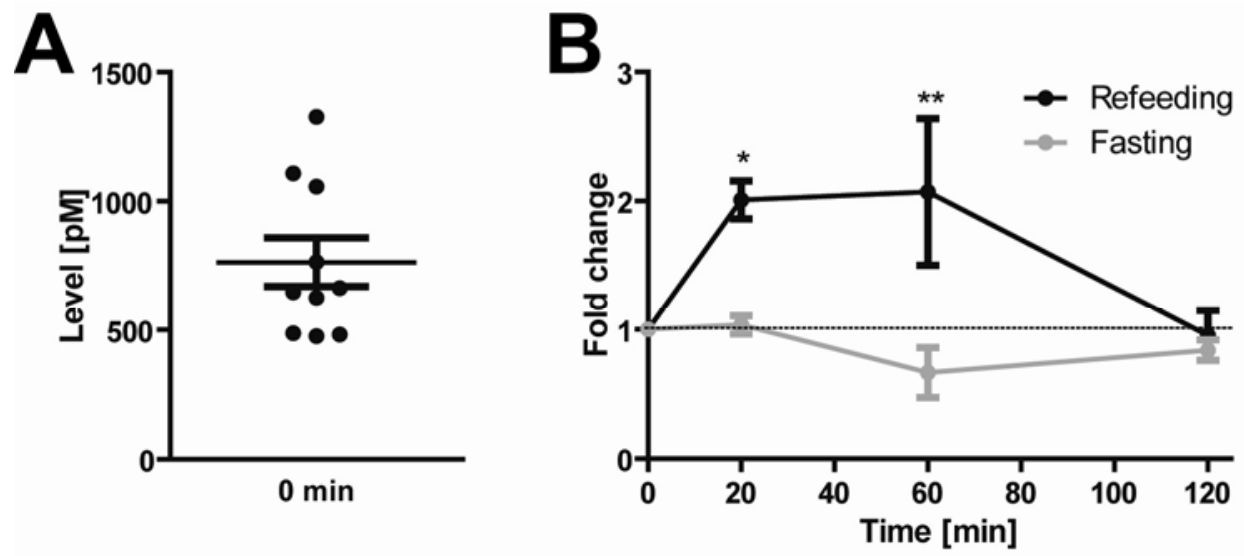

Fig. 16: Oxyntomodulin serum levels increase after food intake in mice. (A) Under fasting conditions basic serum levels of mice vary from approximately $500-1,500$ pM at ZT1. (B) Oxyntomodulin serum level change after refeeding. Basic levels measured under starvation at ZT1 (0 min) were designated as 1 (dotted line). $20 \mathrm{~min}, 60 \mathrm{~min}$ and 120 min after refeeding OXM serum levels were measured again in the same mice. Change in OXM serum level is shown in fold change. Grey: OXM serum levels under ongoing starvation, black: OXM serum levels after refeeding. Data are presented as mean \pm SEM, respectively. 2-way-Anova, Bonferroni: *, $\mathrm{P}<0.05 ; * *, \mathrm{P}<0.01$. 
Remarkably, individual serum levels of OXM were very different at 0 min before refeeding. Variances between approximately 500 and 1,500 pM were detected (Figure 16A). Based on the individual OXM base levels fold changes of OXM after $20 \mathrm{~min}, 60 \mathrm{~min}$ and $120 \mathrm{~min}$ refeeding were calculated. Refeeding causes rapid increase of individual OXM secretion. Already after 20 min feeding time OXM levels were significantly elevated. This effect, with higher variance persists for a minimum of 1 hour. After two hours refeeding OXM returns to basal levels (Figure 16B).

\subsubsection{Injection of OXM}

In order to do in vivo experiments with OXM in mice we decided to provide i.v. injections to mimic the fast elevation of OXM in the blood after refeeding. OXM is rapidly degraded via DPP-4 in vivo [232]. To test the stability of injected OXM we determined the progression of its degradation by RIA. We repeated the experiment done in 2.2.1 with the exception that the mice were not refed at ZT1 but received either a control injection with $\mathrm{NaCl}$ or an OXM injection (final blood concentration $\sim 465 \mathrm{nM}$ ). We collected blood samples $20 \mathrm{~min}, 60 \mathrm{~min}$ and $120 \mathrm{~min}$ after injections and extracted serum which, in turn, was used for the RIA.

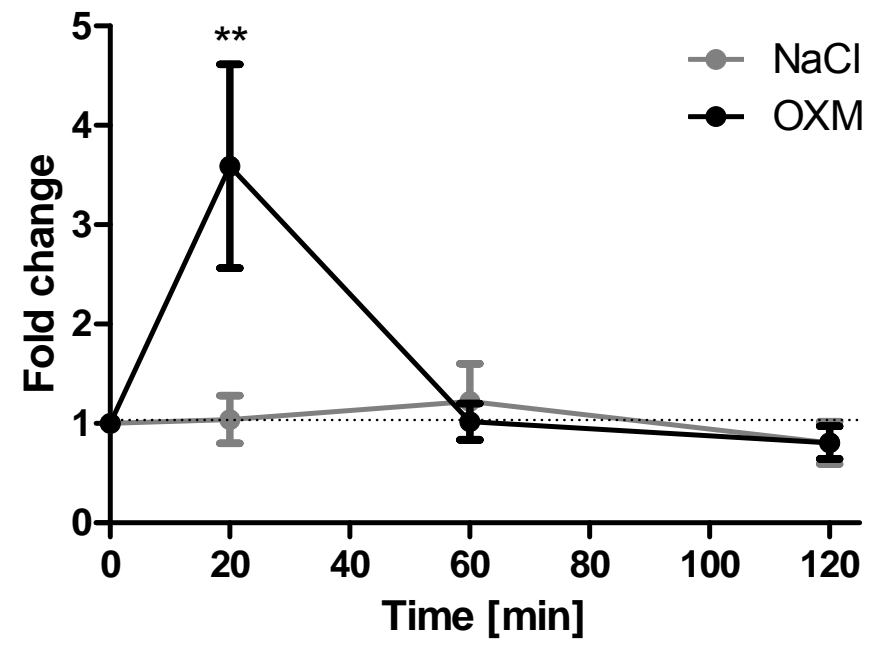

Fig. 17: Injection of Oxyntomodulin increases rapidly its blood concentration, but only for a short time. Basic levels measured under starvation at ZT1 (0 min) were designated as 1 (dotted line). $20 \mathrm{~min}, 60 \mathrm{~min}$ and 120 min after injection OXM serum levels were measured again in the same mice under ongoing starvation. OXM serum level change is shown in fold change. Grey: OXM serum levels after $\mathrm{NaCl}$ injection, black: OXM serum levels after OXM injection. Data are presented as mean $\pm \mathrm{SEM}$, respectively. 2-way-Anova, Bonferroni: ${ }^{* *}, \mathrm{P}<0.01$. 
We observed a significant 3.6 fold increase to $\sim 2,000 \mathrm{pM}$ of serum OXM concentration after 20 min. After 60 min nothing of the complete amount of injected OXM was detectable anymore (Figure 17).

\subsubsection{Clock gene induction after refeeding}

Since we observed strong OXM induction after refeeding in mice in combination with the fact that OXM is able to phase shift PER2::LUC expression in the liver, we investigated the inducibility of Per1 and Per2 after refeeding in the liver. Male WT mice were fasted for $12 \mathrm{~h}$ beginning at ZT13. At ZT1 the control group $(0 \mathrm{~min})$ was killed and liver samples were collected. To examine the effects on Per induction 3 groups were refed with normal chow and liver samples were collected after 20 min, $60 \mathrm{~min}$ and $240 \mathrm{~min}$ of refeeding. Control groups were killed at each time point but were kept under starvation until dead.

Per1 expression increases significantly after 20 min refeeding. After 60 min the induction decreases already. And after 240 min no significant differences in Per1 expression between control animals and refed animals were detectable. In contrast, Per2 expression showed later induction, reaching significance only after $60 \mathrm{~min}$ but is more persistently, since significant high levels are still observable after 240 min (Figure 18).
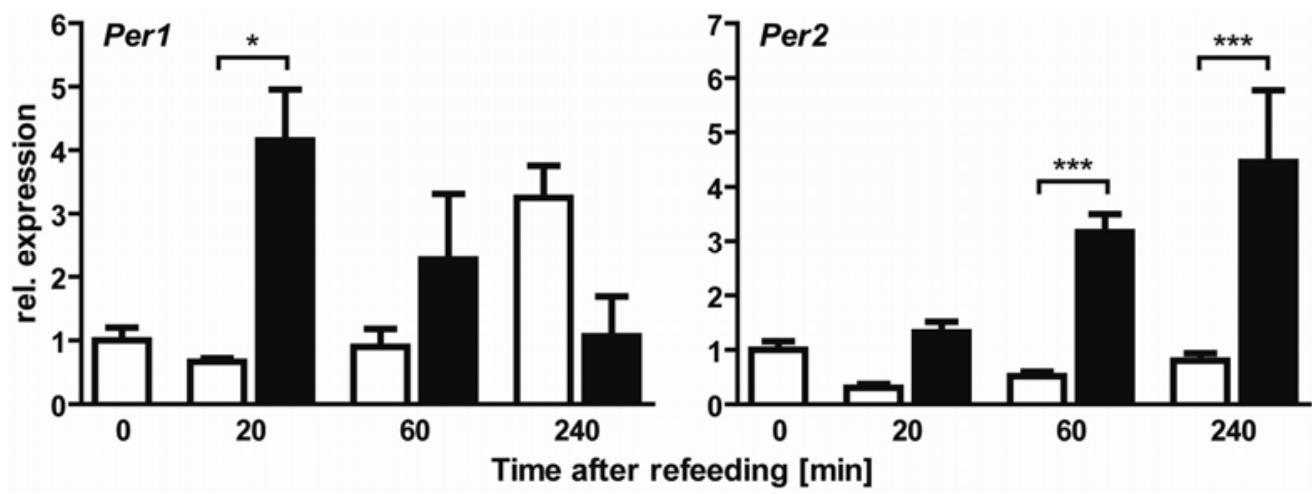

Fig. 18: Per1 and Per2 expression is induced after refeeding at ZT1. Relative mRNA expression levels of Per1 and Per2 were measured under ongoing starvation (white bars) and $20 \mathrm{~min}, 60 \mathrm{~min}$ and $240 \mathrm{~min}$ after refeeding (black bars). The expression levels at ZT1 were designated at 1. Data are presented as mean \pm SEM, respectively. 2-way-Anova, Bonferroni: *, $\mathrm{P}<0.05 ; * * *, \mathrm{P}<0.001$. 


\subsection{OXM actions on clock}

\subsubsection{Induction of liver clock genes in vitro and in vivo}

We showed that refeeding induces OXM secretion as well as Per expression in mice. To test whether OXM might be responsible for the increase of Per1 and Per2 mRNA levels, we treated both cultured liver slices as well as male WT mice with OXM and determined hepatic Per1 and Per2 expression levels.
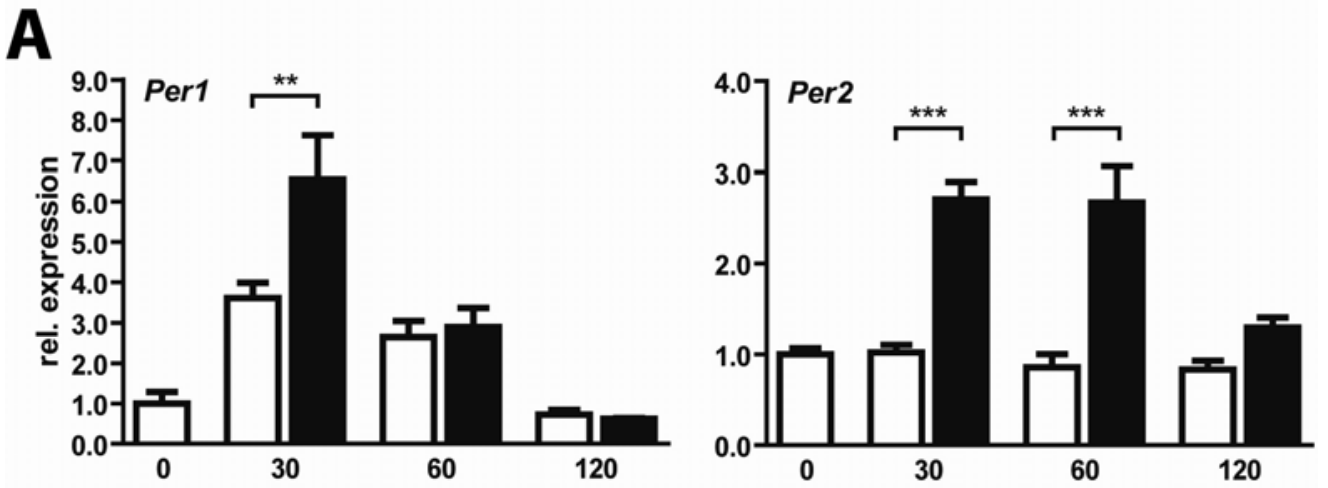

B

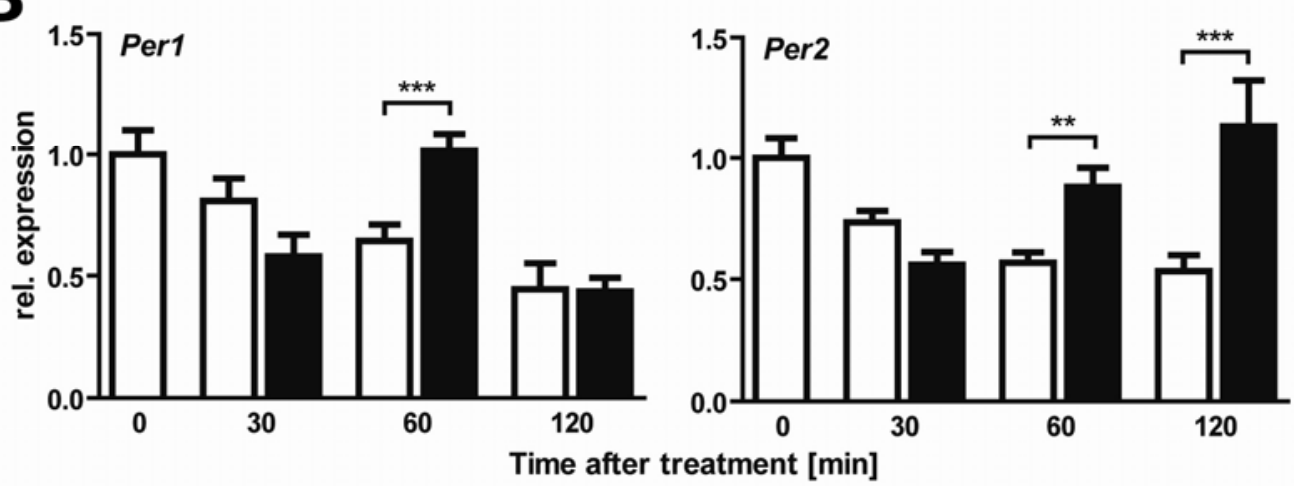

Fig. 19: Oxyntomodulin causes Per1 and Per2 induction in WT liver in vivo and in vitro. (A) WT mice were tail vein injected with OXM ( $455 \mathrm{nM}$, based on acceptance of $2 \mathrm{ml}$ blood per mouse) or NaCl at ZT1. Mice killed directly at ZT1 (0 min) did not receive an injection. After 30,60 and 120 min injected mice were killed and liver samples were collected. Relative mRNA expression of Per genes in liver after OXM treatment (black bars) was compared to $\mathrm{NaCl}$ treatment (white bars). Data were analyzed by qPCR. Data are presented as mean \pm SEM, respectively. 2-way -Anova, Bonferroni: ${ }^{* *}, \mathrm{P}<0.01 ; * *, \mathrm{P}<0.001$. (B) Organotypic WT liver slices were treated with OXM or $\mathrm{NaCl}$ at $\sim 150^{\circ}$. Instead, slices harvested at 0 min were collected immediately without treatment. After 30,60 and 120 min treated liver slices were collected. Induction of clock genes in liver slices via OXM treatment (black bars) is compared to control ( $\mathrm{NaCl}$ ) treatment (white bars). OXM medium concentration was $455 \mathrm{nM}$. Data were analyzed by $\mathrm{qPCR}$ and are presented as mean $\pm \mathrm{SEM}$. Two-way -Anova, Bonferroni: **, P<0.01; ***, P< 0.001 . 
At ZT3 male WT mice received i.v. OXM injections in the tail vein in a comparable concentration as used for the peptide screen and the OXM PRC ( 465 nM). Control animals received the same volume $0.9 \% \mathrm{NaCl}$. A further cohort of animals was killed directly at ZT3 and received no injection. Injected mice were killed after $30 \mathrm{~min}, 60 \mathrm{~min}$ or $120 \mathrm{~min}$ and their livers were isolated and immediately snap-frozen on dry ice. qPCR analyses showed significant Per1 and Per2 induction 30 min after OXM injection. Per1 induction was abolished after $60 \mathrm{~min}$. In contrast, Per2 induction lasted longer and it was still detectable after $60 \mathrm{~min}$. After $120 \mathrm{~min}$ no Per2 induction was detected anymore (Figure 19A).

In order to exclude systemic effects of OXM administration, we performed a comparable experiment with cultured organotypic liver slices from male WT mice. As indicated by former experiments, liver slices were cultured for two days which was the minimum time needed to detect proper Per2 oscillations in PER2::LUC liver slices. Additionally, former experiments with PER2::LUC liver slices showed that most slices were in the right phase for treatment at 2 am. Hence, WT liver slices were all treated at 2 am with either OXM (455 nM) or same volume $\mathrm{NaCl}$. Reference slices were harvested at 2 am without any treatment and snap-frozen in liquid nitrogen. Treated liver slices were collected after $30 \mathrm{~min}, 60 \mathrm{~min}$ and $120 \mathrm{~min}$ (Figure 19B).

Per1 and Per2 expression was significantly increased after $60 \mathrm{~min}$ in OXM treated liver slices. Comparable to the in vivo situation, Per2 induction lasted longer than Per1 induction, but instead expression increased later than for Per1. Significance in both experiments was determined by 2-wayAnova.

\subsubsection{Oxyntomodulin action in the SCN}

RF was shown to have main effects restricted to peripheral organ clocks [85]. In contrast, the $\mathrm{SCN}$ remains unaffected by new feeding schedules. This suggests an uncoupling of the periphery from the central clock. We investigated the impact of OXM on Per1 and Per2 expression in the SCN. Previously, we showed that OXM causes Per1 and Per2 induction in the liver in vivo. Furthermore, we showed that single OXM injections were able to alter the phase of Per2 expression in the liver. From the same animals used for these experiments we also collected the brain and snap-froze it on dry ice. Cryosections of the SCN were used to perform in situ hybridization (ISH) of Per1 and Per2. 
A

\section{$\mathrm{NaCl}$}

\section{Per1}

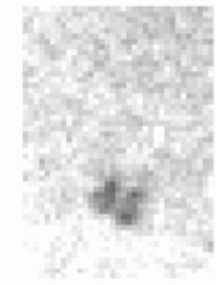

Per2

\section{OXM}
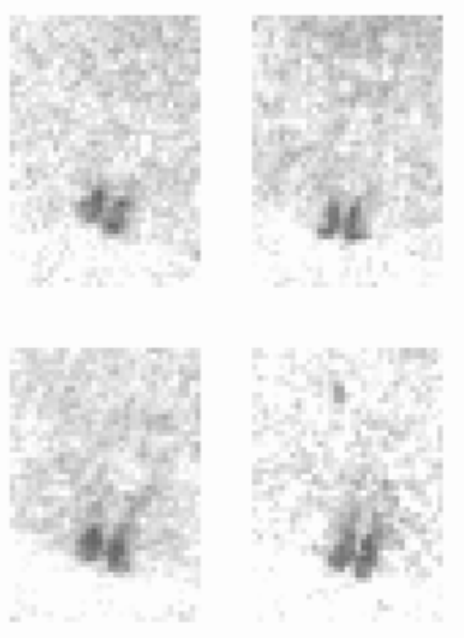

B

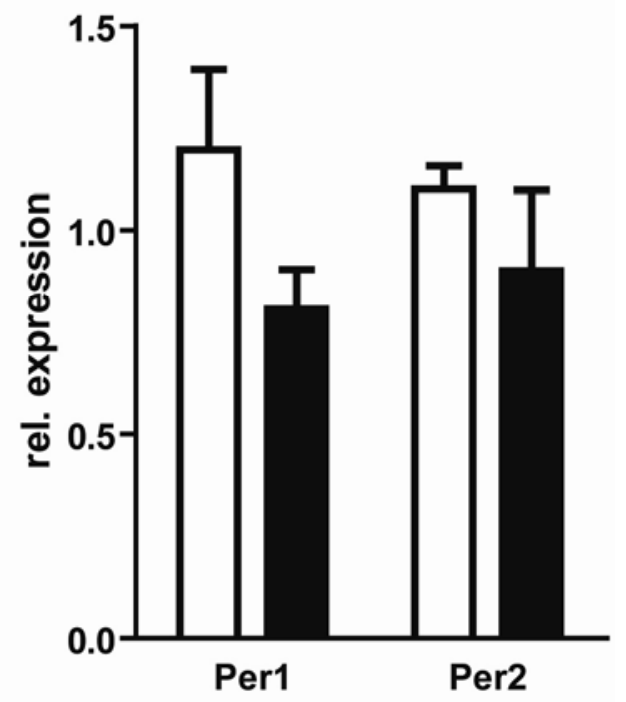

Fig. 20: Oxyntomodulin treatment has no influence on Per1 and Per2 expression in the SCN after 30 min. In situ hybridization from cryosections (A) of same animals used for induction experiments in liver (2.3.1) shows no induction of Per genes in the SCN (B). White bars: control treatment ( $\mathrm{NaCl})$, black bars: OXM treatment. Data are presented as mean \pm SEM, respectively. Mann-Whitney nonparametric t-test: $n s, \mathrm{P}>0.05$.

In contrast to the liver we could not detect an induction of neither Per1 nor Per2 mRNA expression in the brain. Although there is the tendency for a downregulation of both genes none of these effects were significant (Figure 20).

\subsection{Connecting elements between OXM and liver clock}

\subsubsection{Effects of Gcgr and GLP-1r antagonists}

The previous results indicated that OXM has strong impact on the liver clock. Studies of OXM action in mice have demonstrated that OXM can activate both the glucagon and GLP-1 receptors [233]. In order to characterize the receptor which is responsible for the shown clock effects, we decided to use antagonists of GLP-1r and Gcgr. OXM, Glucagon and Ex-4 showed significant phase shifts in the peptide screen. Thus, we suggest that even if the classical GLP-1r might not be expressed 
in the liver (see chapter 2.4.3); the unknown receptor must have a comparable structure and ligand binding characteristics.

\subsubsection{Liver phase shift in vitro in presence of Gcgr and GLP-1r antagonists}

To identify the putative OXM receptor in the liver we used PER2::LUC slices to measure effects of different inhibitors on OXM induced phase shifts. Slice cultures were done like described before. OXM/antagonist treatments were done at $150^{\circ}$ PER2::LUC expression. GLP-1r was blocked by the antagonist Ex9-39 (1 $\mu \mathrm{M}$, [218]) and Gcgr was inhibited by (Des-His1,Glu9)-Glucagon (1-29) amide (d-GLU) $(1 \mu \mathrm{M},[234])$. Antagonists were administered 30 min before treatment with OXM to ensure saturation of receptor binding sites.

As expected, OXM caused a strong phase delay of $-7.86 \mathrm{~h} \pm 0.3658$ (Mean \pm SEM) compared to control treated liver slices $(P<0.0001)$. The phase shift after parallel treatment of OXM and Ex9-39 was still significantly different from control treatment $(P=0.0006)$. However, the phase shift was significantly diminished by previous administration of Ex9-39 $(P<0.0001)$. The phase shift was reduced to $-4.3 \mathrm{~h} \pm 0.40$. In contrast, treatment with $\mathrm{d}-\mathrm{GLU}$ did not have any significant effect on OXM induced PER2::LUC phase delays $(P=0.4004)$. Administration of the antagonists alone did not change the PER2::LUC phase, showing that they do not have any direct effect on the liver clock (Figure 21A).
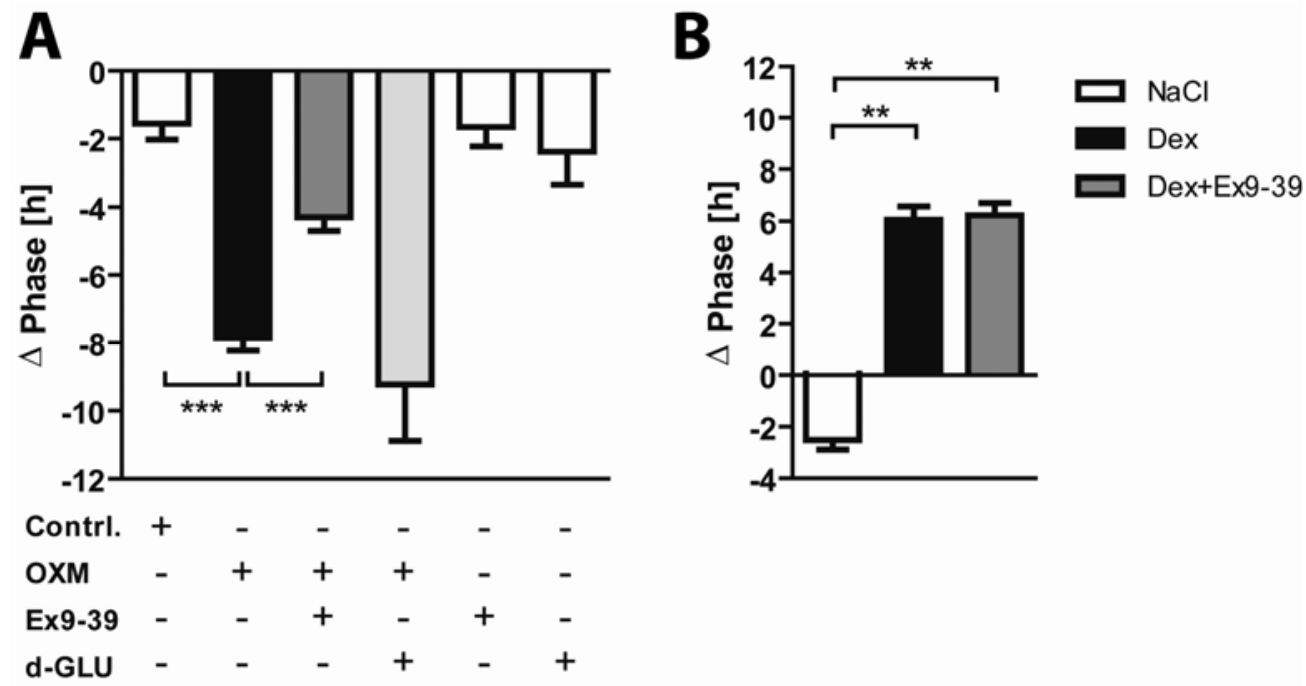

Fig. 21: An unknown GLP-1r-like-receptor is responsible for Per2 induction and phase shift. (A) PER2::LUC organotypic liver slices were treated at $\sim 150^{\circ}$. Phase shifts caused by OXM can be significantly inhibited by additional treatment with GLP-1r antagonist Exendin-9-39 (Ex9-39) but not with Glucagon receptor antagonist (Des-His1,Glu9)-Glucagon (1-29) amide (dGLU). Student's t-test: ***, P < 0,001. (B) Ex9-39 has no influence on dexamethasone induced PER2::LUC phase shifts at $\sim 150^{\circ}$. Mann-Whitney: **, $\mathrm{P}<0.01$. 
To demonstrate that Ex9-39 inhibits phase shifts specifically after OXM treatment, we combined Ex9-39 with dexamethasone treatments. Ex9-39 had no influence on the ability of dexamethasone to phase advance the clock at this time point. With and without blocking of GLP-1r dexamethasone caused significant phase advances of around $6 \mathrm{~h}(P=0.0043)$ (Figure 21B).

\subsubsection{Induction of liver clock genes in presence of Exendin 9-39 in vitro and in vivo}

We next tested, whether Per1 and Per2 induction by OXM is influenced by pre-incubation with Ex9-39. We tested Per expression levels after Ex9-39 administration in vivo and in vitro.

In vivo solutions were applied via i.v. injections in the tail vein. Mice were split into three groups: 1. control group received pure $\mathrm{NaCl}$ injections, 2. positive control group obtained OXM ( 465 $\mathrm{nM})$ and 3. test group was injected with a cocktail of OXM ( 465 nM) and Ex9-39 ( 25 nM). All injections were given at ZT1 and mice were killed 30 min later to isolate livers. As shown before, OXM injection strongly induced Per1 and Per2 expression. When OXM was applied together with Ex9-39 induction of Per1 and Per2 was completely abolished (Figure 22A).
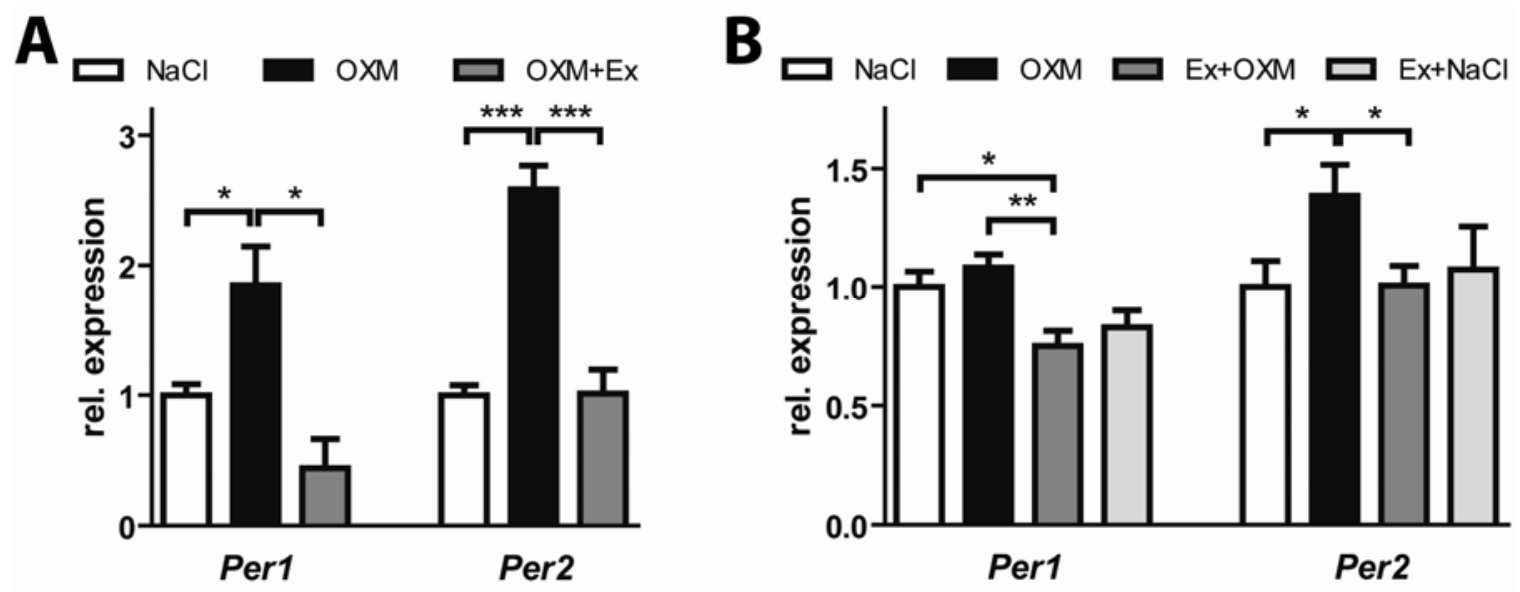

Fig. 22: OXM induced increase of Per1 and Per2 expression can be completely inhibited by additional Ex9-39 treatment in vivo via tail vein injection (A) or in organotypic WT liver slices (B). All data are presented as mean \pm SEM, respectively. Sudent's t-test: *, $\mathrm{P}<0.05 ; * * *, \mathrm{P}<0.001$.

In order to show that these effects were not due to systemic effects but liver specific we repeated this parallel application of OXM and Ex9-39 with cultured organotypic male WT liver slices. The experimental setup was the same as described in 2.3.1. Control liver slices were treated with $\mathrm{NaCl}$, positive controls were done with OXM treatment (455 nM), test slices were pretreated with Ex9-39 $(1 \mu \mathrm{M})$ and after 30 min with OXM (455 nM). Another control group was treated only with 
Ex9-39 $(1 \mu \mathrm{M})$ in order to exclude effects by the antagonist alone. This time OXM led only to a weak induction of Per1 but a significant induction of Per2 expression. However, comparable to the in vivo experiments, both Per1 and Per2 induction was completely abolished when OXM and Ex9-39 were administered in parallel. The antagonist alone had no effect on Per expression (Figure 22B).

\subsubsection{GLP-1r in liver}

OXM is known to bind to both Gcgr and GLP-1r [233]. We suggest that the OXM effect on the liver clock is due to a GLP-1r-like receptor. There is no doubt that the glucagon receptor is present in the liver. Conversely, previous studies have given very inconsistent results, whether there is a hepatic GLP-1r or not $[235,236]$. On the other hand other studies showed that GLP-1 and OXM have strong impact on the liver even if GLP-1 is not able to bind to Gcgr, suggesting the existence of a second, not yet identified, GLP-1r-like-receptor [195, 233, 237].

\subsubsection{Absence of GLP-1r in liver}

Because of this discrepancy, we decided to test GLP-1r appearance in the mouse liver on mRNA and protein levels. We designed PCR primers each overlapping two adjacent exons of GLP-1r. We did that for all 13 exons described at the 'Ensemble data base' except for exon 1, as it mainly contains poly-C and poly-G sequences, which precludes proper primer design. We did RT-PCR with cDNA synthesized from male WT liver collected at time points ZT2, ZT10 and ZT18. We chose different time points to exclude the possibility of low expression at certain times of day. As negative controls we collected livers from GLP-1r knockout mice $\left(\mathrm{GLP}-1 \mathrm{r}^{-/}\right)$at the same time points [238]. Pancreas from WT male mice were chosen as positive controls, as it was unambiguously shown to be locus of GLP-1r $[235,236]$.

We were not able to detect any expression of all these exons neither in the WT nor in the GLP-1r-/- liver. However, the pancreas showed clear expression for all exons. From the same tissues we extracted protein solution to examine whether GLP-1r can be detected. As expected, no GLP-1r was detected in the liver but in the pancreas (Figure 23). 

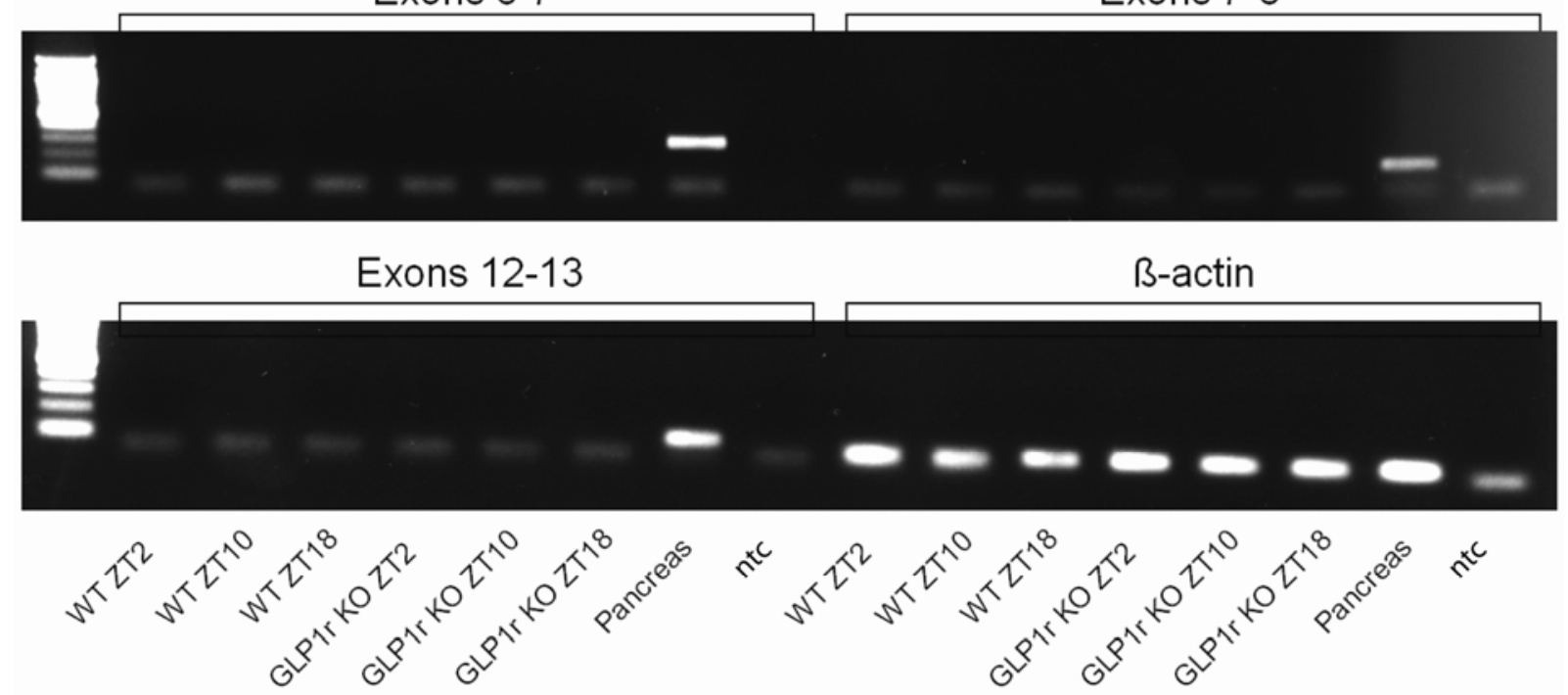

Fig. 23: Absence of GLP-1r in the liver. Representative RT-PCR results from exons 6-7, 7-8, and $12-13$ and $\beta$-actin. WT, Wildtype liver samples; GLP-1r KO, GLP-1r ${ }^{-/-}$liver samples, ZT, Zeitgeber time; ntc, non-template control.

\subsubsection{Induction of liver clock genes in GLP-1- $r^{-/-}$mice in vitro}

Nevertheless, we wanted to know whether OXM has any impact on the liver of GLP-1r/- mice. It was shown before that even without presence of the classical GLP-1r signaling pathways are activated by both GLP-1 and OXM in the liver [195, 239-241].
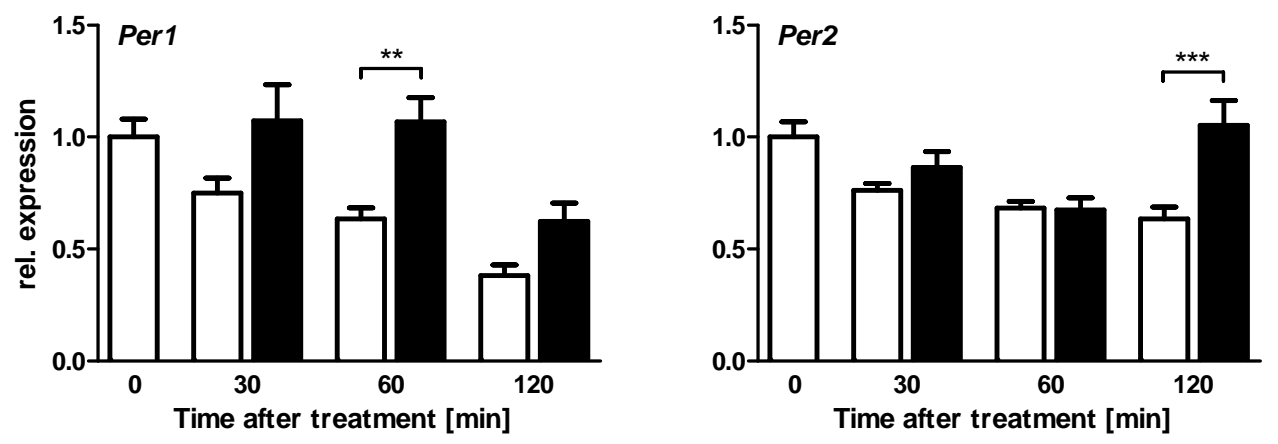

Fig. 24: Oxyntomodulin induces Per1 and Per2 in GLP-1r ${ }^{-/-}$liver in vitro. Organotypic GLP-1r $\mathrm{r}^{-/-}$liver slices were treated with $\mathrm{OXM}$ or $\mathrm{NaCl}$ at $\sim 150^{\circ}$. Instead, slices harvested at 0 min were collected immediately without treatment. After 30,60 and $120 \mathrm{~min}$ treated liver slices were collected. Induction of clock genes in liver slices via OXM treatment (black bars) is compared to control $(\mathrm{NaCl})$ treatment (white bars). OXM medium concentration was $455 \mathrm{nM}$. Data were analyzed by qPCR and are presented as mean \pm SEM. Two-way -Anova, Bonferroni: $* *, P<0.01 ; * * *, P<0.001$. 
To test whether OXM has the same impact on the GLP-1 $\mathrm{r}^{-/-}$liver as on the WT liver, we measured the induction of Pers after OXM administration in vitro. Like described before, we prepared organotypic liver slices from GLP-1r ${ }^{-/-}$mice and cultured them for two days. On the third day at 2 am slices were treated either with OXM (455 nM) or the same volume of $\mathrm{NaCl}$. 60 min after treatment OXM caused a significant induction of Per1 expression with was already absent after $120 \mathrm{~min}$. Per2 expression was induced after 120 min (Figure 24).

\subsubsection{Induction of liver clock genes in GLP-1- ${ }^{-/-}$mice after refeeding}

To test the specificity of Per1 and Per2 gene induction in mice after refeeding, we repeated the same experiment as shown in 2.2.3 with GLP-1r ${ }^{-/-}$mice. We found that Per1 and Per2 expression is slightly induced after 40 min of refeeding. However, when mice received i.v. Ex9-39 injections 1 hour in advance, the induction of both genes was completely abolished (Figure 25).

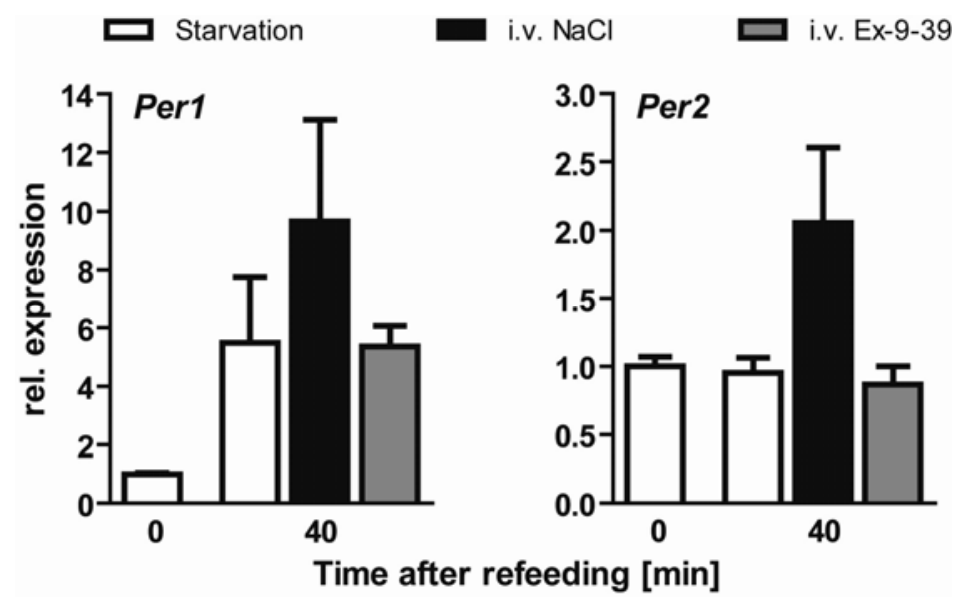

Fig. 25: Per1 and Per2 expression is induced after refeeding in GLP-1 ${ }^{-/-}$mice. Relative mRNA expression levels of Per1 and Per2 were measured under ongoing starvation (white bars), after $\mathrm{NaCl}$ injection and 40 min refeeding (black bars) and after Ex9-39 injection and 40 min refeeding (grey bars). The expression levels at ZT1 were designated at 1. Data are presented as mean \pm SEM, respectively. 


\subsection{Signaling pathways}

\subsubsection{Kinase array}

In former experiments we found that an unidentified GLP-1r must be a compound of the signaling pathway responsible to alter the liver circadian clock. To identify responsible signaling pathways we performed a kinase array. The array determines phosphorylation of 46 different kinases in parallel. We compared liver lysate made from liver slices after $60 \mathrm{~min} \mathrm{NaCl}$ treatment or OXM treatment (455 pM). After 60 min OXM induced both Per1 and Per2 expression significantly in liver slices. Each liver lysate was exposed to a membrane presenting antibodies against the phosphorylated state of the 46 kinases. If the phosphorylation state of a kinase changes after OXM treatment it will bind stronger or weaker to the antibody membrane compared to the membrane for control treatment.

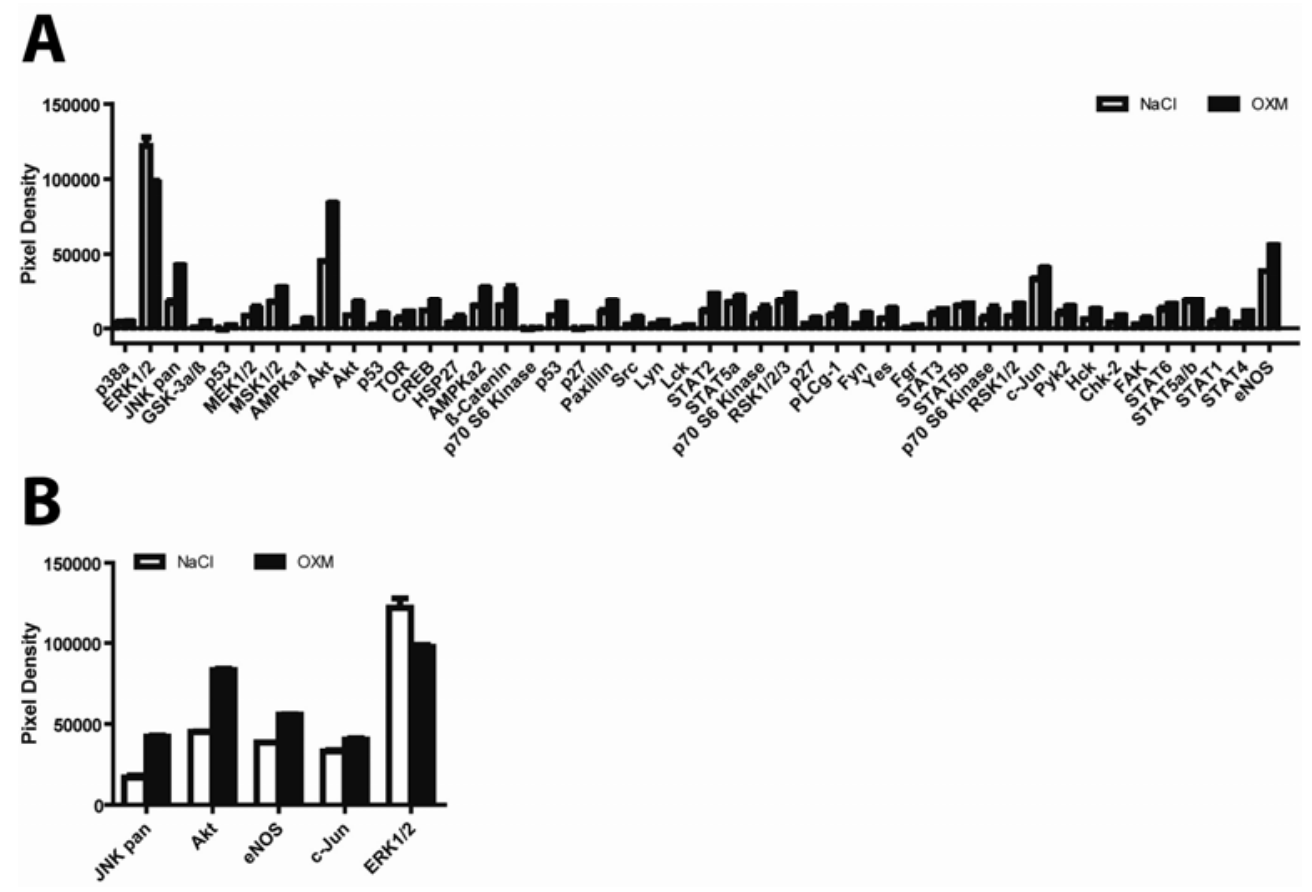

Fig. 26: The Human Phospho-Kinase Array detects phosphorylated proteins in control treated and OXM treated liver slice lysates. (A) Array signals $\left[\mathrm{OD} / \mathrm{mm}^{2}\right]$ from scanned X-ray film images were analyzed using image analysis software. White bars: $\mathrm{NaCl}$ treated liver slices, black bars: OXM treated liver slices. (B) Data from the Human Phospho-Kinase Array were excluded by a threshold of 25,000. Kinases whose average pixel density (Average $=\mathrm{NaCl}+\mathrm{OXM} / 2$ ). JNK pan, Akt, eNOS, C-Jun and ERK1/2 were the only kinases which showed an average pixel density higher than 25,000. Data are sorted by relative change of phosphorylation state after OXM treatment. White bars: $\mathrm{NaCl}$ treated liver slices, black bars: OXM treated liver slices. 
In the first step all 46 kinases were compared (Figure 26A). Extracellular-regulated kinases 1 and 2 (ERK1/2) were strongly phosphorylated after both treatments. After OXM treatment its phosphorylation state tended to decrease. Next we set a threshold to exclude all kinases whose average pixel density was lower than 25,000 (Figure 26B). Thereby we found a relatively high phosphorylation of ERK1/2, c-Jun N-terminal kinase (JNK), PKB (Akt), c-Jun and of endothelial nitric oxide synthase (eNOS). We further excluded ERK1/2, c-Jun and eNOS, because their phosphorylation level did not change more than 50\% after OXM treatment. JNK phosphorylation was increased by $\sim 150 \%$ and PKB phosphorylation by $\sim 85 \%$.

\subsubsection{Investigation of single pathways}

With the help of the kinase array we identified the JNK and PKB pathway as potential candidates for liver clock synchronization. Therefore we tested both pathways more extensive to test their ability to influence circadian oscillations in the liver.

\subsubsection{PKB}

The elevated phosphorylation state of PKB after OXM treatment was confirmed by Western Blot analyses. Liver slices were treated with either $\mathrm{NaCl}$ or OXM and harvested after $30 \mathrm{~min}, 60 \mathrm{~min}$ and $120 \mathrm{~min}$. They were immediately snap-frozen in liquid nitrogen and stored at $-80^{\circ} \mathrm{C}$. Protein lysate was done in a phosphorylation stabilizing lysis buffer. Since OXM significantly increased the level of phosphorylated PKB (p-PKB) after $60 \mathrm{~min}$ and $120 \mathrm{~min}$, the results reinforced the kinase array results (Figure 27).

We directly tested the impact of the PKB pathway on the liver clock by its inhibition with PKB inhibitor IV. PER2::LUC liver slices were pretreated with three different concentrations of PKB inhibitor IV (20 nM, $200 \mathrm{nM}, 2,000 \mathrm{nM}) 1 \mathrm{~h}$ before treatment with OXM. Comparison with control treatments where pretreatment was only done with DMSO, revealed no difference. All concentrations of PKB inhibitor IV alone had no effect on phase shifts (Figure 28). 


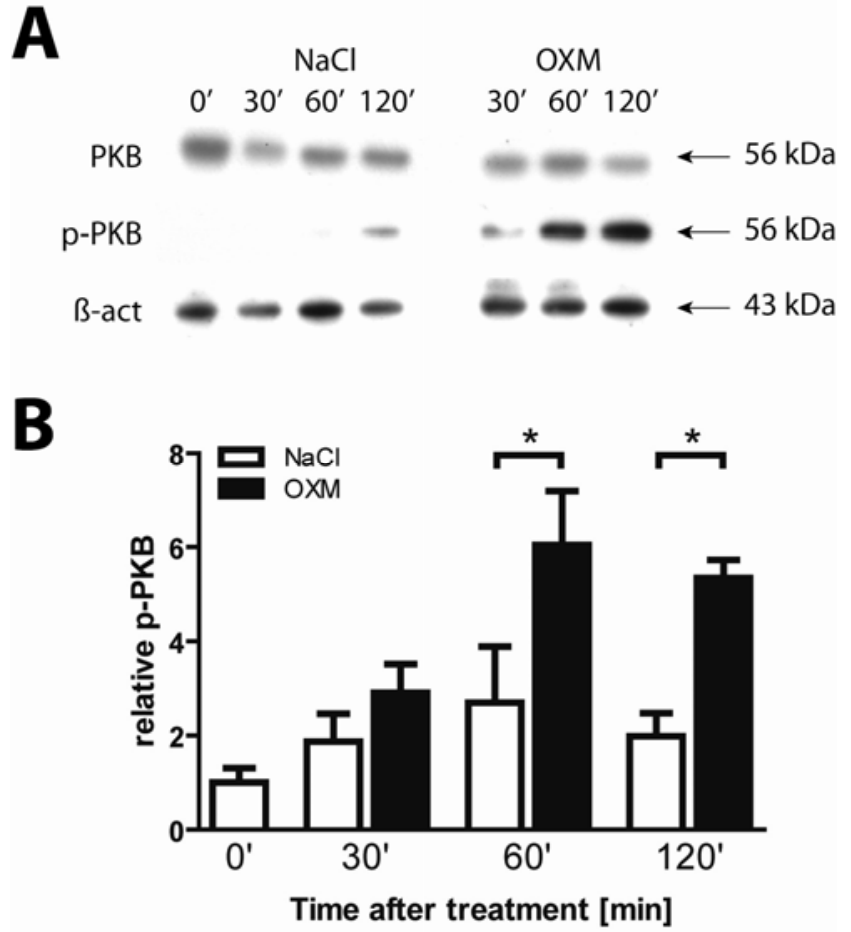

Fig. 27: PKB is phosphorylated by OXM in the liver in vitro. Liver slices were treated with either $\mathrm{NaCl}$ or OXM (455 pM). (A) Before treatment $(0 \mathrm{~min}$ ) and 30,60 and $120 \mathrm{~min}$ after treatments they were harvested and used for immunoblot analyses. U2F65 serves as protein load control. (B) Quantification of p-PKB change in liver slices. Increase of p-PKB in liver slices via OXM treatment (black bars) is compared to control $(\mathrm{NaCl})$ treatment (white bars). Data are presented as mean \pm SEM. Twoway -Anova, Bonferroni: *, P $<0.05$.

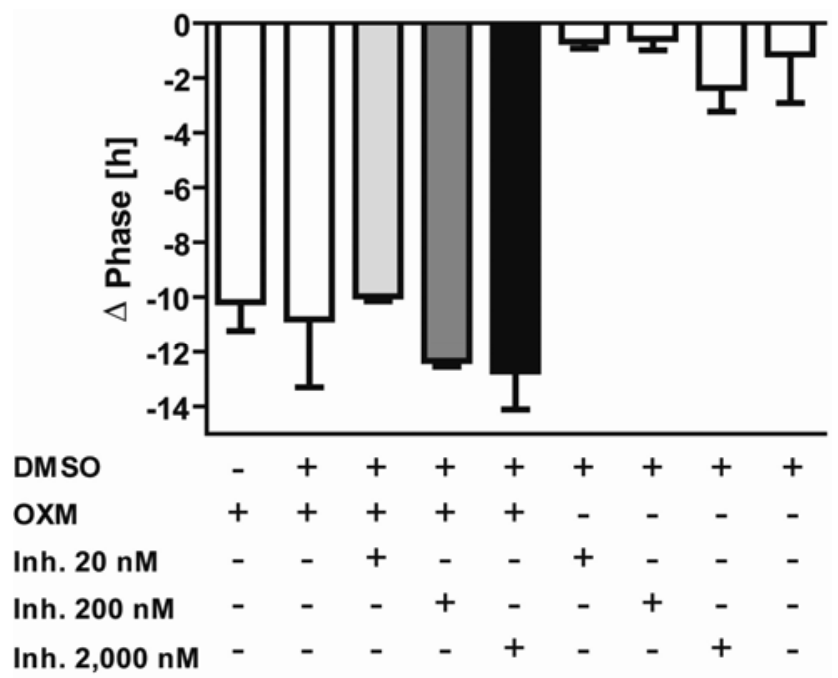

Fig. 28: PKB inhibitor IV has no effect on OXM induced liver clock synchronization. PER2::LUC liver slices were pretreated with three different concentrations of PKB inhibitor IV (20, 200 and 2,000 nM) and $1 \mathrm{~h}$ later with OXM. Control treatments were done with DMSO, OXM, and PKB inhibitor IV in all concentrations alone. 


\subsubsection{JNK}

Next we tested the effect of the JNK inhibitor SP600125 on the phase shifting abilities of OXM in PER2::LUC liver slices [242]. We treated liver slices $1 \mathrm{~h}$ before OXM treatment at a final inhibitor concentration of $10 \mu \mathrm{M}$. Even if the phase shift after SP600125 and OXM was more pronounced than with OXM alone, this difference was not significant (Figure 29).

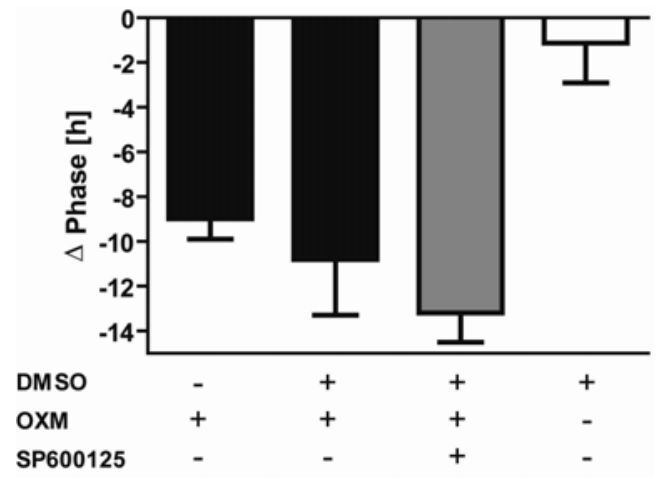

Fig. 29: JNK inhibitor SP600125 has no effect on OXM induced liver clock synchronization. PER2::LUC liver slices were pretreated with JNK inhibitor SP600125 and $1 \mathrm{~h}$ later with OXM. Control treatments were done with DMSO and OXM alone.

\subsubsection{3. $\quad$ CREB}

The candidates identified by the kinase array were not responsible for phase shifts in the liver. Although we could not detect CREB activation in the kinase array, we decided to confirm this result by Western Blot analyses, because of following reasons. Activation of CREB was shown to strongly change the phase of circadian clocks by activation of Per1 and Per2 expression [78]. Furthermore it was already shown to be activated after Ex-4 treatment in the liver [239]. If Ex-4 binds to the same receptor as OXM, it might lead to the activation of the same pathways. For this experiment we used the same liver lysate samples we used for p-PKB. After 30 and 60 min no change in CREB phosphorylation was observed. After 120 min a slight elevation of $p$-CREB occurred but it was not significant (Figure 30). 

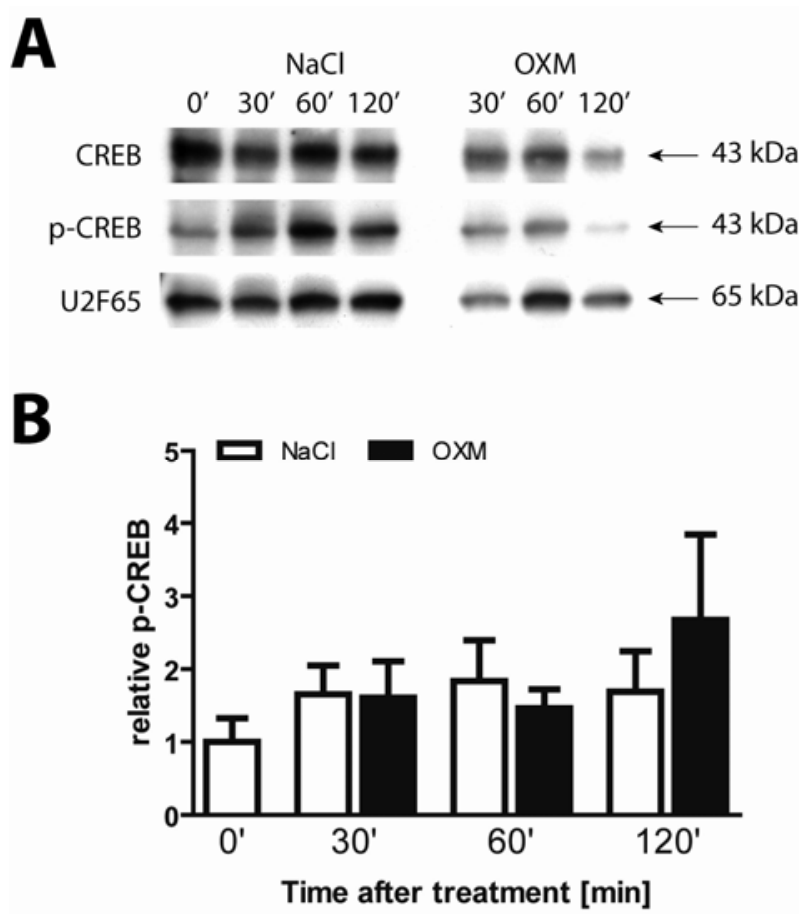

Fig. 30: CREB is not phosphorylated by OXM in the liver in vitro. Liver slices were treated with either $\mathrm{NaCl}$ or OXM (455 pM). (A) Before treatment (0 $\mathrm{min}$ ) and 30,60 and 120 min after treatments they were harvested and used for immunoblot analyses. U2F65 serves as protein load control. (B) Quantification of p-CREB change in liver slices. Change of p-CREB in liver slices via OXM treatment (black bars) is compared to control ( $\mathrm{NaCl}$ ) treatment (white bars). Data are presented as mean \pm SEM.

\subsection{Additional results: Circadian characterization of GLP-1 $r^{-/-}$mice}

We identified or a GLP-1r-like receptor as possible target of OXM mediating its resetting effect on the liver clock. The following experiments with GLP-1r/- mice [238] have been performed to clarify whether the observed effects in WTs were based on the classical GLP-1r or a second unknown one.

In order to exclude some unpredictable circadian phenotypes, GLP-1 $\mathrm{r}^{-/-}$mice were subjected to some standard tests. First, the free-running behavior in DD was tested and compared to WT mice. Second, GLP-1r ${ }^{-1-}$ mice were exposed to RF. During RF activity was measured. Third, clock gene expression was tested either before or after three days of RF. 


\subsubsection{Free-running behavior in DD}

GLP-1r $\mathrm{r}^{-/}$and WT mice were single housed in wheel running cages. For 20 days they were exposed to a 12:12 light/dark (LD) cycle (100 LUX) to test the behavior in entrained conditions. Both genotypes were entirely entrained to LD cycles with a period of $24 \mathrm{~h}$. The activity period during light and dark phase were comparable between GLP-1 $1 r^{-1-}$ and WT mice. Thereafter, mice were kept in DD for another 20 days. As expected, both genotypes shortened their period equivalent (WT to $23.5 \mathrm{~h} \pm$ $\left.0.10, \mathrm{GLP}-1 \mathrm{r}^{-/-} 23.6 \mathrm{~h} \pm 0.05\right)$. Under LD conditions the amount of activity during the light phase and dark phase and total locomotor activity was identical in both genotypes (Figure 31).
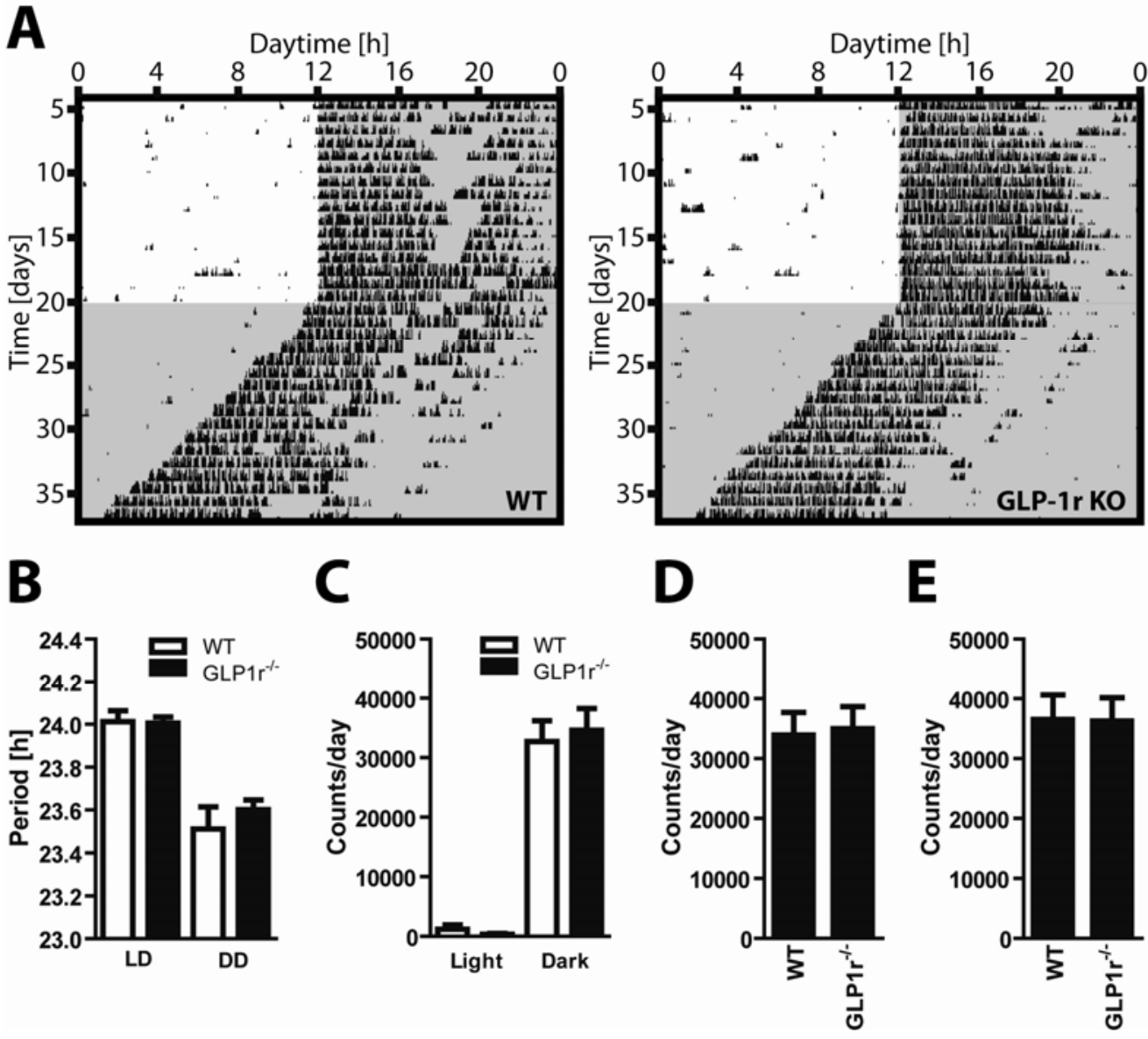

Fig. 31: Circadian characteristics of GLP-1r/- mice. GLP-1 $1 r^{-1-}$ and WT mice were kept for 20 days in 12:12 LD conditions (100 LUX). Afterwards mice were kept in DD to test their free-running nature. (A) Activity is shown in representative actograms. Tick marks represent wheel running activity; dark phases are denoted by gray shading. (B) Quantification of activity period length under LD as well as DD conditions is equal in both genotypes. (C) Locomotor activity during light phase and during dark phase is the same in WT and GLP-1r ${ }^{-/-}$mice. (D, E) Total locomotor activity of both genotypes under LD conditions (D) and DD conditions (E) is equal. 


\subsubsection{Development of food anticipatory activity}

Animals were exposed to RF to determine the occurrence of FAA. Feeding time was shifted in the light phase and gradually reduced to $4 \mathrm{~h}$ per day from ZT6-ZT10. Determination was done by dividing the activity amount within $3 \mathrm{~h}$ before food was expected by the animals with total activity these animals show per day. Under restricted feeding both genotypes showed an identical amount of FAA (Figure 32).
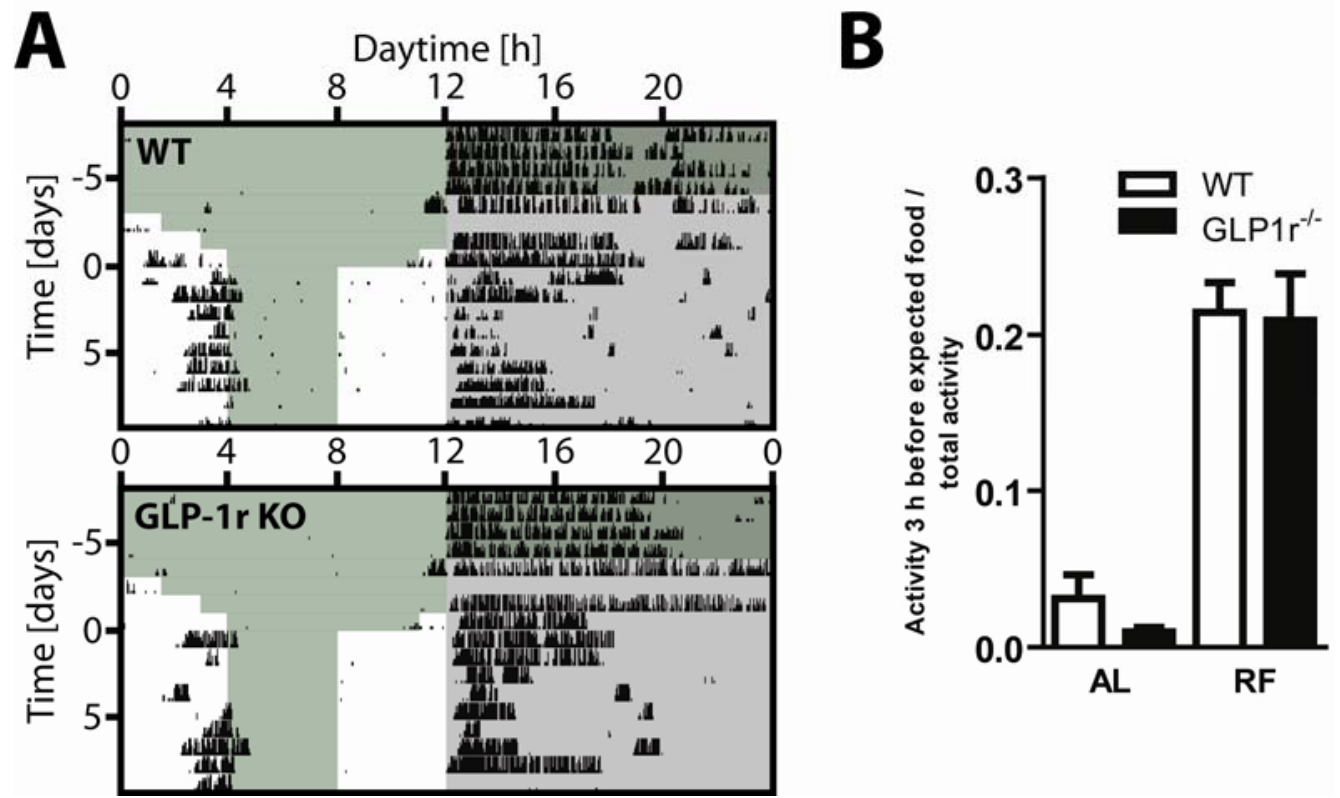

Fig. 32: GLP-1r $\mathrm{r}^{-/}$and WT mice show equal food anticipatory activity. Mice of both genotypes received RF for 10 days. Food availability was restricted only to light phase and then gradually reduced to 4 hours per day (ZT6-ZT10). (A) Representative actograms of both genotypes before and during RF. Tick marks represent wheel running activity; dark phases are denoted by gray shading; feeding time is denoted by green shading. (B) FAA was determined as ratio of activity measured $3 \mathrm{~h}$ before expected food and total activity. Locomotor activity was measured by wheel running revolutions. All quantified data are presented as mean \pm SEM, respectively.

\subsubsection{Clock gene expression in GLP-1r ${ }^{-/-}$under restricted feeding}

Furthermore the expression of clock genes was investigated. Under 12:12 LD conditions GLP$1 \mathrm{r}^{-/-}$and WT animals were killed starting at ZT2 every $4 \mathrm{~h}$ throughout the day. The liver was isolated and snap-frozen on dry ice. With qPCR the rhythmic expression of Per1, Per2 and Bmal1 was 
analyzed. No differences between both genotypes were found. Both amplitude and period were comparable and did not show any abnormalities.

Next we tested the ability of Per1, Per2, Cry1, Bmal1, Rev-erb- $\alpha$ and Dbp to shift under RF. Feeding time was shifted by $12 \mathrm{~h}$, so that food was only available from ZTO-ZT12. After two days of RF, which was supposed to be the half shift time $\left(\mathrm{PS}_{50}\right)$, mice were killed at the same times like the AL fed group and their livers were collected. As expected none of the tested genes made a complete phase shift of $12 \mathrm{~h}$. In WT mice Per1 expression showed a phase advance of $1.5 \mathrm{~h}$, whereas GLP-1r/- mice showed a phase delay of -1.5 h. Per2, Rev-erb- $\alpha$ and Dbp were drastically phase delayed in WT mice by $-6.7 \mathrm{~h},-$ $6.6 \mathrm{~h}$ and $-6.5 \mathrm{~h}$, respectively. In contrast, the same genes measured in the mutant mice showed only phase delays of $-3.0 \mathrm{~h},-0.1 \mathrm{~h}$ and $-1.0 \mathrm{~h}$, respectively. Cry1 and Bmal1 expression was nearly not shifted and no obvious differences between both genotypes were determined (Figure 33).

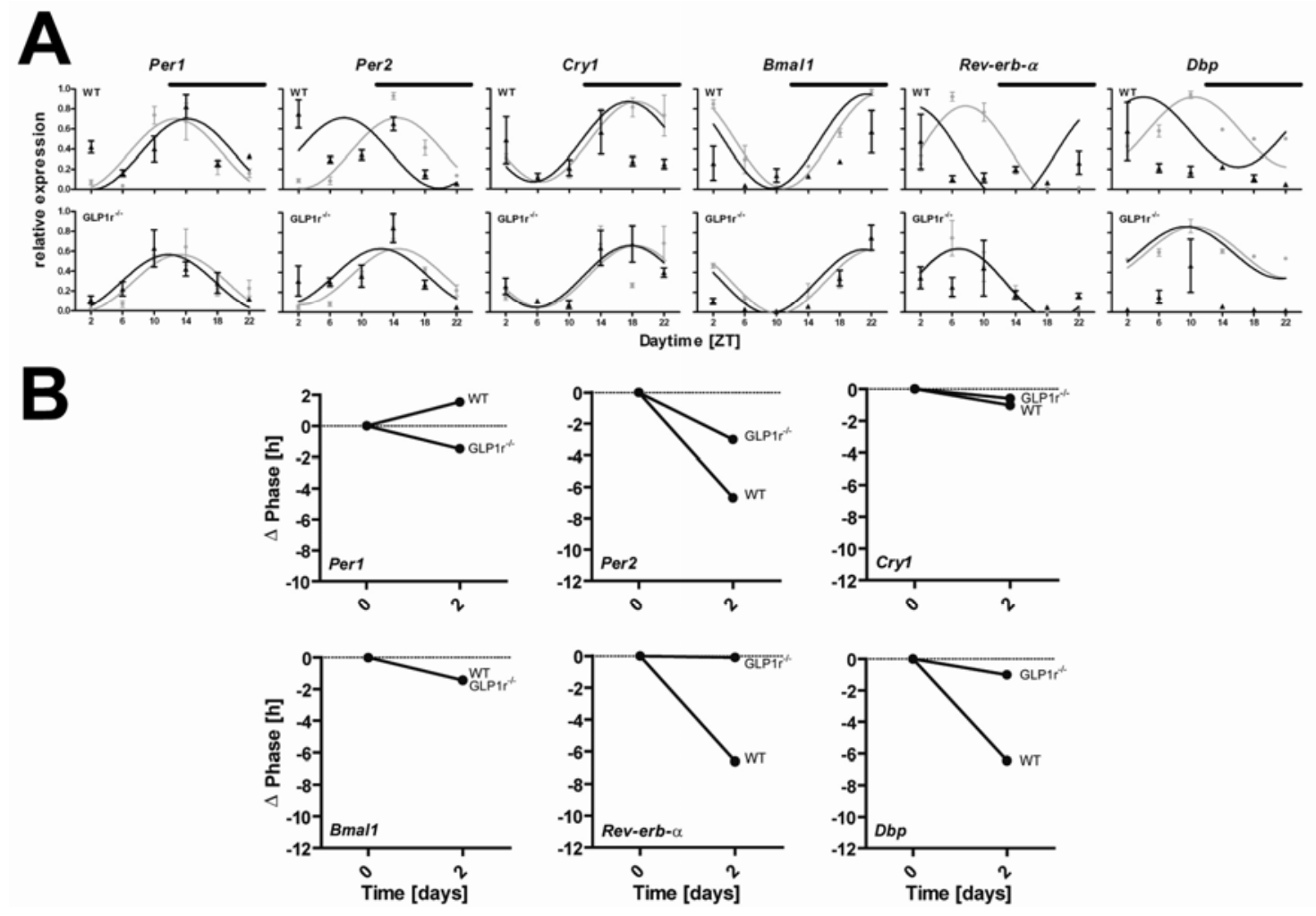

Fig. 33: Phase shift of clock gene expression of GLP-1 $r^{-/-}$and WT mice under RF. (A) Diurnal profiles of both genotypes under AL conditions (day 0 ) and after 2 days of RF (day 2). Profiles were sine wave fitted. Grey: profiles of day 0, black: profiles of day 2, horizontal bar denotes light and dark phase. (B) PS ${ }_{50}$ quantification of clock genes in the liver of both genotypes. 


\section{DISCUSSION}

The mammalian circadian timing system is based on a hierarchical system of dispersed oscillators [30]. The master circadian pacemaker is localized in the SCN, a hypothalamic nucleus composed of numerous coupled rhythmic neurons [40,41]. It receives light information directly by the RHT to entrain the clock to the $24 \mathrm{~h}$ day [34, 35]. The entrained SCN, in turn, coordinates slave oscillators in other brain regions and in peripheral organs such as the liver via multiple output mechanisms. Neuronal connections and humoral signals were shown to keep all peripheral clocks in synchrony [84, 243], but these clocks, including the liver clock, can be uncoupled from the SCN easily. Food was shown to be a strong Zeitgeber, only affecting peripheral organs but not the SCN. If feeding time is restricted to the inactive phase, peripheral clock gene expression is completely inverted, while the SCN stays entrained by light [85]. This finding suggests direct entrainment of peripheral slave oscillators by food-related signals $[85,86]$. To date the nature of these signals remain unknown. Indeed, postprandial hormonal signaling is well described, but none of these factors was convincingly linked to the entrainment of peripheral clocks so far.

\subsection{The gastro-intestinal hormone Oxyntomodulin sets the liver clock}

\subsubsection{The liver clock is synchronized by peptide hormones}

We screened 200 different hormonal peptides which were predominantly gastro-intestinal tract derived. We found ten peptides which changed the endogenous period by more than $3.5 \mathrm{~h}$, three peptides which caused complete arrhythmicity, and six peptides which significantly phase shifted the clock of PER2::LUC liver slices.

Neurotensin lengthened the period by almost 4 hours. It was formerly known, that this peptide is able to phase shift the firing rate of SCN neurons in vitro [244]. Furthermore its portal plasma levels were shown to be inversely correlated with circadian feeding rhythms [245]. Nevertheless an impact on peripheral cocks has never been demonstrated. The neurotransmitter PACAP lengthened the tau by more than $5 \mathrm{~h}$. PACAP has been shown to have an impact on the circadian system. It is colocalized with glutamate in the RHT and mediates the light responsive to the 
SCN [246]. Further, PYY, ß-endorphin, amylin, catestatin, intermedin and salusin- $\alpha$ changed the PER2::LUC expression period by more than $3.5 \mathrm{~h}$, but to date there are no other studies showing any connection between these peptides and the circadian system. A technical explanation for the period lengthening might be weak amplitude in some of the liver slices before the peptide treatments, which might be due to decreased viability of individual liver slices. A low PER2::LUC amplitude would reflect a weak oscillator, which would be more sensitive to external signals. Relations between amplitude, period and phase were already discussed in a study investigating the differences between fibroblasts of individual humans [247]. Of note, we occasionally observed comparable period effects on low amplitude liver slices due to normal handling without any hormonal treatments.

The same might be true for the complete loss of rhythmicity observed after pancreastatin treatment. It is possible that the overall low viability of liver slices leads easily to a disruption of the TTL oscillation or the disconnection between cells, both resulting in an arrhythmic PER2::LUC output signal. In contrast the oscillations of PER2::LUC were relatively stable before treatments with two isoforms of salusin- $\alpha$. In one case the period was lengthened in the other case rhythmicity was abolished. This indicates that salusin- $\alpha$ might act as a circadian clock regulator in the liver that effects period or amplitude rather then phase.

Neurohormone NPY phase advanced the liver clock by $5.8 \mathrm{~h}$. A role for NPY in the circadian system and food intake was shown before [248]. NPY has two different effects on the circadian system of mammals. On one hand, NPY release can change the phase of the clock during the subjective day. On the other hand, NPY can inhibit the phase-shifting effect of light during the night [248]. In the hypothalamus NPY neurons are the most important initiators for hunger revealing a direct connection of NPY to food intake [150]. A recent study of Wiater et al. highlights NPY as a connector of sleep, circadian rhythmicity and food intake. Specific ablation of NPY in the mediobasal hypothalamus leads to hyperphagia, altered circadian feeding rhythms and sleep/wake cycles [249]. Nevertheless, in spite of hepatic NPY innervation which mainly targets liver vessels and the bile duct of the Glisson's sheath [250] no direct influences of NPY on the liver clock were described.

Ghrelin is a peripheral peptide causing hunger and was shown to be rhythmically secreted when animals were fed ad libitum or food deprived [251, 252]. Additionally, it was shown to modulate the firing rate of SCN cells in vitro and in vivo. Furthermore, it has a strong influence on sleep $[253,254]$. Thus, it is strongly connected to the circadian system, but all effects described so far target the CNS and not the periphery. 
Motilin secretion itself was shown to be rhythmic under starvation and similar to ghrelin, motilin level decrease after food intake [255]. But no influence of motilin on the circadian system was ever shown.

Interestingly, our screen yielded four peptides all belonging to the pre-proglucagon family which had strong phase shifting impact on the PER2::LUC expression [186]. GLP-1 abolished rhythmicity completely, whereas Ex-4, OXM and glucagon phase shifted the clock. Especially, OXM and glucagon shifted clock gene expression drastically by $16.5 \mathrm{~h}$ and $17.3 \mathrm{~h}$, respectively. GLP-1, glucagon and OXM were shown to bind two different receptors, either GLP-1r or Gcgr [233]. The nonmammalian GLP-1 derivate Ex-4 is known as a specific GLP-1r agonist [256]. Only little is known about the connection between the pre-proglucagon family and the circadian system. Glucagon was shown be released in anticipation to feeding time under RF [257]. So far, there are no direct connections between GLP-1, OXM and circadian rhythms described. Studies showing rhythmic secretion of both peptides were not done in food deprived objects. Further, it was not clarified, whether both peptide rhythms are endogenously controlled or just react to nutrient uptake [197, 258]. However, the strong impact of all four peptides on PER2::LUC expression in cultured liver slices suggests that peptides coming from the pre-proglucagon gene might affect the liver circadian clock. Glucagon and OXM caused extreme phase shifts compared to the other candidates. Since in this study we concentrate on GI-peptide hormones we focused on OXM and not the pancreatic glucagon for all following studies.

We found NPY as the only peptide which was able to phase advance the liver clock significantly. Possible other candidates were restricted to phase delay the clock. In contrast, the data of many studies suggest that the liver clock is phase advanced by restricted feeding if the feeding time is also advanced $[86,87,94]$. Therefore, it seems more likely that clock gene expression undergoes an advancement. Conversely, our own data show that Per2 expression is phase delayed when feeding time is reversed to food access between ZTO-ZT12, suggesting that the direction of food shifts determines the direction of clock gene expression shifts.

A recent study of Tahara et al. discussed insulin as a possible factor responsible for the synchronization of peripheral organs during RF. They showed that insulin and refeeding both cause an upregulation of Per2 expression and a downregulation of Rev-erb- $\alpha$ expression. Furthermore, they observed phase advances of approximately $2 \mathrm{~h}$ in the liver due to refeeding or insulin injection. The same was shown for insulin treated mouse embryonic fibroblasts. In contrast, in our screen we did not observe any effect of insulin on the phase of the cultured liver slice. 


\subsubsection{Oxyntomodulin secretion is postprandially induced}

OXM was shown to be elevated in humans postprandially [197]. Shortly after food intake, even before the food bolus reaches the OXM producing L-cells in the intestine, OXM is secreted into the blood stream [197]. We could show that secretion of OXM also occurs in mice after refeeding. Mice were starved for $12 \mathrm{~h}$ to be sure that no freshly secreted OXM circulates in the blood and to get a strong stimulation of refeeding at ZT1. We found that the basic serum level of OXM has a high individual variance in mice spanning from $500 \mathrm{pM}$ to $1,500 \mathrm{pM}$. This made it necessary to collect blood of the same mice before and after refeeding and to normalize all data to the OXM basal level. After 20 min, we observed a 2-fold change of OXM which lasted for a minimum of $1 \mathrm{~h}$. Interestingly, OXM levels in humans are 100-fold lower than in mice, but postprandial OXM increase was also roughly 2-fold [197]. After 120 min the OXM concentration went back to initial levels. In humans high OXM levels persist for a minimum of 3 hours.

We also tested the stability of i.v. injected OXM in mice, to determine a injection paradigm, which would mimic the natural OXM release after food uptake. OXM is characterized by its short halflife of $6.4+/-0.5$ min due to rapid DPP-4 degradation [232, 259]. Instead of being refed mice received an injection, leading to a final blood concentration of $\sim 465 \mathrm{nM}$ at ZT1 after $12 \mathrm{~h}$ of fasting. As expected, after $20 \mathrm{~min}$ injected OXM was significantly elevated. The data suggest that the concentration of injected OXM is in an acceptable range as refeeding caused a 2-fold increase, whereas the injection caused a slightly higher 3.5-fold increase. After 60 min OXM was completely degraded. Based on this result we decided for possible following in vivo experiments to inject the mice twice, a second time 40 min after the first injection. In this way OXM levels will be kept high for around $60 \mathrm{~min}$.

\subsubsection{Oxyntomodulin actions on the liver clock}

From our GI-peptide hormone screen OXM emerged as a candidate factor to phase shift the liver clock. To validate OXM actions on the liver clock we performed a DRC and a PRC for OXM. We showed that the induced phase shift was strongly dependent on the concentration of OXM used for the screen. The dosage-dependency revealed that the reaction was not unspecific but based on a real physiological mechanism. 
In a following experiment we wished to assign the response of the liver oscillator in dependence on the treatment phase, to determine the phase of maximum shift due to OXM. The hepatic PRC for OXM showed important differences to other described PRCs established for the SCN or the liver. The light phase response curve of the SCN contains three different zones: a dead zone, where no phase shift can be aroused, a zone when only advances result and a third zone where exclusively phase delays can occur [5]. Balsalobre et al. established a hepatic in vivo Dbp and Rev-erb$\alpha$ PRC for dexamethasone treatments. They could not identify a dead zone, but extended phase advance and phase delay zones [231]. In contrast, our own dexamethasone phase response curve for organotypic liver slices offered a relatively long dead zone, lasting from 240-360', and two clear advance and delay zones. An explanation for this discrepancy might be that Balsalobre et al. did their experiment in vivo and not on cultured liver slices. In addition, they investigated Rev-erb- $\alpha$ and $D b p$, whereas our experiment was based on PER2::LUC data. Interestingly, our OXM PRC showed that OXM only evoked either phase delays or no phase shifts, but no advances at any time point.

Furthermore, we found that both Per1 and Per2 expression were induced due to OXM treatment in vitro and in vivo. The induction in liver slices was much weaker in liver slices than in vivo, suggesting that additional systemic effects amplify the hepatic effects in vivo. Additionally, in vivo Per induction appeared to be earlier than in vitro, which confirmed the influence of systemic signals supporting the liver Per induction. Induction of Per genes was also observed after dexamethasone treatments or serum shocks in fibroblast or hepatoma cells [53, 231]. Light pulses during the dark phase also induce Per expression in the $\operatorname{SCN}[83,188]$. It is widely accepted that resetting of the circadian clock involves acute induction of Per1 and Per2 genes [3, 260]. Albrecht et al. found that Per1 mutant mice are not able to advance and Per2 mutant mice are not able not delay the clock [261]. Furthermore, heat-activated Per expression in Drosophila directly caused phase shifts in locomotor activity [262]. We found that both Per1 and Per2 expression were induced due to OXM treatment in vitro and in vivo. The induction in liver slices was much weaker in liver slices than in vivo, suggesting that additional systemic effects amplify the hepatic effects in vivo. Additionally, in vivo Per induction appeared to be earlier than in vitro, which confirmed the influence of systemic signals supporting the liver Per induction. Induction of Per genes is also observed after dexamethasone treatments or serum shocks in fibroblast or hepatoma cells $[53,231]$. 


\subsubsection{Oxyntomodulin and restricted feeding}

OXM secretion is induced after food intake suggesting that it is involved in mediating the observed phase shifts of the liver clock. We thus wanted to compare the acute effects of food intake and OXM on liver clock gene expression. We fasted mice for $12 \mathrm{~h}$ and reefed them at ZT1. We found acute Per1 induction 20 min after refeeding which did not persist for $60 \mathrm{~min}$. Per2 was induced 60 min after refeeding and lasted for minimum $4 \mathrm{~h}$. Per induction after refeeding was already reported in the studies of Tahara et al., 2011 and Oike et al., 2011 [263, 264]. In contrast to our results Per1 induction was still visible after 1 hour in the latter study. We conclude that the fast induction of OXM in the blood might be responsible for the induction of Per genes after refeeding. RF can be seen as a repetitive refeeding schedule, thus the repeated induction of Per genes due to OXM release might regulate the synchronization of the liver clock under RF conditions.

\subsection{Oxyntomodulin signaling in the liver}

\subsubsection{Oxyntomodulin acts via a GLP-1r-like receptor in the liver}

To date it is not known whether OXM has its own specific receptor distinct of GLP-1r or Gcgr. In 1984 the detection of a specific OXM receptor in isolated rat oxyntic glands was reported [265]. This receptor binds also glucagon, but with a much higher dissociation constant $\left(K_{d}\right)$ value than OXM. On the other hand, synthetic OXM is able to bind to pig hepatic Gcgr, but with only $2 \%$ of the affinity of glucagon [211]. Furthermore, OXM action on rat gastric parietal cells can be inhibited by the GLP-1 receptor antagonist GLP-1(7-36) $\mathrm{NH}_{2}$ [266]. A study on the somatostatin-secreting cell line RIN T3 showed that GLP-1, OXM and glucagon bind with different potencies to the cell's plasma membrane (GLP-1 > OXM > glucagon) [267]. The study of Jorgensen et al. convincingly described the affinity of OXM, glucagon and GLP-1 to both Gcgr and GLP-1r, based on cAMP responses [233]. They showed that only glucagon and OXM are able to cause cAMP accumulation via Gcgr in this setup. Glucagon shows a higher potency than OXM. Conversely, all three peptides activate CAMP via GLP-1r with highest potency for GLP-1 and lowest for glucagon; OXM shows medial binding potencies to GLP-1r. Even though different doses are needed to activate the receptors, all peptides have the ability of maximal CAMP response [233]. In summary, these results show that actions of OXM are partly 
explicable by the activation of GLP-1r or Gcgr. Nevertheless, many other studies also demonstrate that some organs contain an as yet unidentified OXM receptor or, alternatively, a second GLP-1 receptor which can be activated by GLP-1 and OXM [268].

We decided to test the abilities of Ex9-39, a specific antagonist for GLP-1r, and D,-Glu, which is a specific Gcgr antagonist, to prevent OXM-induced phase shifts in liver slices and in vivo [218, 234]. First, we found that only Ex9-39 had the ability to inhibit PER2::LUC phase shifts caused by OXM. DGlu had no impact on the liver clock synchronization in organotypic liver slices. Ex9-39 had some effects, but was not able to inhibit the OXM-induced phase shift completely. This coincides with our findings from our screen that Ex-4 was only able to cause a relatively weak phase shift in comparison to OXM and that GLP-1 had no influence on clock phase at all. Moreover, we showed that Ex9-39 did not have OXM independent properties on the liver clock. Treatments with Ex9-39 alone had no influence on the phase of cultured liver slices and phase shifts caused by dexamethasone were not inhibited by GLP-1r antagonist.

Secondly, we confirmed the action of Ex9-39 on the liver as we tested the induction of Per1 and Per2 after co-treatment with Ex9-39 and OXM. We observed a complete inhibition of Per1 and Per2 induction both in vitro and in vivo. In the in vitro experiment we found that Per1 reacted not as high as in former experiments to OXM. A possible explanation might be that we used WT liver slices instead of PER2::LUC slices to test the induction in vitro. The OXM PRC showed that liver slices had their best treatment phase around $150^{\circ}$. Our experience is that most samples reach $150^{\circ}$ at around 2 am, but with a very high variance of several hours. Thus, we were not able to determine the exact phase of the single WT slices. Nevertheless, we decided to make all WT liver slice treatments at 2 am, suggesting that most of the slices were in the right phase. However, it might be that in this experiment most liver slices were not at the right phase. Consequently, and in accordance with the generated OXM PRC, which shows a relatively narrow time range of high phase shifts, different pronounced effects could have been measured in the WT slices.

We found that OXM shows liver-specific clock effects which are mediated by a receptor with comparable characteristics to GLP-1r. Although some older studies detected low expression of GLP-1r in liver [235, 269, 270] subsequent analyses based on mRNA expression [236, 271, 272], including our own analyses testing 12 of 13 exons of the known pancreatic GLP-1r, refute these results. GLP-1r was detected in pancreatic islets, exocrine pancreas, stomach, duodenum, heart, lung, kidney, brainstem, hippocampus, thalamus and hypothalamus, but not in adipose tissue, liver, skeletal muscle and the SCN [272-275]. However, the presence of a GLP-1 receptor-like protein was shown by immunoblot 
assays in isolated rat hepatocytes by another group [276] suggesting the expression of a second GLP-1 receptor with a comparable structure to GLP-1r, but expressed by from unknown gene.

A GLP-1r independent role of GLP-1 was shown before in many organs [237]. Non-classical binding or signal transduction of either agonists or antagonists, unexpected reactions to Ex9-39 and Ex-4 in the heart of GLP-1r $r^{-/-}$mice leads to the suggestion of a second unknown GLP-1 receptor in this organ [269, 277]. Alternatively, actions of agonist and antagonists were detected in organs not expressing GLP-1r, such as muscles and liver $[268,278]$.

In liver cells effects of GLP-1 were shown which can only be explained by the existence of a second unknown receptor. GLP-1 and Ex-4 activate several pathways in human and rat cultured hepatocytes [239, 241]. In contrast to its glucagon-like action and with regard to its role in glucose output, GLP-1 increases activity of glycogen synthase-A, decreases activity of glycogen phosphorylase$A$ and thereby promotes the incorporation of glucose into glycogen [279]. It was shown that these effects are mediated by a specific GLP-1r-like-receptor because they are also detectable by treating the cells with Ex-4 and can be inhibited after adding Ex9-39 [279-281]. GLP-1 induces facilitation of neural afferents when injected intraportal, but this effect is not changed by Ex9-39 [282]. However, comparable to the effects of the nonapeptide GLP-1(28-36)amide, cleavage product of the enzyme NEP24.11, Ex9-39 weakly inhibits gluconeogenesis [283]. GLP-1(9-36)amide, which has been considered to be biologically inactive, shows insulin-like action in cultured hepatocytes and men [284, 285]. Even though the hepatic receptor for GLP-1 or OXM is not yet identified there is mounting evidence that GLP-1 can bind to hepatocytes or hepatic mitochondria [283, 286]. Although GLP-1 is principally able to bind to Gcgr it was shown that glucagon binding was not affected by GLP-1. At the same time, however, GLP-1 is able to inhibit the effects of glucagon [287]. Interestingly and very important for the present study Ex9-39 does not physically bind to the liver [288]. In contrast, our results show a strong influence of Ex9-39 on organotypic liver slices and in vivo. Also other studies have shown direct influences of Ex9-39 on isolated hepatocytes [276, 280], suggesting that Ex9-39 must somehow signal to the liver.

Only a few studies show a direct impact of OXM on liver function. OXM binds to hepatocyte membranes [211]. Older studies show glucagon-like effects of OXM with increased liver cAMP levels $[195,240]$. Unfortunately it was not clarified if the mechanisms are identical by glucagon or GLP-1. For instance, neither glucose output was measured nor glucagon-associated signaling pathways were investigated. One single study showed that OXM and glucagon stimulate hepatic glycine cleavage system. Treatment with a specific Gcgr antagonist impairs the actions of both peptides [289]. Our 
study shows that OXM stimulates Per1 and Per2 expression in GLP-1r ${ }^{-/-}$liver slices. These findings strongly suggest the existence of a receptor for OXM in the liver which can also bind GLP-1, Ex-4 and Ex9-39, but not d-GLU. This receptor appears structurally related to the receptor which was already described for rat oxyntic glands [265].

\subsubsection{The signaling pathway of Oxyntomodulin remains unknown}

So far, only a few studies investigated the signaling pathways downstream of OXM. In rat parietal cells and baby hamster kidney cells (BHK cells) OXM increases CAMP and CREB phosphorylation [191, 266]. In our study we could exclude an involvement of Gcgr in synchronizing the liver clock in mice, since we found that Gcgr antagonists were not able to abolish OXM dependent phase shifts in liver slices. GLP-1r is known to be coupled to several pathways in the liver and other organs, including, prominently, the activation of CAMP/CREB [290]. After activation of GLP-1r in human hepatocytes with Ex-4 G-protein-coupled receptors and associated signal transduction pathways are activated. It was shown that the phosphorylation levels of CREB, PKB and ERK1/2 are immediately increased [239]. Similarly, PKB, ERK1/2 and additionally p70s6k were activated in rat hepatocytes and human myocytes $[241,291]$.

The CREB pathway is well known to be involved in synchronizing circadian clocks [5, 78-80]. However, neither in the kinase array nor in our immunoblot analysis we could detect an OXMinduced increase of phosphorylated CREB in cultured liver slices. The kinase-array suggested high phosphorylation states of PKB and JNK after OXM administration. Both the PKB pathway and the JNK pathway were shown to influence the circadian clock. A screen of kinase inhibitors revealed that blocking the JNK pathway with SP600125 and the PKB pathway with LY294002 leads to a dosagedependent lengthening of the Per2::Luc expression period in rat-1 cells [292]. On the other hand, activation of GLP-1r with Ex-4 in rat insulinoma cells and in the mouse pancreatic ß-cells prevents JNK activation [293]. On the other hand, PKB is known to inhibit the action of PGC-1 $\alpha$ and of GSK-3B [294, 295]. PGC-1 $\alpha$ and GSK-3ß were both shown to be clock controlled [296, 297]. PGC-1 $\alpha$ stimulates the expression of Bmal1 and Rev-erb- $\alpha$, which, in turn, leads to a higher expression of Per1 and Per2 [296]. Accordingly, an acute upregulation of PGC-1 $\alpha$ might explain the induction of Per1 and Per2 after OXM treatment. Furthermore, PKB inactivates GSK-3ß through phosphorylation [298]. However, active GSK-3ß was shown to interact with the BMAL1 protein leading to its degradation and, thus, 
repressing of Per1 and Per2 transcription [299]. If GSK-3ß is inactivated by PKB, Per1 and Per2 expression might be activated. Consequently, the JNK and the PKB pathway mechanisms might explain the increase of Pers observed after OXM treatment and, thus, the synchronization of the liver clock. However, inhibition of the JNK pathway with SP600125 or of the PKB pathway with PKB inhibitor IV in organotypic liver slices did not prevent OXM caused phase shifts.

In summary, even though we have tested around 40 different targets in the kinase array, Western blots and inhibition experiments, we were not able to uncover a pathway responsible for the phase shifts we observed in liver slices caused by OXM.

\subsubsection{Food entrainment in the liver of GLP-1 $1 r^{-/-}$mice is disturbed}

For several experiments we used GLP-1r ${ }^{-/-}$mice which were generated in David Druckers lab [238]. These mice show normal feeding behavior and body weight, increased insulin sensitivity, abnormal pancreatic Langerhans islet size and increased susceptibility to neuronal injury [300]. To date these mice have never been described for their circadian phenotypes. We could show that GLP$1 r^{-/-}$mice have normal activity periods both under LD and DD conditions. They do not show any differences to WT mice in activity amount neither in LD, DD, nor in total activity. Comparable to WT mice these mice develop the same amount of FAA when exposed to RF. However, we found that food entrainment of the liver in GLP-1r $r^{-/-}$is disturbed, as phase shifts of genes towards the feeding time need longer than in WT mice. We suggest that systemic effects are responsible for this effect, because WT liver does not express GLP-1r, but many other organs, including the brain.

GLP-1r was shown to be expressed in many peripheral organs [272] and in numerous regions throughout the whole brain, but not in the SCN [274, 275]. GLP-1 is known to regulate peripheral glucose homeostasis through the CNS [301]. Additionally, it was shown to inhibit food intake via direct action on the brainstem and the PVN [190]. We suggest that the manifold actions of GLP-1 throughout the body, especially in the CNS, are responsible for acceleration of food induced phase shifts in peripheral clocks. This is suggested by an absence of GLP-1r receptors in the SCN, a brain region which was already shown not to react on $\mathrm{RF}$ [85].

Interestingly, we found a deceleration of food-dependent peripheral phase shifts, but no disturbance in the development of FAA $[116,117]$. Consistent with the slower phase shift of the liver during RF, we found that Per1 and Per2 induction after refeeding were reduced in GLP-1r ${ }^{-/}$mice. Even 
if the induction effect was minor, we were able to completely inhibit it with i.v. injections of Ex9-39. This indicates, that a specific unknown OXM receptor located in the liver, and different from GLP-1r, is partly responsible for Per induction and might, thus, mediate food induced phase shifts of the liver clock.

\subsection{Outlook}

Our study identifies OXM as a postprandial factor secreted by a peripheral organ, which is involved in for the entrainment of the circadian clock of another peripheral organ, the liver. We could show that downstream of the circadian pacemaker, situated in the SCN, regulation of individual tissue clocks occurs directly and only on the level of peripheral organs. The rhythmic corticosterone output of the adrenal was shown to regulate peripheral phase shifts $[18,231]$. Corticosterone release decelerates the phase shifts caused by shifts of the light/dark cycle and administration of the synthetic glucocorticoids analog dexamethasone generates acute phase changes of the liver clock [231]. However, phase shifts of peripheral organs under RF conditions are independent of corticosterone release [86]. OXM may not be the only peripheral hormone which modulates peripheral clocks, it remains to be shown, which other factors contribute to the SCN-independent regulation of tissue oscillators. We could not identify the molecular signaling pathways connecting OXM with the liver clock. Further studies are needed to describe the mechanism by which OXM is able to induce Per1 and Per2 induction and reset/entrain the liver clock. The molecular system could also help in identifying other factors responsible for different organs. We found that the absence of GLP-1r delayed the phase shift of the liver clock under RF and diminishes Per1 and Per2 induction after refeeding but not after treatment with OXM. Additional blocking of the liver receptor with Ex939 inhibited Per1 and Per2 induction after refeeding completely. However, GLP-1 administration had no influence on the liver clock phase. Thus, we suggest a complex network of OXM, GLP-1 and the associated receptors which regulate peripheral clocks food-dependently via the periphery and the CNS. Tissue-specific receptor knockouts or direct administration of OXM, GLP-1 or Ex9-39 to different organs could allow uncovering this network in more detail. Targeting specific brain regions might help to identify neuronal connections between the CNS and peripheral organs which contribute the synchronization. 
Once the detailed mechanisms of food induced peripheral phase shifts are understood, drugs could be developed to inhibit this reaction. Shift workers prevalently eat during the night, which resembles restricted feeding in animals [145]. They suffer significantly more from obesity, diabetes, digestion problems and even cancer [122]. The internal desynchronization caused by night-time eating might advance these symptoms [124]. If the uncoupling of the SCN and the causally determined desynchronization due to food is diminished, the risk for shift workers to develop the described symptoms might be reduced. 


\section{MATERIALS AND METHODS}

\subsection{Animal handling and animal strains}

All animal experiments were done with prior permission by the Office of Consumer Protection and Food Safety of the State of Lower Saxony and in accordance with the German Law of Animal Welfare. If not stated otherwise, mice were provided food and water AL at all times. Animals were either kept in LD cycles or DD. LD cycles were 12 hours light on and 12 hours light off (12:12 LD cycle). "Lights on" was defined as ZTO and "lights off" as ZT12. Light intensity was set to 100 LUX.

\subsubsection{Wild-type mice}

For all experiments with wild-type mice male $\mathrm{C} 57 \mathrm{BL} / 6 \mathrm{~J}$ animals were used. All wild-type mice were 6-24 weeks old.

\subsubsection{PER2::LUC mouse strain}

For luminescence measurements PER2::LUC males of 6-24 weeks age were used [56]. The mouse line produced in the named study contains its natural Per2 alleles coupled to the gene encoding luc which results in a fusion protein composed of both components PER2 and LUC (PER2::LUC) (Figure 34). The emitted luminescence after addition of luciferin allows measuring Per2 expression in vitro and in vivo in real time, because the amounts of Per2 correlate directly with the amounts of emitted photons. 

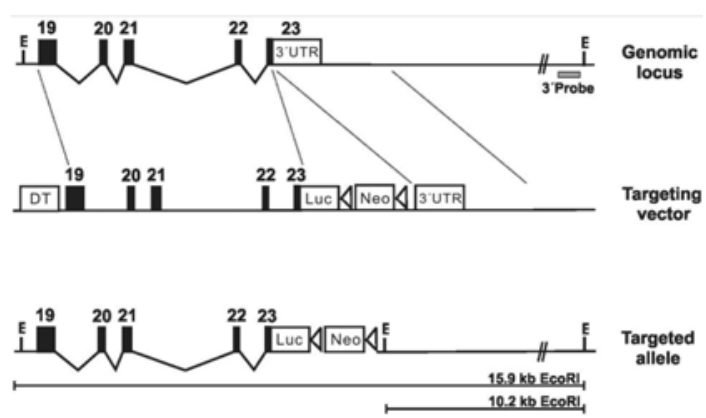

Fig. 34: Diagram of the mPer2 locus, targeting vector, and targeted knock in allele. Exons are indicated by filled blocks with numbers. E, EcoRI; DT, diphtheria toxin A chain; Neo, neomycin resistance gene; triangle, loxP site (from Yoo, et al., 2004).

\subsection{3. $\mathrm{GLP}-1 \mathrm{r}^{-/-}$mouse strain}

GLP-1 $r^{-/-}$mice were provided by Daniel Drucker's laboratory and delivered from Switzerland by Bernard Thorens. These mice lack functional GLP-1r due to a deletion of two exons encoding the first and the third transmembrane domains [238].

\subsection{Animal experiments}

\subsubsection{Pharmacological treatment}

Administration of $\mathrm{NaCl}$, OXM or Ex9-39 was done via i.v. injection into the tail vein. The animal's tail was warmed up with a wet and warm paper tissue to cause local vasodilatation. Afterwards solutions were injected. All substances were diluted in $100 \mu \mathrm{l} 0.9 \% \mathrm{NaCl}$ per mouse. OXM was used at a concentration of $9.3 \mu \mathrm{M}$ so that each mouse has a final blood concentration of $\sim 465$ nM. Ex9-39 used at a final concentration of $0.5 \mu \mathrm{M}$ leading to a final blood concentration of $~ 25 \mathrm{nM}$. These concentrations are based on assumption that each mouse has $2 \mathrm{ml}$ blood. 


\subsubsection{Tissue collection}

Animals were sacrificed at indicated time points by cervical dislocation. For PER2::LUC measurements animals were killed at ZT8. Animals which were killed during the dark phase were handled under red light and eyes were removed to prevent acute light effects on gene expression [188]. Tissue samples were collected and immediately snap-frozen on dry ice or liquid nitrogen. For long-term storage all tissues were kept at $-80^{\circ} \mathrm{C}$.

\subsubsection{Blood collection}

To measure serum OXM concentrations blood was collected. From ZT13 on animals were fasted for 12 hours. After fasting blood collection was done at ZT1 as reference time point. After three days of recovery, mice were fasted again followed by treatments (refeeding, OXM injection). Blood was again collected, but this time $20 \mathrm{~min}, 60 \mathrm{~min}$ and $120 \mathrm{~min}$ after treatment. Mice were carefully fixed under a towel. A small piece of their tail was cut and blood was milked into an Eppendorf tube. To minimize stress, milking was aborted after 2 min.

\subsubsection{Activity monitoring}

To monitor activity mice were individually housed in transparent plastic cages (Tecniplast $1155 \mathrm{M}$ ) that were equipped with a steel running wheel of $115 \mathrm{~mm}$ in diameter (Trixie 6083, Trixie $\mathrm{GmbH}$, Germany). Rotations of the running wheel were measured by a magnetic switch. The signal was transmitted to a computer provided with the activity counting system ClockLab (Actimetrics, Austin St. Evanston, USA).

The cages were placed in black painted boxes where 12 cages find place and can be connected to the computer. The first 7 days of measurement were excluded from the analysis to allow adaption to the running wheel. Cages were changed approximately every 2 weeks at a time point well apart of relevant treatment time points. Running data analysis was performed using the ClockLab analysis software plug-in (Actimetrics) for MatLab (The Mathworks). 


\subsubsection{Restricted feeding}

In order to test the behavior under time restricted feeding conditions, mice were exposed to a 12:12 LD cycle with 100 LUX during the light phase $(Z T 0=9 a m, Z T 12=9 \mathrm{pm})$. Food and water were available ad libitum. After two weeks feeding time was restricted to daytime and the time span of feeding was gradually reduced to $4 \mathrm{~h}$. Food was provided as described in the following schedule:

Day 1: ZT0.5 - ZT11.5,

Day 2: $\quad$ ZT1.5-ZT11,

Day 3: $\quad$ ZT3 - ZT10.5,

Day 4: $\quad$ ZT4 - ZT9.5,

Days 5-12: $\quad$ ZT4 - ZT8.

In a second experiment we tested the ability of the liver clock genes to phase shift under RF

conditions in WT and GLP-1 $1 r^{-/-}$mice. Therefore, feeding time was changed from ad libitum to daytime feeding (ZTO - ZT12) immediately.

\subsection{Tissue culturing}

\subsubsection{Liver slicing}

For liver slices cultures donor animals were killed by cervical dislocation. For luminescence measurements only heterozygous PER2::LUC mice were used. After the peritoneum of the animal was opened, the whole liver was carefully and swiftly dissected using blunt scissors. Here it was important not to damage the attached gall bladder, as it contains digestive substances. The liver was immediately placed in sterile Hanks' balanced salt solution (HBSS; e.g. Invitrogen Cat\# 24020133) on ice. The median liver lobe was dissected and embedded in 3.5-4\% of Low Melting Agarose (e.g. Invitrogen Cat\# 15517022), made with HBSS, at $37^{\circ} \mathrm{C}$ using plastic histology embedding molds. The block was stored on ice until the agarose was completely polymerized. After polymerization the solidified agarose block was glued to the rack of a vibratome (Campden Instruments MA752). The sectioning with the vibratome was done with following settings: 
- Object speed: $2-2.5$,

- Vibration:

6-7,

- Slices: $\quad 300 \mu \mathrm{m}$.

Liver slices were transferred from the basin into a clean Petri dish filled with ice cold HBSS and cut down to rectangles of $2 \times 2 \mathrm{~mm}$ with a scalpel blade.

\subsubsection{Organotypic liver slice culturing}

$\begin{array}{ccl}\text { Culture medium: } & \begin{array}{c}352.5 \mu \mathrm{g} / \mathrm{ml} \\ 10 \mathrm{mM}\end{array} & \text { sodium carbonate (Sigma, \# S7795) } \\ 2 \mathrm{mM} & \text { HEPES buffer (Invitrogen, \# 15630056) } \\ 2 \% & \text { L-glutamine (Invitrogen, \# 25030024) } \\ 25 \mathrm{U} / \mathrm{ml} & \text { B-27 Supplement (Invitrogen, \# 17504044) } \\ & \text { Penicillin/Streptomycin (Invitrogen, \# } \\ & 15070063)\end{array}$

Fill up to $50 \mathrm{ml}$ with D-MEM (high glucose, w/o L-glutamine \& phenol red; Invitrogen Cat\# 31053-044)

$1 \mathrm{ml}$ of culture medium was loaded in $35 \mathrm{~mm}$ Petri dishes. We added sodium D-Luciferin (10 mM stock solution of Invitrogen Cat\# L2912 in PBS, pH 6.3) to a final concentration of $0.1 \mathrm{mM}$. Since D-Luciferin is very light sensitive it was important to avoid direct light from this step on. A culture plate insert (Millipore: PICMORG50) was placed in the Petri dish. The liver slices were carefully placed in the centre of a plate insert. To allow the exchange of gas but not liquids Petri dishes were sealed with silicon fat and round glass cover slips $(\varnothing: 40 \mathrm{~mm})$ and was transferred into the LumiCycle (Actimetrics) in a dry cell culture incubator at $32.5^{\circ} \mathrm{C}$ and $5 \% \mathrm{CO}_{2}$.

\subsubsection{Luminescence measurement}

The LumiCycle was connected to a computer with a special recording program (Actimetrics). Standard settings for the LumiCycle were:

$\begin{array}{ll}\text { Integration time: } & 75 \mathrm{sec} \\ \text { Measurement interval: } & 1 \text { per } 10 \mathrm{~min}\end{array}$




\subsubsection{Liver slice treatment}

Due to the fact that the circadian clock can be reset by temperature changes, the liver slices were kept at approximately $32.5^{\circ} \mathrm{C}$ during treatment. The Petri dishes were taken out of the luminometer and immediately placed in a thick copper plate molded to fit Petri dishes, which was preheated in the incubator. The copper plate together with the Petri dishes was transferred under a sterile cell culture hood and placed on a preheated slice warmer. This made sure that the temperature of the Petri dishes did not decrease. The cover slip sealing the Petri dish was shortly removed. With a forceps the culture membrane with the liver slice on top was taken out of the Petri dish and the treatment substance was immediately added to the medium. The culture membrane was instantly placed back in the Petri dish and moved a bit to mix the medium underneath. The cover slip was replaced on the Petri dish. If necessary more silicon fat was added to seal it properly. The Petri dishes were brought back to the incubator and placed again in the luminometer.

\subsubsection{PER2::LUC data analyse}

Analyses were done with the LumiCycle analysis program (Actimetrics) and Prism software (GraphPad) (Figure 35).

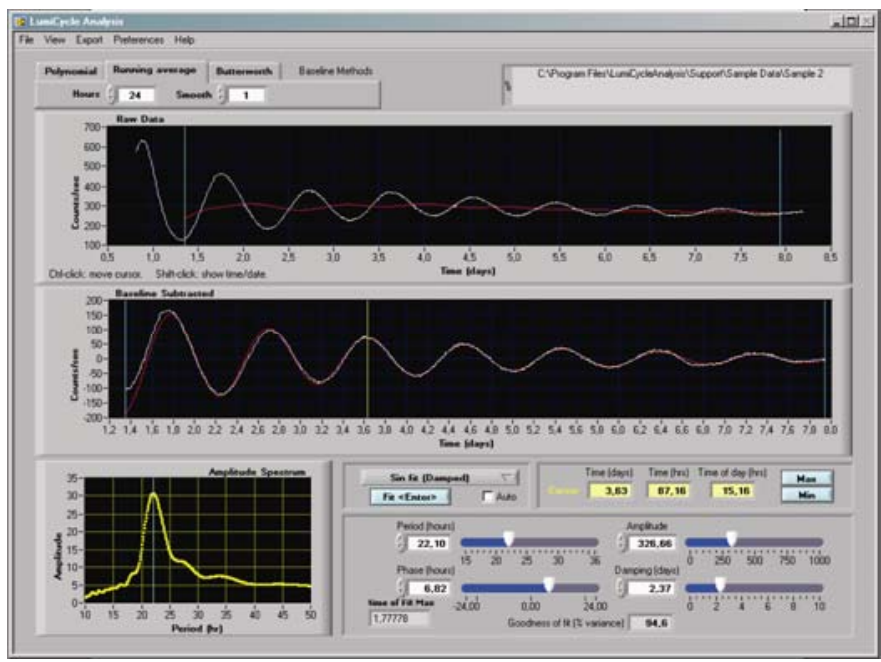

Fig. 35: Surface of the Actimetrics LumiCycle software. The upper panel shows raw data, the lower panel shows baseline subtracted data. With the moveable yellow bar in the baseline subtracted date the peak time was defined. The software gives additional data such as period [h], amplitude, phase[h] and damping [days]. 
The PER2::LUC expression follows a sine wave shape. The intersection of the ascending part of the sine wave with the baseline is defined as $0^{\circ} / 360^{\circ}$, the peak as $90^{\circ}$, the intersection of descending part with the baseline as $180^{\circ}$, and the trough as $270^{\circ}$. The degrees at the time point of treatment were calculated as follows:

$$
T_{p}\left[{ }^{\circ}\right]=\left(\left(T_{p}[h s m]-P_{b t}[h s m]\right): P_{b t}\right) \times 360+90
$$

$$
\begin{array}{r}
T_{p}=\text { treatment phase } \\
\circ=\text { degree }
\end{array}
$$

hsm $=$ hours after start of measurement

$$
P_{b t}=\text { peak before treatment }
$$

If the result was $<360^{\circ}$ the value of 360 was subtracted.

For analyses the raw data were baseline subtracted which was calculated with a running average of $24 \mathrm{~h}$. Peaks were defined as half the distance between two troughs of the sinus. Phase shifts were determined by comparing the time of the next expected peak after the treatment and the actual measurement peak. To display phase shifts a sine wave equation was fitted to the data.

$$
y=\text { Baseline }+ \text { Amplitude } \mathrm{x} \sin (\text { Frequency } \mathrm{x} x+\text { Phase shift) }
$$

To allow a better visual comparison of sine fits of PER2::LUC expression before and after treatment, amplitude and baseline were constrained to be equal.

\subsection{Molecular biology methods}

\subsubsection{Genotyping}

Tail snips ( $3 \mathrm{~mm}$ ) taken at the age of weaning (3-4 weeks) were used as samples. Snips were digested overnight at $55^{\circ} \mathrm{C}$ in $450 \mu$ tail extraction buffer $(200 \mathrm{mM}$ Tris/HCl, pH 8.0, $50 \mathrm{mM}$ EDTA (pH 8.0), and $100 \mathrm{mM} \mathrm{NaCl}, 1 \% \mathrm{SDS})$ plus $15 \mu \mathrm{l}$ Proteinkinase $\mathrm{K}(10 \mathrm{mg} / \mathrm{ml})$. Afterwards DNA was 
precipitated with 100\% EtOH, washed and dissolved in Tris/EDTA (10 mM Tris, pH 8.0, and $1 \mathrm{mM}$ EDTA, pH 8.0). All PCRs were done in with a FelxCycler PCR machine (Analytik Jena, Jena, Germany).

Per2::Luc genotyping:

Setup: $0.5 \mu$ I DNA ( 200ng/ $\mu$ l)

$1.0 \mu$ I Ammonium Buffer

$0.1 \mu \mathrm{l}$ dNTP

$0.2 \mu \mathrm{l}$ Primer forward (Luc_1) $(10 \mu \mathrm{M})$

$0.1 \mu$ Primer reverse (Luc_2) $(10 \mu \mathrm{M})$

$0.1 \mu \mathrm{l}$ Primer reverse (Luc_3) $(10 \mu \mathrm{M})$

$0.2 \mu \mathrm{l}$ Amplicon Taq-Polymerase

$7.8 \mu \mathrm{H} 20$

$10 \mu \mathrm{l}$

Program: $\quad 3: 00 \min 95^{\circ} \mathrm{C}$

$0: 30 \min 94^{\circ} \mathrm{C} \quad 7$
$0: 30 \min 65^{\circ} \mathrm{C}$
$\left.1: 00 \min 72^{\circ} \mathrm{C} \quad\right\rfloor$
7:00 $\min 72^{\circ} \mathrm{C}$
Forever $4^{\circ} \mathrm{C}$

Wild-type band: 200 bp / Per2::Luc band: 720 bp 
$\underline{\text { GLP-1 }} \mathrm{r}^{-/-}$genotyping:

Setup: $0.5 \mu \mathrm{l}$ DNA ( 200ng/ $\mu \mathrm{l})$

$1.0 \mu \mathrm{l}$ Ammonium Buffer

$0.1 \mu \mathrm{ldNTP}$

$0.15 \mu$ l Primer forward olMR0013 (1) $(10 \mu \mathrm{M})$

$0.15 \mu$ l Primer reverse olMR0014 (2) (10 $\mu \mathrm{M})$

$0.25 \mu$ l Primer forward GLP-1R F2 (3) $(10 \mu \mathrm{M})$

$0.25 \mu$ l Primer reverse GLP-1R R2 (4) $(10 \mu \mathrm{M})$

$0.2 \mu \mathrm{l}$ Amplicon Taq-Polymerase

$7.4 \mu \mathrm{l} \mathrm{H}_{2} \mathrm{O}$

$10 \mu \mathrm{l}$

Program (Jena): $\quad 3: 00 \min 95^{\circ} \mathrm{C}$

$1: 00 \min 94^{\circ} \mathrm{C} \quad 7$

$0: 30 \min 62^{\circ} \mathrm{C} \quad x 30$

$0: 30 \min 72^{\circ} \mathrm{C} \quad 」$

$7: 00 \min 72^{\circ} \mathrm{C}$

Forever $4^{\circ} \mathrm{C}$

Wild-type band: 437 bp / Per2::Luc band: 280 bp

\subsubsection{RNA isolation}

RNA was isolated from frozen $\left(-80^{\circ} \mathrm{C}\right)$ tissues with TRIzol (Invitrogen), according to the manufacturer's protocol. Isolated RNA was dissolved in $\mathrm{ddH} 2 \mathrm{O}$ and stored at $-80^{\circ}$. The concentration was determined with the ND-1000 (NanoDrop) spectrophotometer. 


\title{
4.4.3. cDNA synthesis
}

cDNA was synthesized from RNA samples with MulitScribe Reverse Trancription Kit including RNase inhibitor (Applied Biosystems) according to the manufacturer's protocol with the exception that only half of the recommended amount of all reagents per reaction was used and exactly $1 \mu \mathrm{g}$ RNA was applied.

\subsection{4. quantitative real-time PCR (qPCR)}

Quantitative real-time PCR (qPCR) was performed with the CFX96 Real-Time System (Bio-Rad) with iQ-SYBR Green Supermix (Bio-Rad).

\author{
Setup: $5 \mu \mathrm{l}$ cDNA (1:20 dilution) \\ $5 \mu \mathrm{l}$ Primer Mix (1 $\mu \mathrm{M}$ each Primer) \\ $10 \mu \mathrm{l}$ iQ-SYBR Green Supermix \\ $20 \mu \mathrm{l}$

\begin{tabular}{|c|c|c|}
\hline Program: & $7: 00 \min 95^{\circ} \mathrm{C}$ & \\
\hline & $0: 10 \min 95^{\circ} \mathrm{C}$ & 7 \\
\hline & $0: 25 \min 60^{\circ} \mathrm{C}$ & $x 40$ \\
\hline & $0: 20 \min 72^{\circ} \mathrm{C}$ & \lrcorner \\
\hline
\end{tabular}

To determine the amplification efficiency for each primer set, a standard curve was generated with a cDNA dilution series of 1:10, 1:50, 1:250, 1:1,250, 1:6,250 and 1:31,250 and fitted by linear regression. Data analysis was performed with the CFX96 software, assessing the amplification efficiency as the exponent of the base, indicating the amount of cycles needed for doubling the 
amount of cDNA synthesis (in the ideal case 1 = doubling the amount of cDNA each cycle: $E=100 \%$ ). Primer pairs with efficiency lower than $95 \%$ or higher than $105 \%$ were not used for further analyses.

The CFX96 automatically analyzed the $\mathrm{C}_{\mathrm{T}^{-}}$values (threshold cycling numbers) for each well located above a fixed threshold line of 300 . These $C_{T^{-}}$-values depict the cycle number at which the SYBR green fluorescence value reaches the specific threshold, set to a defined position above the background levels for each plate setup. Relative quantification of expression levels by a modified $\Delta \Delta C T$ calculation was performed as described [302]. For analysis we used $\beta$-actin as housekeeping reference gene. Statistical analyses were done with GraphPad Prism software (GraphPad Software, San Diego, USA). All data were normalized against the $C_{T}$-value of $ß$-actin. Circadian profiles of clock gene expression were normalized against the average values of all time points. Induction analyses were normalized against untreated conditions ( $0 \mathrm{~min})$.

\subsubsection{Primer sequences}

\begin{tabular}{lll} 
Gene & DNA-Sequence & GenBank ID \\
B-act fw & 5'-CCCTGAAGTACCCCATTGAA-3' & NM_007393 \\
B-act rev & 5'-AGGTGTGGTGCCAGATCTTC-3' & \\
Bmal1 fw & 5'-CCTAATTCTCAGGGCAGCAGAT-3' & NM_007489 \\
Bmal1 rev & 5'-TCCAGTCTTGGCATCAATGAGT-3' & \\
Cry1 fw & 5'-GTCATTGCAGGAAAATGGGAAG-3' & NM_007771 \\
Cry1 rev & 5'-TAAAGAGGCGGAGAGACAAAGG-3' & \\
Dbp fw & 5'-AATGACCTTTGAACCTGATCCCGCT-3' & NM_016974 \\
Dbp rev & 5'-GCTCCAGTACTTCTCATCCTTCTGT-3' & \\
Per1 fw & 5'-AGTTCCTGACCAAGCCTCGTTAG-3' & NM_011065 \\
Per1 rev & 5-'CCTGCCCTCTCGTTGTCATC-3' & \\
Per2 fw & 5'-GCCAAGTTTGTGGAGTTCCTG-3' & NM_011066 \\
Per2 rev & 5'-CTTGCACCTTGACCAGGTAGG-3' & \\
Rev-erb- $\alpha$ fw & 5'-AGCTCAACTCCCTGGCACTTAC-3' & NM_145434 \\
Rev-erb- $\alpha$ rev & 5'-CTTCTCGGAATGCATGTTGTTC-3' & \\
\multicolumn{2}{l}{ Table 1: Primer pairs used for the quantification of mRNAs by qPCR and Entrez Gene ID. }
\end{tabular}




\begin{tabular}{|c|c|c|c|}
\hline Gene & DNA-Sequence & Length [bp] & GenBank ID \\
\hline \multicolumn{3}{|l|}{ GLP-1r $r^{-/-}$Genot. } & \\
\hline olMR0014 (2) & 5'-AGGTGAGATGACAGGAGATC-3' & & \\
\hline GLP1R F2 (3) & 5'-TACACAATGGGGAGCCCCTA-3' & 437 Intron 6 & \\
\hline GLP1R R2 (4) & 5'-AAGTCATGGGATGTGTCTGGA-3' & & \\
\hline \multicolumn{4}{|l|}{ GLP-1r Exons } \\
\hline Exons 2-3 fw & 5'-CAGAAATGGAGAGAATACCG-3' & 2205 & NM_021332 \\
\hline Exons 2-3 rev & 5'-CAGGCATAGTCATCAAAGGT-3' & & \\
\hline Exons 3-4 fw & 5'-CTTTGATGACTATGCCTGCT-3' & 227 & \\
\hline Exons 3-4 rev & 5'-TCCTTATGTAGCCAGAGACC-3' & & \\
\hline Exons 4-5 fw & 5'-GGTCTCTGGCTACATAAGGA-3' & 226 & \\
\hline Exons 4-5 rev & 5'-CGTACCCCACTGTGTAGATAA-3' & & \\
\hline Exons 5-6 fw & 5'-GCTCCTGTCCCTGTACATTA-3' & 261 & \\
\hline Exons 5-6 rev & 5'-CAGGTTCAGGTGGATGTAGT-3' & & \\
\hline Exons 6-7 fw & 5'-CTACATCCACCTGAACCTGT-3' & 314 & \\
\hline Exons 6-7 rev & 5'-AGCCTATGCTCAGATACAGC-3' & & \\
\hline Exons $7-8 \mathrm{fw}$ & 5'-GTGGCAGCCAACTACTACTG-3' & 221 & \\
\hline Exons 7-8 rev & 5'-CCCTCGTCCTCATAGAGATA-3' & & \\
\hline Exons 8-9 fw & 5'-GGGGGATTGTCAAGTATCTC-3' & 131 & \\
\hline Exons $8-9$ rev & 5'-CCGATAGCAAAGAGAATGG-3' & & \\
\hline Exons $9-10 \mathrm{fw}$ & 5'-GCTGGACTAGGAACTCCAAT-3' & 159 & \\
\hline Exons 9-10 rev & 5'-TTAGCCTTCAGTTTGGAGAC-3' & & \\
\hline Exons $10-11 \mathrm{fw}$ & 5'-ATGTGCAAGACTGACATCAA-3' & 228 & \\
\hline Exons $10-11$ rev & 5'-GGAAGGAAGTGAAGGAGAGT-3' & & \\
\hline Exons $11-12 \mathrm{fw}$ & 5'-GTCATCTTTGCCTTTTGTGAT-3' & 181 & \\
\hline Exons $11-12$ rev & 5'-CAGTACAGGATAGCCACCAT-3' & & \\
\hline Exons $12-13 \mathrm{fw}$ & 5'-TGGCTATCCTGTACTGCTTT-3' & 210 & \\
\hline Exons $12-13 \mathrm{rev}$ & 5'-CTTCATGCTGCAGTCTCTCT-3' & & \\
\hline \multicolumn{4}{|l|}{ Per2::Luc Genot. } \\
\hline Per2::Luc_for & 5'-CGCTGTGTTTACTGCGAGAGTGAGG-3' & & \\
\hline Per2::Luc_rev1 & 5'-CCACAAGATCTTCCCCCTCTTCCG-3' & 200 & \\
\hline Per2::Luc_rev2 & 5'-GTCCCTATCGAAGGACTCTGGCAC-3' & 780 & \\
\hline
\end{tabular}

Table 2: Primer pairs used for Genotyping of GLP-1 $r^{-/-}$and PER2::LUC mice or for detection of GLP-1r in liver tissue by PCR, product lengt and Entrez Gene ID. 


\subsection{Histological methods}

\subsubsection{Cryosections}

Snap-frozen tissue was embedded in O.C.T. compound (Tissue-Tek). Cryosections were done with the CM3050 (Leica) cryostat with following settings:

Chamber temperature: $-16^{\circ} \mathrm{C}$,

Object temperature: $\quad-18^{\circ} \mathrm{C}$,

Slices: $\quad 12 \mu \mathrm{m}$.

\subsubsection{In situ hybridization}

The probes for Per1 and Per2 were done as described [188]. The Per1 probe corresponds to nucleotides 1 to 619 (GenBank accession number AF022992). The Per2 probe was made from a cDNA corresponding to nucleotides 229 to 768 of GenBank AF036893). PCR products had already been cloned into pCR II Topo vector using TOPO TA Cloning Kit (Invitrogen) [303]. The vectors containing Per1 and Per2 were used to propagate single clones in LB medium (1\% (w/v) tryptone, 0.5\% (w/v) yeast extract, $1 \%(\mathrm{w} / \mathrm{v}) \mathrm{NaCl}, 1 \mathrm{mg} / \mathrm{ml}$ ampicillin). Maxi preparation of plasmid DNA was performed using QIAfilter Plasmid Maxi Kit (Qiagen) following the manufacturer's protocol. Linearization of vectors for in vitro transcription was done with EcoR I. ${ }^{35}$ S-UTP (PerkinElmer, Monza, Italy) labeled RNA probes were made using RNA Transcription Kit (Maxi Script Labeling Kit, Ambion, Austin, USA) with T7, T3 or SP6 RNA polymerases. $1 \mu$ g linearized plasmid template was used in a standard setup sufficient for about 24 slides. Transcription setup for ${ }^{35}$ S-UTP labeled antisense RNA probes for clock gene transcripts were performed as described:

- $1 \mu \mathrm{g}$

linearized cDNA template (or 500 ng if PCR product is used)

- $8 \mu \mathrm{l}$

DEPC $\mathrm{H}_{2} \mathrm{O}$

- $2 \mu l$

10x Transcription buffer

- $1 \mu \mathrm{l}$

each rATP, rCTP and rGTP

- $1 \mu \mathrm{l}$

RNase inhibitor

- $5 \mu \mathrm{l}$

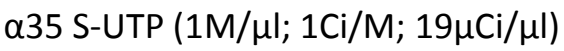

- $1 \mu \mathrm{l}$

RNA Polymerase 
Solution was gently mixed by pipetting up and down and incubated for $2 \mathrm{~h}$ at $37^{\circ} \mathrm{C} / 400 \mathrm{rpm}$ in a Thermomixer (Eppendorf). To degrade the template a DNase step followed:

- $19 \mu \mathrm{l} \quad$ DEPC-H2O

- $\quad 1.7 \mu \mathrm{l} \quad \mathrm{MgCl} 2(0.3 \mathrm{M})$

- $1 \mu \mathrm{l} \quad$ DNase I (2 U)

Solution was gently mixed by pipetting up and down and afterwards incubated for $15 \mathrm{~min}$ at $37^{\circ} \mathrm{C} /$ $400 \mathrm{rpm}$ in a Thermomixer (Eppendorf). The probe was prepared as followed:

- $\quad 100 \mu \mathrm{l}$ DEPC- H2O

- $100 \mu \mathrm{l}$ yeast tRNA $(1 \mathrm{mg} / \mathrm{ml})$

- $250 \mu \mathrm{l} \quad \mathrm{NH} 4 \mathrm{Ac}(4 \mathrm{M})$

- $1 \mathrm{ml} \quad \mathrm{EtOH}(100 \%)$

The solution was vortexed and incubated on ice for $10 \mathrm{~min}$. Then it was spun down for $15 \mathrm{~min}$ at $4^{\circ} \mathrm{C}$ / 14,000 rpm. The supernatant was carefully removed and the pellet resuspended in:

- $\quad 200 \mu \mathrm{l}$ DEPC- H2O.

- $200 \mu \mathrm{l} \quad \mathrm{NH} 4 \mathrm{Ac}(4 \mathrm{M})$

- $800 \mu \mathrm{l}$ EtOH $(100 \%)$

The solution was vortexed and incubated on ice for $10 \mathrm{~min}$. Thereafter it was spun down for $10 \mathrm{~min}$ at $4^{\circ} \mathrm{C} / 14,000 \mathrm{rpm}$ and the supernatant was discarded. Then the pellet was dissolved in:

- $100 \mu$ ISH Hybridisation Buffer (HybMix, Ambion).

The radioactivity of $2 \mu \mathrm{l}$ of the dissolved sample was measured in a beta-counter with $5 \mathrm{ml}$ scintillator cocktail. Usually incorporation yields $1-6 \times 10^{6} \mathrm{cpm}$ in a $2 \mu \mathrm{l}$ sample. The probe was diluted with HybMix (Ambion, USA) up to $100 \mu \mathrm{l}$ per slide and 1/100 volume $1 \mathrm{M}$ Dithiothreitol (DTT) (Biomol, Hamburg, Germany) was added. The probes were stored on ice if used on the same day or at $-80^{\circ} \mathrm{C}$ for up to 1 week. In the next step the cryoslices were fixed and acetylated: 
- $5 \min \quad 0.9 \% \mathrm{NaCl}$

- 5 min PBS

- 20 min $4 \%$ PFA (pH 7.4 in PBS)

- 5 min PBS

- $5 \mathrm{~min}$ Proteinase $\mathrm{K}(4 \mathrm{\mu g} / \mu \mathrm{l}$ in $50 \mathrm{mM}$ Tris/ $\mathrm{HCl}, 5 \mathrm{mM}$ EDTA, $\mathrm{pH} 8.5)$

- $5 \min \quad 0.2 \mathrm{~N} \mathrm{HCL}$

- 5 min PBS

- 20 min $4 \%$ PFA (pH 7.4 in PBS)

- $3 \mathrm{~min} \quad 0.1 \mathrm{M}$ triethanolamine/ $\mathrm{HCl} \mathrm{pH} \mathrm{8.0;} \mathrm{stir} \mathrm{with} \mathrm{stir} \mathrm{bar}$ add freshly $750 \mu$ l acetic anhydride on $250 \mathrm{ml}$ solution

- 7 min add another $750 \mu l$ acetic anhydride freshly; stir with stir bar

- 5 min PBS

- $\quad 5 \min \quad 0.9 \% \mathrm{NaCl}$

- 30 sec each $30 / 50 / 70 / 80 / 95 \%$ ethanol

- $2 \times 1 \mathrm{~min} \quad 100 \%$ ethanol

The cryoslices were air-dried at a RNase-free place.

Hybridization was performed in humidified chambers (5x SSC, $50 \%$ (v/v) formamide) in a hybridization oven over night (at least $16 \mathrm{hrs}$ ) at $55-58^{\circ} \mathrm{C}$. Probe was given on the slides (100 $\mu \mathrm{l}$ per slide) and spread over the whole area using a pipette tip before covering with a cover slip. Posthybridization was performed the next day and probe was removed by washing as follows:

- 10 min

- $20 \mathrm{~min}$

- 30 min

- 30 min

- 30 min

- $15 \min$ $64^{\circ} \mathrm{C}$

2x SSC + 40 mM ß-mercaptoethanol (ß-

MeSH, Sigma-Aldrich, St. Louis, USA)

cover slips were removed using forceps

$2 \times \mathrm{SSC}+40 \mathrm{mM}$ beta-MeSH

2x SSC/ $50 \%$ formamide $+40 \mathrm{mM}$ ß-MeSH

1x NTE (50 mM NaCl, 10 mM Tris/

$\mathrm{HCl}, 5$ mM EDTA, pH 8) + 40 mM ß-MeSH

RNase A $(20 \mu \mathrm{g} / \mathrm{ml})$ in NTE (add freshly)

$1 \times$ NTE 


$\begin{array}{lll}-30 \mathrm{~min} & 64^{\circ} \mathrm{C} & 2 \times \mathrm{SSC} / 50 \% \text { formamide }+40 \mathrm{mM} \text { ß-MeSH } \\ \text { - } 15 \mathrm{~min} & \text { RT } & 2 \times \mathrm{SSC} \\ \text { - } 15 \mathrm{~min} & \text { RT } & 0,1 \times \mathrm{SSC} \\ \text { - } 30 \mathrm{sec} & \text { RT } & \text { each } 30 / 50 / 70 \% \mathrm{EtOH}+0.3 \mathrm{M} \\ & & \text { ammoniumacetate } \\ \text { - } 30 \mathrm{sec} & \text { RT } & \text { each } 95 / 100 / 100 \% \mathrm{EtOH}\end{array}$

The slides were air-dried before they were exposed to a Biomax MS film (Kodak)

Exposed films were developed with the X-omat1000 (Kodak) and analyzed with a densitometer (BioRad, GS-800 calibrated densitometer) and the associated software (QuantityOne). Three sections per brain were used and for each tissue background subtracted from adjacent tissue areas on the same slide. Measurements from different animals/experiments were combined for statistically analysis performed with GraphPad Prism software (GraphPad Software, San Diego, USA).

\subsection{Immunological methods}

\subsubsection{Radio immune assay (RIA)}

After blood collection, it was kept at $4^{\circ} \mathrm{C}$ in $0.5 \mathrm{ml}$ Eppendorf tubes. Blood cells were spun down for $20 \mathrm{~min}, 2,000 \mathrm{~g}$ at $4^{\circ} \mathrm{C}$. The supernatant was transferred into a new tube and stored at $80^{\circ} \mathrm{C}$. The amount of OXM was determined by RIA (Phoenix Pharmaceutics, Karlsruhe, Germany) according to the manufacturer's protocol with the exception that only half of the recommended amount of all reagents per reaction was used.

\subsubsection{Western Blot}

For all Western Blot analyses following solutions were used. The solutions were filled up with MilliQ water to the denoted volume: 
5x SDS Loading Buffer (pH 7.4, $10 \mathrm{ml})$ :

- $2.5 \mathrm{ml}$ 1M Tris/HCl ph6.8 (250 mM)

- $\quad 0.771$ g DDT

- $0.05 \mathrm{~g} \quad$ Bromphenol Blue

- $5 \mathrm{ml}$

$50 \%$ Glycerol

- $1 \mathrm{~g}$

SDS

Lysis buffer (pH 7.4, $200 \mathrm{ml})$ :

- $2.38 \mathrm{~g}$ HEPES (50 mM)

- 840 mg NaF (100 mM)

- $890 \mathrm{mg} \mathrm{Na}{ }_{4} \mathrm{O}_{7} \mathrm{P}_{2}(10 \mathrm{mM})$

- 298 mg EDTA (4 mM)

Freshly:

- $1 \% \quad N P-40$

- $4 \%$ Protease Solution (Roche, Mannheim, Germany)

- $0.1 \% \quad$ B-MeSH

- $2 \mathrm{mM} \quad \mathrm{Na}_{3} \mathrm{VO}_{4}$

10x Electrophoresis Buffer (1,000 ml):

- $\quad 30.2 \mathrm{~g} \quad$ Tris

- $188 \mathrm{~g} \quad$ Glycine

- $100 \mathrm{ml} 10 \%$ SDS

10x Transfer Buffer (pH 8.3, 1,000 ml):

- $29 \mathrm{~g}$ Glycine

- $58 \mathrm{~g} \quad$ Tris

- $\quad 3.7 \mathrm{~g}$ SDS 
$1 \times$ Transfer Buffer (1,000 ml)

- $100 \mathrm{ml} 10 x$ Transfer

- $200 \mathrm{ml}$ Methanol

- $700 \mathrm{ml} \mathrm{H} 2 \mathrm{O}$

10x TBS (pH 7.4, 1,000 ml)

- $80 \mathrm{~g} \quad \mathrm{NaCl}$

- $2 \mathrm{~g} \mathrm{KCl}$

- $30 \mathrm{~g} \quad$ Tris

$1 \times$ TBS-T $(1,000 \mathrm{ml})$

- $100 \mathrm{ml} 10 x$ TBS

- $1 \mathrm{ml}$ Tween 20

Protein solutions were performed with liver slices in phosphatase inhibitor including lysis buffer:

- $250 \mu \mathrm{l}$ lysis buffer were prepare per liver slice and cooled down to $4^{\circ} \mathrm{C}$,

- liver slices were homogenized with pistils (Kimble Chase, Vineland, USA) in a $1.5 \mathrm{ml}$ Eppendorf tube,

- centrifuged: $13.000 \mathrm{rpm}, 20 \mathrm{~min}, 4^{\circ} \mathrm{C}$,

- liquid phase was transferred into a new tube,

Protein concentrations were determined by Bradford assay (Bio-Rad, München, Germany) according to the manufacturer's protocol using a photometer (BioPhotometer, Eppendorf). Aliquots of protein solution were made and stored at $-80^{\circ} \mathrm{C}$. During the preparation of Western blot gels, protein solutions were thawed on ice to protect sensitive phosphorylations. For proteins with a size between 60 and $40 \mathrm{kDa}$ we used $10 \%$ or $12 \%$ gels which were prepared according to the following prescription:

- glass plates were put into frame,

- the frame including glass plates (chamber) were clamped on rack and sealed,

- chamber was filled with $5 \mathrm{ml}$ liquid resolving gel, 
- $1 \mathrm{ml}$ 2-propanol was immediately added on top of the gel to get a straight border,

- after polymerization it was turned upside down to get rid of 2-propanol,

- chamber was filled up with $1 \mathrm{ml}$ stacking gel and

- a comb was put in.

For usage the gel was assembled in an electrophoresis chamber which in turn was filled with electrophoresis buffer. When protein solutions were thawed the sample could be prepared for immunoblotting:

- the samples were diluted to get a comparable amount of protein,

- 20-50 $\mu \mathrm{g}$ protein were filled up with ice cold lysis buffer,

- $1 / 3$ of the volume $1 \times$ SDS loading buffer was added and

- samples were denaturated at $95^{\circ} \mathrm{C}$ for $8 \mathrm{~min}$ and

- $\quad k e p t$ on ice for another $8 \mathrm{~min}$.

After denaturation the samples were loaded on the gels with capillary tips. A power supply was connected to the electrophoresis chamber:

- 20 - 30 min at $50 \mathrm{~V}$ (samples run through stacking gel and concentrate at the beginning of the resolving gel),

- 60 - 90 min at $120 \mathrm{~V}$ (proteins are separated within the resolving gel),

When the proteins were separated according their size, they could be blotted in a transfer chamber to a PVDF membrane (Roche) to become accessible for antibodies:

- the membrane was activated in methanol for 5 min and then

- rocked in ice cold $1 x$ transfer buffer for $5 \mathrm{~min}$,

- The gel was shortly washed in $\mathrm{ddH} 20$ and

- incubated 3-5 min in ice cold $1 x$ transfer buffer.

- Meanwhile the transfer chamber was prepared and filled with ice cold $1 x$ transfer buffer $\rightarrow$ the gel and membrane were clamped between sponges and Whatman paper.

- Current was applied for $70 \mathrm{~min}$ at $400 \mathrm{~mA}$. 
Once the proteins were blotted on the membrane they were incubated with a first antibody against the protein of interest:

- the membrane was rocked for $60-90 \mathrm{~min}$ in blocking solution (5\% milk/BSA) to block unspecific binding sites for the antibody.

- Afterwards membranes were incubated in first antibody solution made from blocking solution and antibody at $4^{\circ} \mathrm{C}$ over night.

The membrane was incubated with a secondary antibody against the first antibody. This antibody was related to horseradish peroxidase HRP. HRP was used to cleave a chemiluminescent agent, and the reaction product produces luminescence in proportion to the amount of protein:

- The membrane was rocked for $1 \mathrm{~h}$ at room temperature in secondary antibody solution, made from blocking solution and secondary antibody.

- The membrane was dried carefully with paper tissues and

- incubated for $5 \mathrm{~min}$ in chemiluminescent solution (swimming on $1 \mathrm{ml}$ solution with protein side being in contact with solution).

A photographic film was placed against the membrane, and exposure to the light from the reaction created an image of the antibodies bound to the blot. Exposed films were developed with the X-omat1000 (Kodak) and analyzed with a densitometer (Bio-Rad, GS-800 calibrated densitometer) and the associated software (QuantityOne). Statistical analysis was done with GraphPad Prism software (GraphPad Software, San Diego, USA). All data were normalized against untreated tissues (0 $\min )$.

\subsubsection{Kinase Array}

To detect phosphorylated kinases liver slices were used which either control treated with $\mathrm{NaCl}$ or with OXM. We used a Human Phospho-Kinase Array Kit (R\&D, Minneapolis, USA) according to the manufacturer's protocol. Most antibodies of this kit designed for human samples showed high crossreactivity with mouse proteins, suggesting that this human kit is applicable for mice as well (Table 3). 
MATERIALS AND METHODS

\begin{tabular}{|c|c|c|c|}
\hline Target & $\begin{array}{c}\text { \% homology } \\
\text { him total }\end{array}$ & $\begin{array}{c}\text { \% homology at } \\
\text { phospho site } \\
\text { hum }\end{array}$ & Comments \\
\hline p38a (MAPK14) & 98 & 100 & Detects mouse and rat. \\
\hline EFK1/2 & 9698 & 100 & Should theoretically work. \\
\hline JNK pan & 99 & 100 & Detects mouse and rat. \\
\hline GSK-3 2 / & $93 / 99$ & 100 & Detects mouse and rat. \\
\hline MEK1/2 & $98 / 94$ & 10006 & Unknawn \\
\hline MSK1/2 & $97 / 95$ & $95 / 100$ & Detects mouse. Fat unknoen. \\
\hline CREB & 88 & 100 & Detects mouse. Rat unknorn. \\
\hline HSP27 & 83 & 80 & Unknown \\
\hline AMPKa1 & 98 & 100 & Detects mouse. Rat uniknawn. \\
\hline AMPK $\approx 2$ & & & Unknown \\
\hline TOR & 97 & 100 & Should theoreticelly work. \\
\hline Sre & 98 & 100 & Should theoretically work. \\
\hline Lyn & 98 & 100 & Unknown \\
\hline Lek & 98 & 160 & Unknawn \\
\hline Fyn & 99 & 100 & Should theoretically work. \\
\hline Yeg & 85 & 160 & Unkncwn \\
\hline Fgr & 84 & 80 & Unknown \\
\hline$H \delta k$ & 89 & 96 & \multirow{2}{*}{$\begin{array}{l}\text { Unknown } \\
\text { Unknawn }\end{array}$} \\
\hline STAT2 & 71 & 80 & \\
\hline STAT3 & 99 & 100 & Detects mouse. Fat unknown. \\
\hline STAT5A & 99 & 100 & Detects mouse. Rist unknown. \\
\hline STAT5B & 98 & 90 & Detects mouse. Ragt unknowen. \\
\hline STAT 5AMB & & & Detects mouse. Rat unknown. \\
\hline STATE & 85 & 96 & Unknown \\
\hline Chk-2 & & & Unknown \\
\hline B-Catenin & 98 & & Detects mouse. Rat unknowen. \\
\hline Akt pan (S473) & 98 & 90 & Detocts mouse and rat. \\
\hline Fak & 97 & 100 & Should theoretically work. \\
\hline p70S5K [T389) & 99 & 100 & Detects mouse. Fat unknawn. \\
\hline pro9sk (Te2119424) & 98 & 100 & Detects mouse. Rat unknown. \\
\hline p70S8K (T22g) & 98 & 100 & Detects mouse. Rat unknown. \\
\hline p53 [S3962] & 77 & 60 & Unknown \\
\hline $\mathrm{p} 53$ [S46] & 77 & 46 & \multirow{2}{*}{$\begin{array}{l}\text { Unknown } \\
\text { Unknown }\end{array}$} \\
\hline p53 [S15] & 77 & 80 & \\
\hline Akt (T308) & 98 & 160 & Detects mouse. Rat unkngen. \\
\hline RESK $(5360)$ & 98 & 100 & Detects mouse. Rat unknoen. \\
\hline RSK $(S 221)$ & 98 & 100 & Detects mouse. Rat unknown. \\
\hline p27/KIP1(T198) & 87 & & Unknawn \\
\hline p27/KIP1 (T157) & 87 & 70 & Unknown \\
\hline colun & 95 & 100 & Detects mouse. Rat unknoun. \\
\hline eNOS & 94 & 100 & Unknown \\
\hline Paxiln & 93 & 96 & Unknown \\
\hline PLOY1 & 93 & 100 & Unknown \\
\hline Pyk2 & 91 & 100 & Unknown \\
\hline STAT4 (Y693) & 94 & 100 & Detects mouse. Rat unknown. \\
\hline STAT1 & 93 & 90 & Unknown \\
\hline
\end{tabular}

Table 3: Cross-reactivity of human antibodies used in the human kinase array kit with mouse proteins. Data from R\&D company. 


\section{REFERENCES}

1. Hildebrandt, G., Moser, M. \& Lehofer, M., Chronobiologie \& Chronomedizin. Hippokrates 1998.

2. Grant, P.R., The priming of periodical cicada life cycles. Trends Ecol Evol, 2005. 20(4): p. 169-74.

3. Dunlap, J.C., Molecular bases for circadian clocks. Cell, 1999. 96(2): p. 271-90.

4. $\quad$ Aschoff, J., Die 24-Stunden-Periodik der Maus unter konstanten Umgebungsbedingungen Naturwissenschaften, 1951. Volume 38(Number 21): p. 506-507.

5. Daan, S. and C.S. Pittendrigh, A Functional analysis of circadian pacemakers in nocturnal rodents. Journal of Comparative Physiology A: Neuroethology, Sensory, Neural, and Behavioral Physiology, 1976. Volume 106(Number 3): p. 223-355.

6. $\quad$ Edery, I., Circadian rhythms in a nutshell. Physiol Genomics, 2000. 3(2): p. 59-74.

7. Challet, E., et al., Synchronization of the molecular clockwork by light- and food-related cues in mammals. Biol Chem, 2003. 384(5): p. 711-9.

8. DeCoursey, P.J., et al., Circadian performance of suprachiasmatic nuclei (SCN)-lesioned antelope ground squirrels in a desert enclosure. Physiol Behav, 1997. 62(5): p. 1099-108.

9. $\quad$ Halberg, F., et al., Physiologic 24-hour periodicity in human beings and mice, the lighting regimen and daily routine. In: Photoperiodism and Related Phenomena in Plants and Animals. Assn. Adv. Sci., 1959: p. 803-878.

10. De Mairan, M., Observation botanique. Hist. de l’Acad. Royal Sciences, Paris, p1, 1729.

11. Kleinhoonte, A., Über die durch das Licht regulierten autonomen Bewegungen der Canavalia-blätter. Arch Neerl Sci Exactes 5, 1929: p. 1-110.

12. Buenning, E., Stern, K, Über die tagesperiodischen Bewegungen der Primarblätter von Phaseolus multiflorus. Ber Deutsche Bot Ges, 1930. 48: p. 227-252.

13. Johnson, M., Effect of continuous light on periodic spontaneous activity of white-footed mice ( Peromyscus ). J Exp Zool, 1939. 82: p. 315-328.

14. Sulzman, F.M., et al., Neurospora circadian rhythms in space: a reexamination of the endogenousexogenous question. Science, 1984. 225: p. 232-4.

15. Pittendrigh, C.S., Temporal organization: reflections of a Darwinian clock-watcher. Annu Rev Physiol, 1993. 55: p. 16-54.

16. Schibler, U. and F. Naef, Cellular oscillators: rhythmic gene expression and metabolism. Curr Opin Cell Biol, 2005. 17(2): p. 223-9.

17. Daan, S., Clocks and hourglass timers in behavioural cycles. Comparative Aspects of Circadian Clocks, ed. T.H.a.T.I. Honma. 1987, Sapporo Hokkaido University Press.

18. Kiessling, S., G. Eichele, and H. Oster, Adrenal glucocorticoids have a key role in circadian resynchronization in a mouse model of jet lag. J Clin Invest, 2010. 120(7): p. 2600-9.

19. Pittendrigh, C.S., On Temperature Independence in the Clock System Controlling Emergence Time in Drosophila. Proc Natl Acad Sci U S A, 1954. 40(10): p. 1018-29.

20. Aschoff, J. and H. Tokura, Circadian activity rhythms in squirrel monkeys: entrainment by temperature cycles. J Biol Rhythms, 1986. 1(2): p. 91-9.

21. Bünning, E., Zur Kenntnis der erblichen Tagesperiodizitat bei den Primarblattern von Phaseolus multiflorus. Jahrb wiss Bot. Vol. 81. 1935. 
22. Konopka, R.J. and S. Benzer, Clock mutants of Drosophila melanogaster. Proc Natl Acad Sci U S A, 1971. 68(9): p. 2112-6.

23. Ralph, M.R. and M. Menaker, A mutation of the circadian system in golden hamsters. Science, 1988. 241(4870): p. 1225-7.

24. Lowrey, P.L., et al., Positional syntenic cloning and functional characterization of the mammalian circadian mutation tau. Science, 2000. 288(5465): p. 483-92.

25. Hardin, P.E., J.C. Hall, and M. Rosbash, Feedback of the Drosophila period gene product on circadian cycling of its messenger RNA levels. Nature, 1990. 343(6258): p. 536-40.

26. Honma, S., et al., Dec1 and Dec2 are regulators of the mammalian molecular clock. Nature, 2002. 419(6909): p. 841-4.

27. Rossner, M.J., et al., Disturbed clockwork resetting in Sharp-1 and Sharp-2 single and double mutant mice. PLoS One, 2008. 3(7): p. e2762.

28. Mitsui, S., et al., Antagonistic role of E4BP4 and PAR proteins in the circadian oscillatory mechanism. Genes Dev, 2001. 15(8): p. 995-1006.

29. Lopez-Molina, L., et al., The DBP gene is expressed according to a circadian rhythm in the suprachiasmatic nucleus and influences circadian behavior. EMBO J, 1997. 16(22): p. 6762-71.

30. Reppert, S.M. and D.R. Weaver, Coordination of circadian timing in mammals. Nature, 2002. 418(6901): p. 935-41.

31. Jetten, A.M., S. Kurebayashi, and E. Ueda, The ROR nuclear orphan receptor subfamily: critical regulators of multiple biological processes. Prog Nucleic Acid Res Mol Biol, 2001. 69: p. 205-47.

32. Panda, S. and J.B. Hogenesch, It's all in the timing: many clocks, many outputs. J Biol Rhythms, 2004. 19(5): p. 374-87.

33. Garbarino-Pico, E. and C.B. Green, Posttranscriptional regulation of mammalian circadian clock output. Cold Spring Harb Symp Quant Biol, 2007. 72: p. 145-56.

34. Hendrickson, A.E., N. Wagoner, and W.M. Cowan, An autoradiographic and electron microscopic study of retino-hypothalamic connections. Z Zellforsch Mikrosk Anat, 1972. 135(1): p. 1-26.

35. Moore, R.Y. and N.J. Lenn, A retinohypothalamic projection in the rat. J Comp Neurol, 1972. 146(1): p. $1-14$.

36. Page, T.L., Transplantation of the cockroach circadian pacemaker. Science, 1982. 216(4541): p. 73-5.

37. Handler, A.M. and R.J. Konopka, Transplantation of a circadian pacemaker in Drosophila. Nature, 1979. 279(5710): p. 236-8.

38. Allada, R. and B.Y. Chung, Circadian organization of behavior and physiology in Drosophila. Annu Rev Physiol, 2010. 72: p. 605-24.

39. Gaston, S. and M. Menaker, Pineal function: the biological clock in the sparrow? Science, 1968. 160(832): p. 1125-7.

40. Moore, R.Y. and V.B. Eichler, Loss of a circadian adrenal corticosterone rhythm following suprachiasmatic lesions in the rat. Brain Res, 1972. 42(1): p. 201-6.

41. Stephan, F.K. and I. Zucker, Circadian rhythms in drinking behavior and locomotor activity of rats are eliminated by hypothalamic lesions. Proc Natl Acad Sci U S A, 1972. 69(6): p. 1583-6.

42. Inouye, S.T. and H. Kawamura, Persistence of circadian rhythmicity in a mammalian hypothalamic "island" containing the suprachiasmatic nucleus. Proc Natl Acad Sci U S A, 1979. 76(11): p. 5962-6.

43. Miche, S. and C.S. Colwell, Cellular communication and coupling within the suprachiasmatic nucleus. Chronobiol Int, 2001. 18(4): p. 579-600. 
44. Ralph, M.R., et al., Transplanted suprachiasmatic nucleus determines circadian period. Science, 1990. 247(4945): p. 975-8.

45. Michel, S. and C.S. Colwell, Cellular communication and coupling within the suprachiasmatic nucleus. Chronobiol Int, 2001. 18(4): p. 579-600.

46. Kramer, A., et al., Regulation of daily locomotor activity and sleep by hypothalamic EGF receptor signaling. Science, 2001. 294(5551): p. 2511-5.

47. Cheng, M.Y., et al., Prokineticin 2 transmits the behavioural circadian rhythm of the suprachiasmatic nucleus. Nature, 2002. 417(6887): p. 405-10.

48. Silver, R., et al., A diffusible coupling signal from the transplanted suprachiasmatic nucleus controlling circadian locomotor rhythms. Nature, 1996. 382(6594): p. 810-3.

49. Welsh, D.K., et al., Individual neurons dissociated from rat suprachiasmatic nucleus express independently phased circadian firing rhythms. Neuron, 1995. 14(4): p. 697-706.

50. Liu, C., et al., Cellular construction of a circadian clock: period determination in the suprachiasmatic nuclei. Cell, 1997. 91(6): p. 855-60.

51. Sun, Z.S., et al., RIGUI, a putative mammalian ortholog of the Drosophila period gene. Cell, 1997. 90(6): p. 1003-11.

52. Plautz, J.D., et al., Independent photoreceptive circadian clocks throughout Drosophila. Science, 1997. 278(5343): p. 1632-5.

53. Balsalobre, A., F. Damiola, and U. Schibler, A serum shock induces circadian gene expression in mammalian tissue culture cells. Cell, 1998. 93(6): p. 929-37.

54. Yamamoto, T., et al., Transcriptional oscillation of canonical clock genes in mouse peripheral tissues. BMC Mol Biol, 2004. 5: p. 18.

55. Yamazaki, S., et al., Ontogeny of circadian organization in the rat. J Biol Rhythms, 2009. 24(1): p. 5563.

56. Yoo, S.H., et al., PERIOD2::LUCIFERASE real-time reporting of circadian dynamics reveals persistent circadian oscillations in mouse peripheral tissues. Proc Natl Acad Sci U S A, 2004. 101(15): p. 533946.

57. Nagoshi, E., et al., Circadian gene expression in individual fibroblasts: cell-autonomous and selfsustained oscillators pass time to daughter cells. Cell, 2004. 119(5): p. 693-705.

58. Guo, H., et al., Suprachiasmatic regulation of circadian rhythms of gene expression in hamster peripheral organs: effects of transplanting the pacemaker. J Neurosci, 2006. 26(24): p. 6406-12.

59. Storch, K.F., et al., Extensive and divergent circadian gene expression in liver and heart. Nature, 2002. 417(6884): p. 78-83.

60. Kornmann, B., et al., System-driven and oscillator-dependent circadian transcription in mice with a conditionally active liver clock. PLoS Biol, 2007. 5(2): p. e34.

61. Oishi, K., et al., Genome-wide expression analysis of mouse liver reveals CLOCK-regulated circadian output genes. J Biol Chem, 2003. 278(42): p. 41519-27.

62. Ishikawa, K. and T. Shimazu, Circadian rhythm of liver glycogen metabolism in rats: effects of hypothalamic lesions. Am J Physiol, 1980. 238(1): p. E21-5.

63. Panda, S., et al., Coordinated transcription of key pathways in the mouse by the circadian clock. Cell, 2002. 109(3): p. 307-20.

64. Gachon, F., et al., The circadian PAR-domain basic leucine zipper transcription factors DBP, TEF, and HLF modulate basal and inducible xenobiotic detoxification. Cell Metab, 2006. 4(1): p. 25-36.

65. Miller, B.H., et al., Circadian and CLOCK-controlled regulation of the mouse transcriptome and cell proliferation. Proc Natl Acad Sci U S A, 2007. 104(9): p. 3342-7. 
66. Lamia, K.A., K.F. Storch, and C.J. Weitz, Physiological significance of a peripheral tissue circadian clock. Proc Natl Acad Sci U S A, 2008. 105(39): p. 15172-7.

67. Le Martelot, G., et al., REV-ERBalpha participates in circadian SREBP signaling and bile acid homeostasis. PLoS Biol, 2009. 7(9): p. e1000181.

68. Mistlberger, R.E. and D.J. Skene, Social influences on mammalian circadian rhythms: animal and human studies. Biol Rev Camb Philos Soc, 2004. 79(3): p. 533-56.

69. Mistlberger, R.E. and D.J. Skene, Nonphotic entrainment in humans? J Biol Rhythms, 2005. 20(4): p. 339-52.

70. Honma, K. and S. Honma, The SCN-independent clocks, methamphetamine and food restriction. European Journal of Neuroscience, 2009. 30(9): p. 1707-1717.

71. Richter, C.P., Psychopathology of periodic behavior in animals and man. Proc Annu Meet Am Psychopathol Assoc, 1967. 55: p. 205-27.

72. Belenky, M.A., et al., Melanopsin retinal ganglion cells receive bipolar and amacrine cell synapses. J Comp Neurol, 2003. 460(3): p. 380-93.

73. Freedman, M.S., et al., Regulation of mammalian circadian behavior by non-rod, non-cone, ocular photoreceptors. Science, 1999. 284(5413): p. 502-4.

74. Lockley, S.W., et al., Relationship between melatonin rhythms and visual loss in the blind. J Clin Endocrinol Metab, 1997. 82(11): p. 3763-70.

75. Provencio, I., et al., A novel human opsin in the inner retina. J Neurosci, 2000. 20(2): p. 600-5.

76. Hirota, T. and Y. Fukada, Resetting mechanism of central and peripheral circadian clocks in mammals. Zoolog Sci, 2004. 21(4): p. 359-68.

77. Xia, Z., et al., Calcium influx via the NMDA receptor induces immediate early gene transcription by a MAP kinase/ERK-dependent mechanism. J Neurosci, 1996. 16(17): p. 5425-36.

78. Gau, D., et al., Phosphorylation of CREB Ser142 regulates light-induced phase shifts of the circadian clock. Neuron, 2002. 34(2): p. 245-53.

79. Gillette, M.U. and S.A. Tischkau, Suprachiasmatic nucleus: the brain's circadian clock. Recent Prog Horm Res, 1999. 54: p. 33-58; discussion 58-9.

80. Obrietan, K., S. Impey, and D.R. Storm, Light and circadian rhythmicity regulate MAP kinase activation in the suprachiasmatic nuclei. Nat Neurosci, 1998. 1(8): p. 693-700.

81. Oster, H., et al., cGMP-dependent protein kinase II modulates mPer1 and mPer2 gene induction and influences phase shifts of the circadian clock. Curr Biol, 2003. 13(9): p. 725-33.

82. Ding, J.M., et al., Resetting the biological clock: mediation of nocturnal CREB phosphorylation via light, glutamate, and nitric oxide. J Neurosci, 1997. 17(2): p. 667-75.

83. Yan, L. and R. Silver, Differential induction and localization of mPer1 and mPer2 during advancing and delaying phase shifts. European Journal of Neuroscience, 2002. 16(8): p. 1531-40.

84. Cailotto, C., et al., Effects of nocturnal light on (clock) gene expression in peripheral organs: a role for the autonomic innervation of the liver. PLoS One, 2009. 4(5): p. e5650.

85. Damiola, F., et al., Restricted feeding uncouples circadian oscillators in peripheral tissues from the central pacemaker in the suprachiasmatic nucleus. Genes Dev, 2000. 14(23): p. 2950-61.

86. Stokkan, K.A., et al., Entrainment of the circadian clock in the liver by feeding. Science, 2001. 291(5503): p. 490-3.

87. Hara, R., et al., Restricted feeding entrains liver clock without participation of the suprachiasmatic nucleus. Genes Cells, 2001. 6(3): p. 269-78. 
88. Abe, H., S. Honma, and K. Honma, Daily restricted feeding resets the circadian clock in the suprachiasmatic nucleus of CS mice. Am J Physiol Regul Integr Comp Physiol, 2007. 292(1): p. R60715 .

89. Mendoza, J., et al., Feeding cues alter clock gene oscillations and photic responses in the suprachiasmatic nuclei of mice exposed to a light/dark cycle. J Neurosci, 2005. 25(6): p. 1514-22.

90. Caldelas, I., et al., Timed hypocaloric feeding and melatonin synchronize the suprachiasmatic clockwork in rats, but with opposite timing of behavioral output. European Journal of Neuroscience, 2005. 22(4): p. 921-9.

91. Novakova, M., et al., Restricted feeding regime affects clock gene expression profiles in the suprachiasmatic nucleus of rats exposed to constant light. Neuroscience, 2011.

92. Shibata, S., Y. Tahara, and A. Hirao, The adjustment and manipulation of biological rhythms by light, nutrition, and abused drugs. Adv Drug Deliv Rev, 2010. 62(9-10): p. 918-27.

93. Dibner, C., U. Schibler, and U. Albrecht, The mammalian circadian timing system: organization and coordination of central and peripheral clocks. Annu Rev Physiol, 2010. 72: p. 517-49.

94. Hirao, A., et al., A balanced diet is necessary for proper entrainment signals of the mouse liver clock. PLoS One, 2009. 4(9): p. e6909.

95. Hirao, A., et al., Combination of starvation interval and food volume determines the phase of liver circadian rhythm in Per2::Luc knock-in mice under two meals per day feeding. Am J Physiol Gastrointest Liver Physiol, 2010. 299(5): p. G1045-53.

96. Le Minh, N., et al., Glucocorticoid hormones inhibit food-induced phase-shifting of peripheral circadian oscillators. EMBO J, 2001. 20(24): p. 7128-36.

97. Rosenfeld, P., et al., Ontogeny of the type 2 glucocorticoid receptor in discrete rat brain regions: an immunocytochemical study. Brain Res, 1988. 470(1): p. 119-27.

98. Asher, G., et al., SIRT1 regulates circadian clock gene expression through PER2 deacetylation. Cell, 2008. 134(2): p. 317-28.

99. Nakahata, Y., et al., Circadian control of the NAD+ salvage pathway by CLOCK-SIRT1. Science, 2009. 324(5927): p. 654-7.

100. Reinke, H., et al., Differential display of DNA-binding proteins reveals heat-shock factor 1 as a circadian transcription factor. Genes Dev, 2008. 22(3): p. 331-45.

101. Richter, C.P., A behavioristic study of the activity of the rat Comparative psychology monographs, 1922. 1(2): p. 1-55.

102. Shirley, M., Studies in activity. II. Activity rhythms; age and activity; activity after rest Journal of Comparative Psychology (1921), 1928. Volume 8(2): p. 159-186.

103. Carneiro, B.T. and J.F. Araujo, The food-entrainable oscillator: a network of interconnected brain structures entrained by humoral signals? Chronobiol Int, 2009. 26(7): p. 1273-89.

104. Reid, L.S. and F.W. Finger, The rat's adjustment to 23-hour food-deprivation cycles. J Comp Physiol Psychol, 1955. 48(2): p. 110-3.

105. Bolles, R.C. and J. De Lorge, The rat's adjustment to a-diurnal feeding cycles. J Comp Physiol Psychol, 1962. 55: p. 760-2.

106. Bolles, R.C. and L.W. Stokes, Rat's anticipation of diurnal and a-diurnal feeding. J Comp Physiol Psychol, 1965. 60(2): p. 290-4.

107. Edmonds, S.C. and N.T. Adler, The multiplicity of biological oscillators in the control of circadian running activity in the rat. Physiol Behav, 1977. 18(5): p. 921-30.

108. Stephan, F.K., Forced dissociation of activity entrained to $T$ cycles of food access in rats with suprachiasmatic lesions. J Biol Rhythms, 1989. 4(4): p. 467-79. 
109. Krieger, D.T., H. Hauser, and L.C. Krey, Suprachiasmatic nuclear lesions do not abolish food-shifted circadian adrenal and temperature rhythmicity. Science, 1977. 197(4301): p. 398-9.

110. Boulos, Z., A.M. Rosenwasser, and M. Terman, Feeding schedules and the circadian organization of behavior in the rat. Behav Brain Res, 1980. 1(1): p. 39-65.

111. Stephan, F.K., Limits of entrainment to periodic feeding in rats with suprachiasmatic lesions. Journal of Comparative Physiology A, 1981. Volume 143(Number 4): p. 401-410.

112. Stephan, F.K., Resetting of a feeding-entrainable circadian clock in the rat. Physiol Behav, 1992. 52(5): p. 985-95.

113. Rosenwasser, A.M., R.J. Pelchat, and N.T. Adler, Memory for feeding time: possible dependence on coupled circadian oscillators. Physiol Behav, 1984. 32(1): p. 25-30.

114. Stephan, F.K., The "other" circadian system: food as a Zeitgeber. J Biol Rhythms, 2002. 17(4): p. 28492.

115. Davidson, A.J., S.L. Cappendijk, and F.K. Stephan, Feeding-entrained circadian rhythms are attenuated by lesions of the parabrachial region in rats. Am J Physiol Regul Integr Comp Physiol, 2000. 278(5): p. R1296-304.

116. Davidson, A.J., et al., Is the food-entrainable circadian oscillator in the digestive system? Genes Brain Behav, 2003. 2(1): p. 32-9.

117. Feillet, C.A., et al., Lack of food anticipation in Per2 mutant mice. Curr Biol, 2006. 16(20): p. 2016-22.

118. Landgraf, D., A. Shostak, and H. Oster, Clock genes and sleep. Pflugers Arch, 2011.

119. Akerstedt, T., et al., Disturbed sleep in shift workers, day workers, and insomniacs. Chronobiol Int, 2008. 25(2): p. 333-48.

120. Arble, D.M., et al., Circadian disruption and metabolic disease: findings from animal models. Best Pract Res Clin Endocrinol Metab, 2010. 24(5): p. 785-800.

121. Arendt, J., Shift work: coping with the biological clock. Occup Med (Lond), 2010. 60(1): p. 10-20.

122. Knutsson, A., Health disorders of shift workers. Occup Med (Lond), 2003. 53(2): p. 103-8.

123. Brown, D.L., et al., Rotating night shift work and the risk of ischemic stroke. Am J Epidemiol, 2009. 169(11): p. 1370-7.

124. Foster, R.G. and K. Wulff, The rhythm of rest and excess. Nat Rev Neurosci, 2005. 6(5): p. 407-14.

125. Rajaratnam, S.M. and J. Arendt, Health in a 24-h society. Lancet, 2001. 358(9286): p. 999-1005.

126. Alfredsson, L., R. Karasek, and T. Theorell, Myocardial infarction risk and psychosocial work environment: an analysis of the male Swedish working force. Soc Sci Med, 1982. 16(4): p. 463-7.

127. Kawachi, I., et al., Prospective study of shift work and risk of coronary heart disease in women. Circulation, 1995. 92(11): p. 3178-82.

128. Steenland, K. and L. Fine, Shift work, shift change, and risk of death from heart disease at work. Am J Ind Med, 1996. 29(3): p. 278-81.

129. Biggi, N., et al., Metabolic syndrome in permanent night workers. Chronobiol Int, 2008. 25(2): p. 44354.

130. Schernhammer, E.S., et al., Rotating night shifts and risk of breast cancer in women participating in the nurses' health study. J Natl Cancer Inst, 2001. 93(20): p. 1563-8.

131. Schernhammer, E.S., et al., Rotating night shifts and risk of skin cancer in the nurses' health study. J Natl Cancer Inst, 2011. 103(7): p. 602-6.

132. Poole, E.M., E.S. Schernhammer, and S.S. Tworoger, Rotating night shift work and risk of ovarian cancer. Cancer Epidemiol Biomarkers Prev, 2011. 20(5): p. 934-8. 
133. Matsuo, T., et al., Control mechanism of the circadian clock for timing of cell division in vivo. Science, 2003. 302(5643): p. 255-9.

134. Gery, S., et al., The clock gene Per2 links the circadian system to the estrogen receptor. Oncogene, 2007. 26(57): p. 7916-20.

135. Ozturk, N., et al., Loss of cryptochrome reduces cancer risk in p53 mutant mice. Proc Natl Acad Sci U S A, 2009. 106(8): p. 2841-6.

136. Stevens, R.G. and S. Davis, The melatonin hypothesis: electric power and breast cancer. Environ Health Perspect, 1996. 104 Suppl 1: p. 135-40.

137. Cos, S. and E.J. Sanchez-Barcelo, Melatonin and mammary pathological growth. Front Neuroendocrinol, 2000. 21(2): p. 133-70.

138. Ihre, B., Müller, R, Gastric and duodenal ulcer. Acta Medica Scandinavica, 1943. Volume 116(Issue 1): p. Pages 1-115.

139. Theorell, T. and T. Akerstedt, Day and night work: changes in cholesterol, uric acid, glucose and potassium in serum and in circadian patterns of urinary catecholamine excretion. A longitudinal crossover study of railway workers. Acta Med Scand, 1976. 200(1-2): p. 47-53.

140. Nagaya, T., et al., Markers of insulin resistance in day and shift workers aged 30-59 years. Int Arch Occup Environ Health, 2002. 75(8): p. 562-8.

141. Koller, M., M. Kundi, and R. Cervinka, Field studies of shift work at an Austrian oil refinery. I: Health and psychosocial wellbeing of workers who drop out of shiftwork. Ergonomics, 1978. 21(10): p. 835-47.

142. Boggild, H. and A. Knutsson, Shift work, risk factors and cardiovascular disease. Scand J Work Environ Health, 1999. 25(2): p. 85-99.

143. Niedhammer, I., F. Lert, and M.J. Marne, Prevalence of overweight and weight gain in relation to night work in a nurses' cohort. Int J Obes Relat Metab Disord, 1996. 20(7): p. 625-33.

144. Atkinson, G., et al., Exercise, energy balance and the shift worker. Sports Med, 2008. 38(8): p. 671-85.

145. Salgado-Delgado, R., et al., Internal desynchronization in a model of night-work by forced activity in rats. Neuroscience, 2008. 154(3): p. 922-31.

146. Arble, D.M., et al., Circadian timing of food intake contributes to weight gain. Obesity (Silver Spring), 2009. 17(11): p. 2100-2.

147. Salgado-Delgado, R., et al., Food intake during the normal activity phase prevents obesity and circadian desynchrony in a rat model of night work. Endocrinology, 2010. 151(3): p. 1019-29.

148. Filipski, E., et al., Circadian disruption accelerates liver carcinogenesis in mice. Mutat Res, 2009. 680(1-2): p. 95-105.

149. Davidson, A.J., et al., Chronic jet-lag increases mortality in aged mice. Curr Biol, 2006. 16(21): p. R914-6.

150. Stanley, S., et al., Hormonal regulation of food intake. Physiol Rev, 2005. 85(4): p. 1131-58.

151. Broadwell, R.D. and M.W. Brightman, Entry of peroxidase into neurons of the central and peripheral nervous systems from extracerebral and cerebral blood. J Comp Neurol, 1976. 166(3): p. 257-83.

152. Sawchenko, P.E. and L.W. Swanson, The organization and biochemical specificity of afferent projections to the paraventricular and supraoptic nuclei. Prog Brain Res, 1983. 60: p. 19-29.

153. Bernardis, L.L. and L.L. Bellinger, The dorsomedial hypothalamic nucleus revisited: 1986 update. Brain Res, 1987. 434(3): p. 321-81.

154. Rohner, F., et al., Immediate effect of lesion of the ventromedial hypothalamic area upon glucoseinduced insulin secretion in anaesthetized rats. Diabetologia, 1977. 13(3): p. 239-42. 
155. Marsh, D.J., et al., Melanin-concentrating hormone 1 receptor-deficient mice are lean, hyperactive, and hyperphagic and have altered metabolism. Proc Natl Acad Sci U S A, 2002. 99(5): p. 3240-5.

156. Qu, D., et al., A role for melanin-concentrating hormone in the central regulation of feeding behaviour. Nature, 1996. 380(6571): p. 243-7.

157. Tschop, M., D.L. Smiley, and M.L. Heiman, Ghrelin induces adiposity in rodents. Nature, 2000. 407(6806): p. 908-13.

158. Wren, A.M., et al., Ghrelin enhances appetite and increases food intake in humans. J Clin Endocrinol Metab, 2001. 86(12): p. 5992.

159. Cummings, D.E. and J. Overduin, Gastrointestinal regulation of food intake. J Clin Invest, 2007. 117(1): p. 13-23.

160. Cui, G. and H.L. Waldum, Physiological and clinical significance of enterochromaffin-like cell activation in the regulation of gastric acid secretion. World J Gastroenterol, 2007. 13(4): p. 493-6.

161. Fukumoto, K., et al., Synergistic action of gastrin and ghrelin on gastric acid secretion in rats. Biochem Biophys Res Commun, 2008. 374(1): p. 60-3.

162. Elmquist, J.K., et al., Distributions of leptin receptor mRNA isoforms in the rat brain. J Comp Neurol, 1998. 395(4): p. 535-47.

163. Fei, H., et al., Anatomic localization of alternatively spliced leptin receptors (Ob-R) in mouse brain and other tissues. Proc Natl Acad Sci U S A, 1997. 94(13): p. 7001-5.

164. Hakansson, M.L., et al., Leptin receptor immunoreactivity in chemically defined target neurons of the hypothalamus. J Neurosci, 1998. 18(1): p. 559-72.

165. Elias, C.F., et al., Leptin differentially regulates NPY and POMC neurons projecting to the lateral hypothalamic area. Neuron, 1999. 23(4): p. 775-86.

166. Qi, Y., et al., Adiponectin acts in the brain to decrease body weight. Nat Med, 2004. 10(5): p. 524-9.

167. Corp, E.S., et al., Localization of 125I-insulin binding sites in the rat hypothalamus by quantitative autoradiography. Neurosci Lett, 1986. 70(1): p. 17-22.

168. Track, N.S., R.S. McLeod, and A.V. Mee, Human pancreatic polypeptide: studies of fasting and postprandial plasma concentrations. Can J Physiol Pharmacol, 1980. 58(12): p. 1484-9.

169. Ueno, N., et al., Decreased food intake and body weight in pancreatic polypeptide-overexpressing mice. Gastroenterology, 1999. 117(6): p. 1427-32.

170. Zipf, W.B., et al., Blunted pancreatic polypeptide responses in children with obesity of Prader-Willi syndrome. J Clin Endocrinol Metab, 1981. 52(6): p. 1264-6.

171. Wisen, O., et al., Plasma concentrations of regulatory peptides in obesity following modified sham feeding (MSF) and a liquid test meal. Regul Pept, 1992. 39(1): p. 43-54.

172. Konturek, S.J., A. Pucher, and T. Radecki, Comparison of vasoactive intestinal peptide and secretin in stimulation of pancreatic secretion. J Physiol, 1976. 255(2): p. 497-509.

173. Chung, I., et al., Dual inhibitory mechanism of secretin action on acid secretion in totally isolated, vascularly perfused rat stomach. Gastroenterology, 1994. 107(6): p. 1751-8.

174. Langhans, W., Role of the liver in the control of glucose-lipid utilization and body weight. Curr Opin Clin Nutr Metab Care, 2003. 6(4): p. 449-55.

175. Adrian, T.E., et al., Human distribution and release of a putative new gut hormone, peptide YY. Gastroenterology, 1985. 89(5): p. 1070-7.

176. Fu-Cheng, X., et al., Mechanisms of peptide $Y Y$ release induced by an intraduodenal meal in rats: neural regulation by proximal gut. Pflugers Arch, 1997. 433(5): p. 571-9. 
177. Michel, M.C., et al., XVI. International Union of Pharmacology recommendations for the nomenclature of neuropeptide $Y$, peptide YY, and pancreatic polypeptide receptors. Pharmacol Rev, 1998. 50(1): p. 143-50.

178. Batterham, R.L., et al., Gut hormone PYY(3-36) physiologically inhibits food intake. Nature, 2002. 418(6898): p. 650-4.

179. Batterham, R.L., et al., Inhibition of food intake in obese subjects by peptide YY3-36. N Engl J Med, 2003. 349(10): p. 941-8.

180. Chaudhri, O.B., et al., Gastrointestinal satiety signals. Annu Rev Physiol, 2008. 70: p. 239-55.

181. Kanatani, A., et al., Role of the Y1 receptor in the regulation of neuropeptide Y-mediated feeding: comparison of wild-type, Y1 receptor-deficient, and Y5 receptor-deficient mice. Endocrinology, 2000. 141(3): p. 1011-6.

182. Larsson, L.I., F. Sundler, and R. Hakanson, Immunohistochemical localization of human pancreatic polypeptide (HPP) to a population of islet cells. Cell Tissue Res, 1975. 156(2): p. 167-71.

183. Liddle, R.A., et al., Cholecystokinin bioactivity in human plasma. Molecular forms, responses to feeding, and relationship to gallbladder contraction. J Clin Invest, 1985. 75(4): p. 1144-52.

184. Gibbs, J., R.C. Young, and G.P. Smith, Cholecystokinin decreases food intake in rats. J Comp Physiol Psychol, 1973. 84(3): p. 488-95.

185. Bi, S., et al., A role for NPY overexpression in the dorsomedial hypothalamus in hyperphagia and obesity of OLETF rats. Am J Physiol Regul Integr Comp Physiol, 2001. 281(1): p. R254-60.

186. Mojsov, S., et al., Preproglucagon gene expression in pancreas and intestine diversifies at the level of post-translational processing. J Biol Chem, 1986. 261(25): p. 11880-9.

187. Tang-Christensen, M., N. Vrang, and P.J. Larsen, Glucagon-like peptide containing pathways in the regulation of feeding behaviour. Int J Obes Relat Metab Disord, 2001. 25 Suppl 5: p. S42-7.

188. Albrecht, U., et al., A differential response of two putative mammalian circadian regulators, mper1 and mper2, to light. Cell, 1997. 91(7): p. 1055-64.

189. Turton, M.D., et al., A role for glucagon-like peptide-1 in the central regulation of feeding. Nature, 1996. 379(6560): p. 69-72.

190. Abbott, C.R., et al., The inhibitory effects of peripheral administration of peptide YY(3-36) and glucagon-like peptide-1 on food intake are attenuated by ablation of the vagal-brainstem-hypothalamic pathway. Brain Res, 2005. 1044(1): p. 127-31.

191. Baggio, L.L., et al., Oxyntomodulin and glucagon-like peptide-1 differentially regulate murine food intake and energy expenditure. Gastroenterology, 2004. 127(2): p. 546-58.

192. Naslund, E., et al., Prandial subcutaneous injections of glucagon-like peptide-1 cause weight loss in obese human subjects. Br J Nutr, 2004. 91(3): p. 439-46.

193. Verdich, C., et al., A meta-analysis of the effect of glucagon-like peptide-1 (7-36) amide on ad libitum energy intake in humans. J Clin Endocrinol Metab, 2001. 86(9): p. 4382-9.

194. Kervran, A., P. Blache, and D. Bataille, Distribution of oxyntomodulin and glucagon in the gastrointestinal tract and the plasma of the rat. Endocrinology, 1987. 121(2): p. 704-13.

195. Bataille, D., et al., Bioactive enteroglucagon (oxyntomodulin): present knowledge on its chemical structure and its biological activities. Peptides, 1981. 2 Suppl 2: p. 41-4.

196. Holst, J.J., Evidence that enteroglucagon (II) is identical with the C-terminal sequence (residues 33-69) of glicentin. Biochem J, 1982. 207(3): p. 381-8.

197. Le Quellec, A., et al., Oxyntomodulin-like immunoreactivity: diurnal profile of a new potential enterogastrone. J Clin Endocrinol Metab, 1992. 74(6): p. 1405-9. 
198. Dubrasquet, M., D. Bataille, and C. Gespach, Oxyntomodulin (glucagon-37 or bioactive enteroglucagon): a potent inhibitor of pentagastrin-stimulated acid secretion in rats. Biosci Rep, 1982. 2(6): p. 391-5.

199. Jarrousse, C., et al., Oxyntomodulin and its C-terminal octapeptide inhibit liquid meal-stimulated acid secretion. Peptides, 1986. 7 Suppl 1: p. 253-6.

200. Schjoldager, B.T., et al., Oxyntomodulin: a potential hormone from the distal gut. Pharmacokinetics and effects on gastric acid and insulin secretion in man. Eur J Clin Invest, 1988. 18(5): p. 499-503.

201. Schjoldager, B.T., et al., GLP-1 (glucagon-like peptide 1) and truncated GLP-1, fragments of human proglucagon, inhibit gastric acid secretion in humans. Dig Dis Sci, 1989. 34(5): p. 703-8.

202. Wojdemann, M., et al., Inhibition of sham feeding-stimulated human gastric acid secretion by glucagonlike peptide-2. J Clin Endocrinol Metab, 1999. 84(7): p. 2513-7.

203. Loud, F.B., et al., Inhibition of meal-stimulated gastric acid secretion in man by exogenous and endogenous pancreatic glucagon. Scand J Gastroenterol, 1978. 13(7): p. 795-8.

204. Christiansen, J., J.J. Holst, and E. Kalaja, Inhibition of gastric acid secretion in man by exogenous and endogenous pancreatic glucagon. Gastroenterology, 1976. 70(5 PT.1): p. 688-92.

205. Schjoldager, B., et al., Oxyntomodulin from distal gut. Role in regulation of gastric and pancreatic functions. Dig Dis Sci, 1989. 34(9): p. 1411-9.

206. Chernish, S.M., et al., Comparison of the effects of glucagon and atropine sulfate on gastric emptying. Am J Gastroenterol, 1978. 70(6): p. 581-6.

207. Maida, A., et al., The glucagon-like peptide-1 receptor agonist oxyntomodulin enhances beta-cell function but does not inhibit gastric emptying in mice. Endocrinology, 2008. 149(11): p. 5670-8.

208. Mojsov, S., G.C. Weir, and J.F. Habener, Insulinotropin: glucagon-like peptide I (7-37) co-encoded in the glucagon gene is a potent stimulator of insulin release in the perfused rat pancreas. J Clin Invest, 1987. 79(2): p. 616-9.

209. Holst, J.J., et al., Truncated glucagon-like peptide I, an insulin-releasing hormone from the distal gut. FEBS Lett, 1987. 211(2): p. 169-74.

210. Drucker, D.J., et al., Glucagon-like peptide I stimulates insulin gene expression and increases cyclic AMP levels in a rat islet cell line. Proc Natl Acad Sci U S A, 1987. 84(10): p. 3434-8.

211. Baldissera, F.G., et al., Oxyntomodulin (glicentin-(33-69)): pharmacokinetics, binding to liver cell membranes, effects on isolated perfused pig pancreas, and secretion from isolated perfused lower small intestine of pigs. Regul Pept, 1988. 21(1-2): p. 151-66.

212. Jarrousse, C., D. Bataille, and B. Jeanrenaud, A pure enteroglucagon, oxyntomodulin (glucagon 37), stimulates insulin release in perfused rat pancreas. Endocrinology, 1984. 115(1): p. 102-5.

213. Biedzinski, T.M., et al., The effect of oxyntomodulin (glucagon-37) and glucagon on exocrine pancreatic secretion in the conscious rat. Peptides, 1987. 8(6): p. 967-72.

214. Dakin, C.L., et al., Oxyntomodulin inhibits food intake in the rat. Endocrinology, 2001. 142(10): p. 4244-50.

215. Wynne, K., et al., Subcutaneous oxyntomodulin reduces body weight in overweight and obese subjects: a double-blind, randomized, controlled trial. Diabetes, 2005. 54(8): p. 2390-5.

216. Tang-Christensen, M., et al., Central administration of GLP-1-(7-36) amide inhibits food and water intake in rats. Am J Physiol, 1996. 271(4 Pt 2): p. R848-56.

217. McMahon, L.R. and P.J. Wellman, PVN infusion of GLP-1-(7-36) amide suppresses feeding but does not induce aversion or alter locomotion in rats. Am J Physiol, 1998. 274(1 Pt 2): p. R23-9. 
218. Serre, V., et al., Exendin-(9-39) is an inverse agonist of the murine glucagon-like peptide-1 receptor: implications for basal intracellular cyclic adenosine 3',5'-monophosphate levels and beta-cell glucose competence. Endocrinology, 1998. 139(11): p. 4448-54.

219. Dakin, C.L., et al., Repeated ICV administration of oxyntomodulin causes a greater reduction in body weight gain than in pair-fed rats. Am J Physiol Endocrinol Metab, 2002. 283(6): p. E1173-7.

220. Dakin, C.L., et al., Peripheral oxyntomodulin reduces food intake and body weight gain in rats. Endocrinology, 2004. 145(6): p. 2687-95.

221. Long, R.T., et al., Bifidobacterium as an oral delivery carrier of oxyntomodulin for obesity therapy: inhibitory effects on food intake and body weight in overweight mice. Int J Obes (Lond), 2010. 34(4): p. 712-9.

222. Cohen, M.A., et al., Oxyntomodulin suppresses appetite and reduces food intake in humans. J Clin Endocrinol Metab, 2003. 88(10): p. 4696-701.

223. Wynne, K., et al., Oxyntomodulin increases energy expenditure in addition to decreasing energy intake in overweight and obese humans: a randomised controlled trial. Int J Obes (Lond), 2006. 30(12): p. 1729-36.

224. Flint, A., et al., The effect of glucagon-like peptide-1 on energy expenditure and substrate metabolism in humans. Int J Obes Relat Metab Disord, 2000. 24(3): p. 288-98.

225. Chaudhri, O.B., et al., Differential hypothalamic neuronal activation following peripheral injection of GLP-1 and oxyntomodulin in mice detected by manganese-enhanced magnetic resonance imaging. Biochem Biophys Res Commun, 2006. 350(2): p. 298-306.

226. Cortright, R.N. and G.L. Dohm, Mechanisms by which insulin and muscle contraction stimulate glucose transport. Can J Appl Physiol, 1997. 22(6): p. 519-30.

227. Nordlie, R.C., J.D. Foster, and A.J. Lange, Regulation of glucose production by the liver. Annu Rev Nutr, 1999. 19: p. 379-406.

228. Erlinger, S., Review article: new insights into the mechanisms of hepatic transport and bile secretion. $\mathrm{J}$ Gastroenterol Hepatol, 1996. 11(6): p. 575-9.

229. Valenzuela, J.E., J.H. Walsh, and J.I. Isenberg, Effect of gastrin on pancreatic enzyme secretion and gallbladder emptying in man. Gastroenterology, 1976. 71(3): p. 409-11.

230. Redinger, R.N., Fat storage and the biology of energy expenditure. Transl Res, 2009. 154(2): p. 52-60.

231. Balsalobre, A., et al., Resetting of circadian time in peripheral tissues by glucocorticoid signaling. Science, 2000. 289(5488): p. 2344-7.

232. Zhu, L., et al., The role of dipeptidyl peptidase IV in the cleavage of glucagon family peptides: in vivo metabolism of pituitary adenylate cyclase activating polypeptide-(1-38). J Biol Chem, 2003. 278(25): p. 22418-23.

233. Jorgensen, R., et al., Oxyntomodulin differentially affects glucagon-like peptide-1 receptor beta-arrestin recruitment and signaling through Galpha(s). J Pharmacol Exp Ther, 2007. 322(1): p. 148-54.

234. Post, S.R., P.G. Rubinstein, and H.S. Tager, Mechanism of action of des-His1-[Glu9]glucagon amide, a peptide antagonist of the glucagon receptor system. Proc Natl Acad Sci U S A, 1993. 90(5): p. 1662-6.

235. Campos, R.V., Y.C. Lee, and D.J. Drucker, Divergent tissue-specific and developmental expression of receptors for glucagon and glucagon-like peptide-1 in the mouse. Endocrinology, 1994. 134(5): p. 215664.

236. Dunphy, J.L., R.G. Taylor, and P.J. Fuller, Tissue distribution of rat glucagon receptor and GLP-1 receptor gene expression. Mol Cell Endocrinol, 1998. 141(1-2): p. 179-86.

237. Abu-Hamdah, R., et al., Clinical review: The extrapancreatic effects of glucagon-like peptide-1 and related peptides. J Clin Endocrinol Metab, 2009. 94(6): p. 1843-52. 
238. Scrocchi, L.A., et al., Glucose intolerance but normal satiety in mice with a null mutation in the glucagon-like peptide 1 receptor gene. Nat Med, 1996. 2(11): p. 1254-8.

239. Aviv, V., et al., Exendin-4 promotes liver cell proliferation and enhances the PDX-1-induced liver to pancreas transdifferentiation process. J Biol Chem, 2009. 284(48): p. 33509-20.

240. Bataille, D., et al., "Enterolglucagon': a specific effect on gastric glands isolated from the rat fundus. Evidence for an "oxyntomodulin' action. Biosci Rep, 1981. 1(2): p. 151-5.

241. Redondo, A., et al., Cell signaling of the GLP-1 action in rat liver. Mol Cell Endocrinol, 2003. 204(1-2): p. 43-50.

242. Bennett, B.L., et al., SP600125, an anthrapyrazolone inhibitor of Jun N-terminal kinase. Proc Natl Acad Sci U S A, 2001. 98(24): p. 13681-6.

243. Guo, H., et al., Differential control of peripheral circadian rhythms by suprachiasmatic-dependent neural signals. Proc Natl Acad Sci U S A, 2005. 102(8): p. 3111-6.

244. Meyer-Spasche, A., H.E. Reed, and H.D. Piggins, Neurotensin phase-shifts the firing rate rhythm of neurons in the rat suprachiasmatic nuclei in vitro. European Journal of Neuroscience, 2002. 16(2): p. 339-44.

245. George, J.K., et al., Neurotensin levels in the hepatic-portal circulation are inversely related to the circadian feeding cycle in rats. Endocrinology, 1987. 121(1): p. 7-13.

246. Harmar, A.J., An essential role for peptidergic signaling in the control of circadian rhythms in the suprachiasmatic nuclei. J Neuroendocrinol, 2003. 15(4): p. 335-8.

247. Brown, S.A., et al., Molecular insights into human daily behavior. Proc Natl Acad Sci U S A, 2008. 105(5): p. 1602-7.

248. Yannielli, P.C. and M.E. Harrington, Neuropeptide $Y$ in the mammalian circadian system: effects on light-induced circadian responses. Peptides, 2001. 22(3): p. 547-56.

249. Wiater, M.F., et al., Circadian Integration of Sleep/Wake and Feeding Requires NPY-Receptor Expressing Neurons in the Mediobasal Hypothalamus. Am J Physiol Regul Integr Comp Physiol, 2011.

250. Ding, W.G., H. Kitasato, and H. Kimura, Development of neuropeptide Y innervation in the liver. Microsc Res Tech, 1997. 39(4): p. 365-71.

251. Bodosi, B., et al., Rhythms of ghrelin, leptin, and sleep in rats: effects of the normal diurnal cycle, restricted feeding, and sleep deprivation. Am J Physiol Regul Integr Comp Physiol, 2004. 287(5): p. R1071-9.

252. LeSauter, J., et al., Stomach ghrelin-secreting cells as food-entrainable circadian clocks. Proc Natl Acad Sci U S A, 2009. 106(32): p. 13582-7.

253. Yannielli, P.C., et al., Ghrelin effects on the circadian system of mice. J Neurosci, 2007. 27(11): p. 28905.

254. Taheri, S., et al., Short sleep duration is associated with reduced leptin, elevated ghrelin, and increased body mass index. PLoS Med, 2004. 1(3): p. e62.

255. Funakoshi, A., et al., Diurnal profile of plasma motilin concentrations during fasting and feeding in man. Gastroenterol Jpn, 1985. 20(5): p. 446-56.

256. Eng, J., et al., Isolation and characterization of exendin-4, an exendin-3 analogue, from Heloderma suspectum venom. Further evidence for an exendin receptor on dispersed acini from guinea pig pancreas. J Biol Chem, 1992. 267(11): p. 7402-5.

257. Diaz-Munoz, M., et al., Anticipatory changes in liver metabolism and entrainment of insulin, glucagon, and corticosterone in food-restricted rats. Am J Physiol Regul Integr Comp Physiol, 2000. 279(6): p. R2048-56. 
258. Mingrone, G., et al., Circadian rhythms of GIP and GLP1 in glucose-tolerant and in type 2 diabetic patients after biliopancreatic diversion. Diabetologia, 2009. 52(5): p. 873-81.

259. Kervran, A., et al., Metabolic clearance rates of oxyntomodulin and glucagon in the rat: contribution of the kidney. Regul Pept, 1990. 31(1): p. 41-52.

260. Lowrey, P.L. and J.S. Takahashi, Genetics of the mammalian circadian system: Photic entrainment, circadian pacemaker mechanisms, and posttranslational regulation. Annu Rev Genet, 2000. 34: p. 533562.

261. Albrecht, U., et al., MPer1 and mper2 are essential for normal resetting of the circadian clock. J Biol Rhythms, 2001. 16(2): p. 100-4.

262. Edery, I., J.E. Rutila, and M. Rosbash, Phase shifting of the circadian clock by induction of the Drosophila period protein. Science, 1994. 263(5144): p. 237-40.

263. Tahara, Y., et al., Refeeding after fasting elicits insulin-dependent regulation of Per2 and Rev-erbalpha with shifts in the liver clock. J Biol Rhythms, 2011. 26(3): p. 230-40.

264. Oike, H., et al., Feeding cues and injected nutrients induce acute expression of multiple clock genes in the mouse liver. PLoS One, 2011. 6(8): p. e23709.

265. Depigny, C., et al., [Demonstration of a specific receptor site for glucagon-37 (oxyntomodulin/bioactive enteroglucagon) in rat oxyntic glands]. C R Acad Sci III, 1984. 299(16): p. 677-80.

266. Schepp, W., et al., Oxyntomodulin: a cAMP-dependent stimulus of rat parietal cell function via the receptor for glucagon-like peptide-1 (7-36)NH2. Digestion, 1996. 57(6): p. 398-405.

267. Gros, L., et al., Glucagon-like peptide-1-(7-36) amide, oxyntomodulin, and glucagon interact with a common receptor in a somatostatin-secreting cell line. Endocrinology, 1993. 133(2): p. 631-8.

268. Tomas, E. and J.F. Habener, Insulin-like actions of glucagon-like peptide-1: a dual receptor hypothesis. Trends Endocrinol Metab, 2010. 21(2): p. 59-67.

269. Ban, K., et al., Cardioprotective and vasodilatory actions of glucagon-like peptide 1 receptor are mediated through both glucagon-like peptide 1 receptor-dependent and -independent pathways. Circulation, 2008. 117(18): p. 2340-50.

270. $\quad$ Egan, J.M., et al., Glucagon-like peptide-1(7-36) amide (GLP-1) enhances insulin-stimulated glucose metabolism in 3T3-L1 adipocytes: one of several potential extrapancreatic sites of GLP-1 action. Endocrinology, 1994. 135(5): p. 2070-5.

271. Wei, Y. and S. Mojsov, Tissue-specific expression of the human receptor for glucagon-like peptide-I: brain, heart and pancreatic forms have the same deduced amino acid sequences. FEBS Lett, 1995. 358(3): p. 219-24.

272. Bullock, B.P., R.S. Heller, and J.F. Habener, Tissue distribution of messenger ribonucleic acid encoding the rat glucagon-like peptide-1 receptor. Endocrinology, 1996. 137(7): p. 2968-78.

273. Ahren, B., GLP-1 and extra-islet effects. Horm Metab Res, 2004. 36(11-12): p. 842-5.

274. Merchenthaler, I., M. Lane, and P. Shughrue, Distribution of pre-pro-glucagon and glucagon-like peptide-1 receptor messenger RNAs in the rat central nervous system. J Comp Neurol, 1999. 403(2): p. 261-80.

275. Shughrue, P.J., M.V. Lane, and I. Merchenthaler, Glucagon-like peptide-1 receptor (GLP1-R) mRNA in the rat hypothalamus. Endocrinology, 1996. 137(11): p. 5159-62.

276. Ding, X., et al., Exendin-4, a glucagon-like protein-1 (GLP-1) receptor agonist, reverses hepatic steatosis in ob/ob mice. Hepatology, 2006. 43(1): p. 173-81.

277. Ban, K., et al., Glucagon-like peptide (GLP)-1(9-36)amide-mediated cytoprotection is blocked by exendin(9-39) yet does not require the known GLP-1 receptor. Endocrinology, 2010. 151(4): p. 1520-31. 
278. Luque, M.A., et al., Glucagon-like peptide-1 (GLP-1) and glucose metabolism in human myocytes. J Endocrinol, 2002. 173(3): p. 465-73.

279. Lopez-Delgado, M.I., et al., Effects of glucagon-like peptide 1 on the kinetics of glycogen synthase a in hepatocytes from normal and diabetic rats. Endocrinology, 1998. 139(6): p. 2811-7.

280. Alcantara, A.I., et al., Exendin-4 agonist and exendin(9-39)amide antagonist of the GLP-1(7-36)amide effects in liver and muscle. Arch Biochem Biophys, 1997. 341(1): p. 1-7.

281. Valverde, I., et al., Glucagon-like peptide 1: a potent glycogenic hormone. FEBS Lett, 1994. 349(2): p. 313-6.

282. Nishizawa, M., et al., The hepatic vagal reception of intraportal GLP-1 is via receptor different from the pancreatic GLP-1 receptor. J Auton Nerv Syst, 2000. 80(1-2): p. 14-21.

283. Tomas, E., V. Stanojevic, and J.F. Habener, GLP-1-derived nonapeptide GLP-1(28-36)amide targets to mitochondria and suppresses glucose production and oxidative stress in isolated mouse hepatocytes. Regul Pept, 2011. 167(2-3): p. 177-84.

284. Tomas, E., V. Stanojevic, and J.F. Habener, GLP-1 (9-36) amide metabolite suppression of glucose production in isolated mouse hepatocytes. Horm Metab Res, 2010. 42(9): p. 657-62.

285. Elahi, D., et al., GLP-1 (9-36) amide, cleavage product of GLP-1 (7-36) amide, is a glucoregulatory peptide. Obesity (Silver Spring), 2008. 16(7): p. 1501-9.

286. Villanueva-Penacarrillo, M.L., et al., Glucagon-like peptide-1 binding to rat hepatic membranes. J Endocrinol, 1995. 146(1): p. 183-9.

287. Ikezawa, Y., et al., Glucagon-like peptide-1 inhibits glucagon-induced glycogenolysis in perivenous hepatocytes specifically. Regul Pept, 2003. 111(1-3): p. 207-10.

288. Mukai, E., et al., GLP-1 receptor antagonist as a potential probe for pancreatic beta-cell imaging. Biochem Biophys Res Commun, 2009. 389(3): p. 523-6.

289. Mabrouk, G.M. and J.T. Brosnan, Activation of the hepatic glycine cleavage enzyme system by glucagon and glucagon-related peptides. Can J Physiol Pharmacol, 1997. 75(9): p. 1096-100.

290. Baggio, L.L. and D.J. Drucker, Biology of incretins: GLP-1 and GIP. Gastroenterology, 2007. 132(6): p. 2131-57.

291. Gonzalez, N., et al., Effect of GLP-1 on glucose transport and its cell signaling in human myocytes. Regul Pept, 2005. 126(3): p. 203-11.

292. Yagita, K., et al., Mini screening of kinase inhibitors affecting period-length of mammalian cellular circadian clock. Acta Histochem Cytochem, 2009. 42(3): p. 89-93.

293. Natalicchio, A., et al., Exendin-4 prevents c-Jun $\mathrm{N}$-terminal protein kinase activation by tumor necrosis factor-alpha (TNFalpha) and inhibits TNFalpha-induced apoptosis in insulin-secreting cells.

Endocrinology, 2010. 151(5): p. 2019-29.

294. Li, X., et al., Akt/PKB regulates hepatic metabolism by directly inhibiting PGC-1alpha transcription coactivator. Nature, 2007. 447(7147): p. 1012-6.

295. Cross, D.A., et al., Inhibition of glycogen synthase kinase-3 by insulin mediated by protein kinase B. Nature, 1995. 378(6559): p. 785-9.

296. Liu, C., et al., Transcriptional coactivator PGC-1alpha integrates the mammalian clock and energy metabolism. Nature, 2007. 447(7143): p. 477-81.

297. Iitaka, C., et al., A role for glycogen synthase kinase-3beta in the mammalian circadian clock. J Biol Chem, 2005. 280(33): p. 29397-402.

298. Harwood, A.J., Regulation of GSK-3: a cellular multiprocessor. Cell, 2001. 105(7): p. 821-4.

299. Sahar, S., et al., Regulation of BMAL1 protein stability and circadian function by GSK3beta-mediated phosphorylation. PLoS One, 2010. 5(1): p. e8561. 
300. Ayala, J.E., et al., Glucagon-like peptide-1 receptor knockout mice are protected from high-fat dietinduced insulin resistance. Endocrinology, 2010. 151(10): p. 4678-87.

301. Knauf, C., et al., Brain glucagon-like peptide-1 increases insulin secretion and muscle insulin resistance to favor hepatic glycogen storage. J Clin Invest, 2005. 115(12): p. 3554-63.

302. Pfaffl, M.W., A new mathematical model for relative quantification in real-time RT-PCR. Nucleic Acids Res, 2001. 29(9): p. e45.

303. Oster, H., et al., Disruption of mCry2 restores circadian rhythmicity in mPer2 mutant mice. Genes Dev, 2002. 16(20): p. 2633-8. 


\section{CURRICULUM VITAE}

\section{Dominic Landgraf}

* 17.04.1982 in Fulda, Germany

\section{EDUCATION}

February 2008 -

Present

March 2007 -

December 2007

October 2004 -

March 2007

October 2004

October 2002 -

October 2004

$2001-$

2002

2001
PHD CANDIDATE

"Metabolic synchronization of the liver circadian clock".

Max Planck Institute for biophysical chemistry, Göttingen, Germany, University of Göttingen

DIPLOMA THESIS

"Expression and function of acetylcholine receptors in murine embryonic stem cells"

Technical University of Darmstadt, Germany

DIPLOMA EXAM

Developmental biology, Animal physiology and ecology

Technical University of Darmstadt, Germany

"VORDIPLOM"

Technical University of Darmstadt, Germany

BASIC STUDIES OF BIOLOGY

Technical University of Darmstadt, Germany

Civilian Service: Emergency medical technician - basic

Red Cross, Fulda, Germany

"Abitur" from German secondary school

Winfried Schule, Fulda, Germany

\section{PUBLICATIONS}

Landgraf, D. Shostak, A., and Oster, H. (2011). Clock genes and sleep. Pflugers Arch

Landgraf, D. Barth, M. Layer, P.G., and Sperling, L.E. (2010). Acetylcholine as a possible signaling molecule in embryonic stem cells: studies on survival, proliferation and death. Chem Biol Interact 187, 115-119.

Sperling, L.E., Steinert, G., Boutter, J., Landgraf, D., Hescheler, J. Pollet, D. and Layer, P.G. (2008). Characterization of cholinesterase expression during murine embryonic stem cell differentiation. Chem Biol Interact 175, 156-160.

\section{POSTER PRESENTATIONS}

June 2011

July 2009
ENDO2011, $93^{\text {rd }}$ Annual Meeting \& EXPO, Boston, USA

Landgraf D., Oster H.: Metabolic Synchronization of the Liver Circadian Clock

EUCLOCK Summer School, Przegorzaly, Poland

Landgraf D., Oster H.: Metabolic Synchronization of the Liver Circadian Clock 


\section{ACKNOWLEDGEMENTS}

First of all I would like to thank Henrik Oster for the opportunity to work in his group. Under his supervision I could gain enormous scientific experience. Henrik was always willing to share his great knowledge and was always receptive for new ideas, scientific problems, and also criticism. He taught me to have a critical view on results and impressed me again and again with his competence to overview complex problems and to find solutions.

I would like to thank Gregor Eichele for his general support. He generously offered me to work in his lab and allowed me to use all facilities and materials. I would like to thank him especially for funding my job application travel to the USA.

Ernst A. Wimmer I would like to thank for accepting to examine my thesis.

Special thanks go to my colleagues for making the group so secure and familiar. Jana did not only help me to overcome scientific problems and without Nadine's sense of humour (which she already demonstrated on her first day together with me in the histology room) my time in the lab would not have been the same. Judit was one of the most helpful people I have ever met. I was lucky to find such good friends at my workplace. I am also thankful to my other colleagues as they are Johanna, Maggie, Brid, Anton, Alexei and Anthony. I knew that I could count on their help at any time and all of them contributed to the good atmosphere in our lab.

Meiner Freundin Silke bin ich dankbar für ihr Dasein als gute Freundin, Kollegin und kritische Begutachterin meiner Arbeit. Trotz einer Distanz von 7554,2 km war sie immer für mich da.

Allen voran danke ich meiner Mutter Iris und meinem Vater Rainer. Auf meinem ganzen bisherigen Weg haben sie mich stets voll unterstützt und mich in meinen Zielen bestärkt. Zusammen mit meinem Bruder Marc und seiner Familie, leisteten sie immer großen moralischen Beistand und haben all meine Höhen und Tiefen mit mir zusammen durchlebt. Danke auch für die andere großzügige "Stütze“, vor allem im letzen Jahr.

Ich danke euch von ganzem Herzen!

Dominic 